$$
\begin{gathered}
\text { Universidade de São Paulo } \\
\text { Escola de Educação Física e Esporte } \\
\text { Departamento de Biodinâmica do Movimento do Corpo Humano }
\end{gathered}
$$

\title{
PERFIL DE microRNAs NO CORAÇÃO DE CAMUNDONGOS TREINADOS E QUE SUPEREXPRESSAM ECA2: PAPEL NO REMODELAMENTO CARDÍACO
}

\author{
Aluno: André Casanova Silveira \\ Orientadora: Prof ${ }^{\mathrm{a}} \mathrm{Dr}{ }^{\mathrm{a}}$ Edilamar Menezes de Oliveira \\ Laboratório de Bioquímica e Biologia Molecular do Exercício
}

São Paulo 
PERFIL DE microRNAs NO CORAÇÃO DE CAMUNDONGOS TREINADOS E QUE SUPEREXPRESSAM ECA2: PAPEL NO REMODELAMENTO CARDÍACO

Projeto de pesquisa apresentado à Comissão de Pós-Graduação da Escola de Educação Física e Esporte da Universidade de São Paulo como requisito para obtenção do grau de Mestre em Educação Física.

Área de Concentração: Estudos Biodinâmicos da Educação Física e Esporte

Orientadora: Profa. Dra.Edilamar Menezes de Oliveira 

Catalogação da Publicação

Serviço de Biblioteca

Escola de Educação Física e Esporte da Universidade de São Paulo

Silveira, André Casanova

Perfil de microRNAs no coração de camundongos treinados e

que superexpressam ECA2: papel no remodelamento cardíaco /

André Casanova Silveira. -- São Paulo: [s.n.], 2017.

$77 \mathrm{p}$.

Dissertação (Mestrado) - Escola de Educação Física e Esporte da Universidade de São Paulo.

Orientadora: Profa. Dra. Edilamar Menezes de Oliveira

1. Treinamento físico 2. Hipertrofia cardíaca 3. Sistema renina angiotensina I. Título. 


\title{
PERFIL DE microRNAs NO CORAÇÃO DE CAMUNDONGOS TREINADOS E QUE SUPEREXPRESSAM ECA2: PAPEL NO REMODELAMENTO CARDÍACO.
}

\author{
RESUMO \\ Autor: André C. Silveira \\ Orientadora: Edilamar M. Oliveira
}

\begin{abstract}
A hipertrofia cardíaca é caracterizada como um aumento da massa cardíaca e é considerada um mau prognóstico e está associada as diversas formas de insuficiência cardíaca. No entanto, outra forma de resposta hipertrófica pode ser gerada por meio do treinamento físico, o qual produz aumento proporcional da espessura da parede, levando ao fenótipo conhecido como "coração de atleta", onde há uma preservação ou melhora na função cardíaca. Ambos fenótipos de remodelamento cardíaco estão estritamente associados às vias canônicas e não canônicas do sistema renina angiotensina (SRA). Estudo prévio do nosso grupo demonstrou, que o treinamento físico aeróbio alterou a expressão de microRNAs envolvidos na regulação do SRA, em especial na regulação da expressão das enzimas chave deste sistema, a enzima conversora de angiotensina 1 (ECA) e enzima conversora de angiotensina 2 (ECA2). Porém, ainda pouco se sabe sobre o papel dos microRNAs na modulação do SRA local cardíaco em resposta ao treinamento físico. O presente estudo teve como objetivo traçar o perfil de expressão de microRNAs entre camundongos treinados e com superexpressão de ECA2 cardíaca. Nós utilizamos para isso, camundongos da linhagem C57BL/6 divididos em três grupos experimentais: 1) Sedentário 2) Grupo Treinado e com 3) superexpressão de ECA2 no coração. A superexpressão de ECA2 cardíaca resultou em aumento da massa cardíaca e na alteração de 14 microRNAs em relação ao grupo controle e o treinamento aeróbio embora não tenha apresentado alteração na massa cardíaca, alterou 4 microRNAs em relação ao controle. Destes microRNAs, 3 microRNAs (133a-5p, -208a-3p e -215) foram confirmados por RT-qPCR. A busca por alvos preditos destes microRNAs gerou uma lista de 418 genes que resultou em 24 vias de sinalização via KEGG Pathway. Destas, atenção foi dada para as vias próhipertróficas de PI3K e MAPK que são conhecidas por participarem do remodelamento cardíaco fisiológico e patológico.
\end{abstract}

Palavras chave: Sistema Renina- Angiotensina, Treinamento Físico, Hipertrofia Cardíaca. 


\title{
MICRORNA PROFILE IN THE HEART OF MICE TRAINED AND OVEREXPRESSING ECA2: ROLE IN CARDIAC REMODELING.
}

\author{
ABSTRACT \\ Author: André C. Silveira \\ Professor: Edilamar M. Oliveira
}

Cardiac hypertrophy is characterized as an increase in heart mass and is considered a poor prognostic sign, being associated with the various forms of heart failure. However, another form of hypertrophic response can be generated through physical training, which produces a proportional increase in wall thickness, leading to the phenotype known as the "athlete's heart," where there is preservation or improvement in cardiac function. Both phenotypes of cardiac remodeling are strictly associated with the canonical and noncanonical pathways of the renin angiotensin system (RAS). A previous study of our group demonstrated that aerobic physical training altered the expression of microRNAs involved in the regulation of RAS, especially in the regulation of the expression of the key enzymes of this system, angiotensin converting enzyme 1 (ACE) and angiotensin converting enzyme 2 (ACE2). However, little is known about the role of microRNAs in modulating cardiac local RAS in response to physical training. The present study aimed to identify the expression profile of microRNAs between trained mice and mice with overexpression of cardiac ACE2. We used C57BL/6 lineage mice divided into three experimental groups: 1) Sedentary 2) Trained Group and 3) overexpression of cardiac ACE2. The overexpression of cardiac ACE2 resulted in an increase in cardiac mass and in the alteration of 14 microRNAs in relation to the control group and the aerobic training, although it did not present alterations in the cardiac mass, altered 4 microRNAs in relation to the control. Of these microRNAs, 3 microRNAs (-133a-5p, -208a-3p and 215-5p) were confirmed by RT-qPCR. The search for predicted targets of these microRNAs generated a list of 418 genes that resulted in 24 signaling pathways via KEGG Pathway. Of these, attention was given to the pro-hypertrophic pathways of $\mathrm{PI} 3 \mathrm{~K}$ and MAPK that are known to participate in physiological and pathological cardiac remodeling.

Keywords: Renin-Angiotensin System, Physical Training, Cardiac Hypertrophy. 


\section{Folha de avaliação}

Silveira, André Casanova

PERFIL DE microRNAs NO CORAÇÃO DE CAMUNDONGOS TREINADOS E QUE SUPEREXPRESSAM ECA2:

PAPEL NO REMODELAMENTO CARDÍACO

Dissertação apresentada à Escola de Educação Física e Esporte da Universidade de São Paulo, como requisito parcial para a obtenção do título de Mestre em Ciências Área de Concentração: Biodinâmica do Movimento do Corpo Humano

Orientadora: $\operatorname{Prof}^{\mathrm{a}} \mathrm{Dr}^{\mathrm{a}}$ Edilamar Menezes de Oliveira Laboratório de Bioquímica e Biologia Molecular do Exercício

Aprovado em:

\section{Banca examinadora}

$\begin{array}{ll}\text { Prof.(a) } \operatorname{Dr}(\mathrm{a}) & \text { Instituição__ } \\ \text { Julgamento_ } & \text { Assinatura } \\ \text { Prof.(a) } \operatorname{Dr}(\mathrm{a}) & \text { Assituição_ } \\ \text { Julgamento } & \text { Instituição_ } \\ \text { Prof.(a) Dr(a) } & \text { Assinatura } \\ \text { Julgamento } & \text { Instituição_ } \\ \text { Prof.(a) Dr(a) } & \text { Assinatura }\end{array}$




\section{AGRADECIMENTOS}

Ao entrar no laboratório pela primeira vez em 2011, fui muito bem acolhido e me senti parte da "casa". Agradeço imensamente a minha orientadora Edilamar Menezes de Oliveira pelos dias de congresso, discussões, aulas e os momentos de descontração também (embora não pareça, orientadores são humanos também). A senhora, engrandeceu de uma forma única a minha formação acadêmica e pessoal.

Também agradeço por este acolhimento em especial aos companheiros de laboratório Tiago Fernandes e Ursula Soci, vocês contribuíram bastante para o meu crescimento pessoal e profissional.

Agradeço também a paciência dos companheiros de laboratório que me aguentaram durante esses anos, tanto durante os dias de mau humor como nos de bom humor, ambos são difíceis, eu sei. Em especial a Camila Gatto, Gabriel Tobias, Rodrigo Souza e Ney Robson.

Agradeço ao amigo Alexadre de Souza Pereira, o "Shrek" por ser sempre o mais paciente e dar os melhores conselhos nas horas difíceis.

Agradecimento em especial aos meus irmãos por opção Nametala e João Gomes, vocês são luzes importantes na minha vida.

Agradeço a minha família, Reinaldo Silveira, meu pai e Silvana Casanova, minha mãe, por sempre me apoiarem e confiarem plenamente em minhas decisões. Agradeço infinitamente a minhas avós maravilhosas, Dona Ophelia e Dona Juju. Agradecimento especial in memorian ao meu avô, Antonio Silveira, o senhor sempre será meu exemplo de vida. Amo vocês.

Agradeço minha esposa, Luciana Darro Canela, por me apoiar, aguentar e ainda ter a coragem de casar comigo.

Por fim, gostaria de agradecer a cada professor e funcionário da Escola de Educação Física e Esporte da Universidade de São Paulo. Agradeço a CAPES pela Bolsa concedida. 
"We've always defined ourselves by the ability to overcome the impossible. And we count these moments. These moments when we dare to aim higher, to break barriers, to reach for the stars, to make the unknown known. We count these moments as our proudest achievements. But we lost all that. Or perhaps we've just forgotten that we are still pioneers. And we've barely begun. And that our greatest accomplishments cannot be behind us, because our destiny lies above us." (Fala do personagem Cooper- Trecho retirado do Filme- Interestelar- 2014). 


\section{SUMÁRIO}

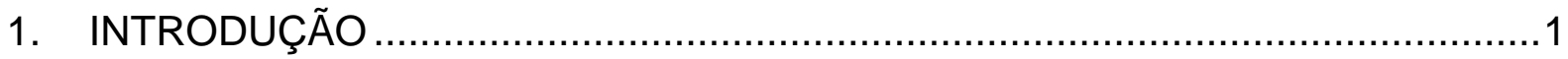

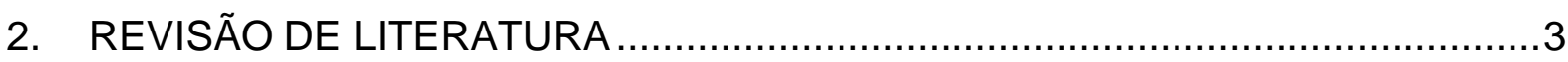

2.1 Efeito Cardioprotetor do Treinamento Físico …….........................................

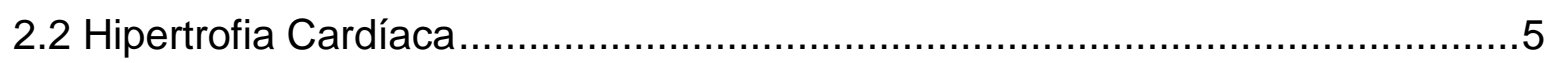

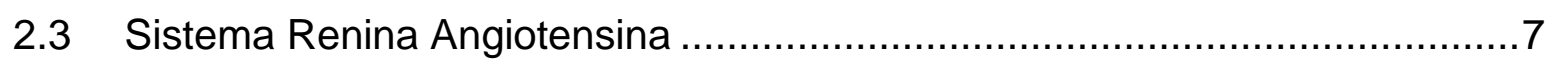

2.4 Sistema Renina Angiotensina e Coração ………….................................10

2.4 Sistema Renina Angiotensina e Exercício Físico ......................................13

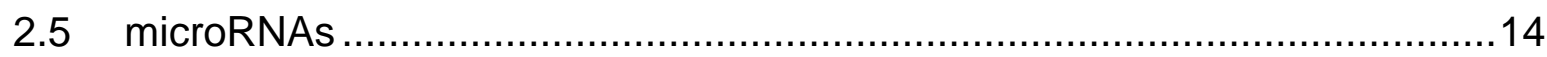

2.7 Sistema Renina Angiotensina e microRNAs .............................................15

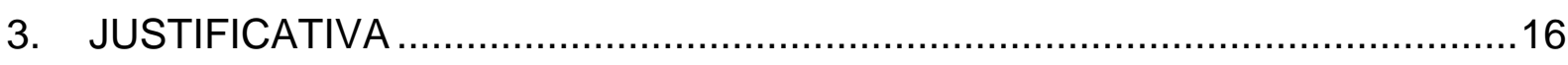

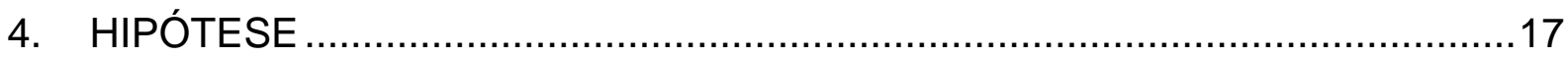

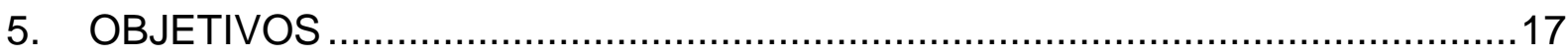

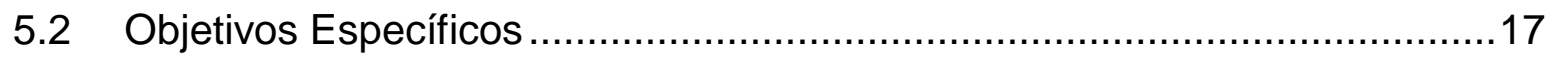

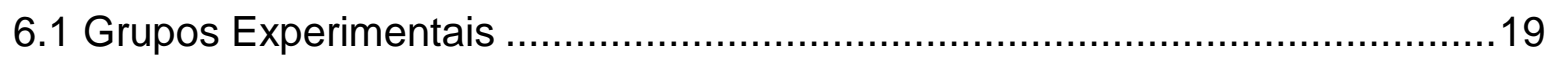

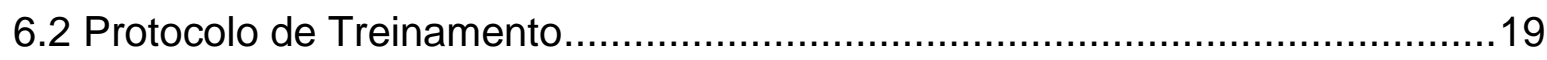

6.3 Avaliações das Respostas Hemodinâmicas ................................................19

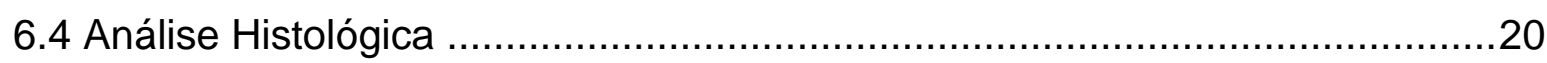

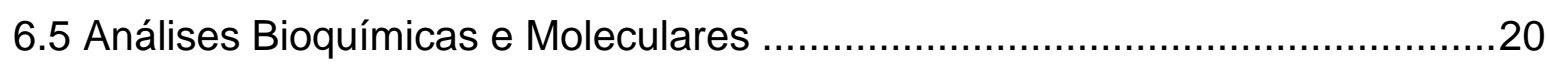

6.5.1 Obtenção do Plasma e Coleta do Tecido Cardíaco ...................................20

6.5.2 Determinação das Concentrações de Angiotensinas no plasma ...............21

6.5.3 Atividade da Enzima Citrato Sintase ...................................................22

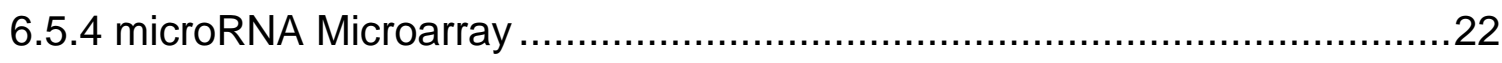

6.5.5 Análise da Expressão Gênica Utilizando qPCR após Transcrição Reversa .23

6.5.5 Quantificação da Expressão de Proteínas por Western Blot.....................25

6.7 Predição Bioinformática para Análise in silico: ................................................26

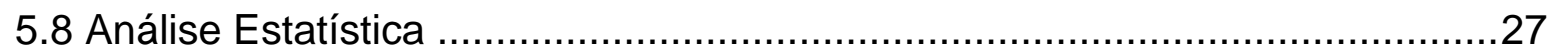

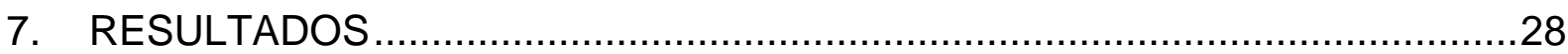

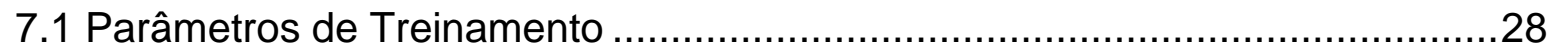

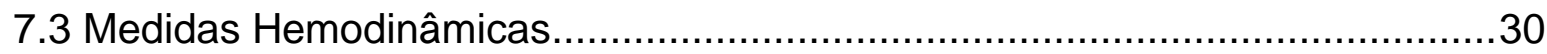




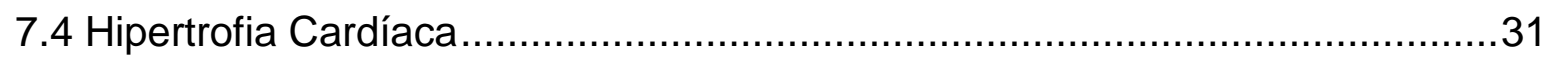

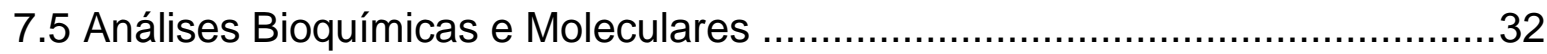

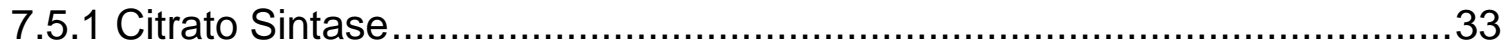

7.5.2 Marcadores de Hipertrofia Cardíaca ..................................................33

7.5.3 Expressão Gênica do Colágeno IAI e Colágeno 3AI................................34

7.5.4 Expressão Gênica, Proteica e Atividade da enzima Conversora de

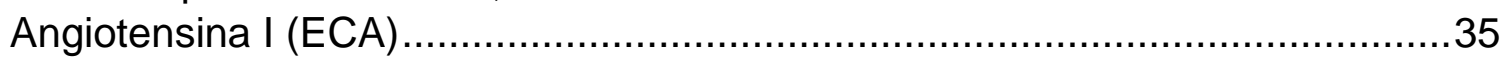

7.5.5 Expressão Gênica, Proteica e Atividade da Enzima Conversora de

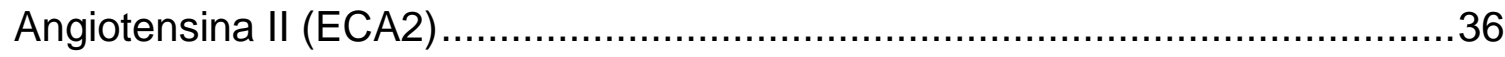

7.5.6 High Performance Liquid Chromatography (HPLC) no Plasma. ................37

7.5.7 Receptores do Sistema Renina Angiotensina. .........................................38

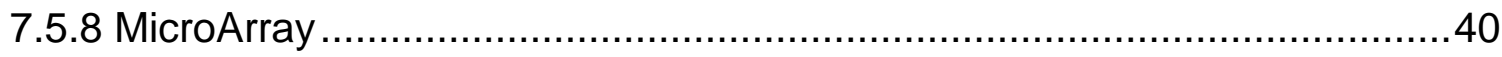

6.6 RT- qPCR- Confirmação dos microRNas do Array .........................................43

7.7 MicroRNAs para análise de bioinformática .................................................

7.8 Expressão Gênica dos Genes Alvo para os MicroRNAs -133a-5p, -208a-3p e -

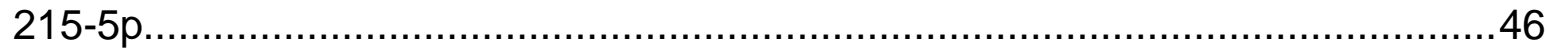

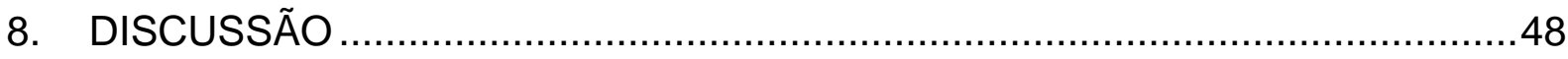

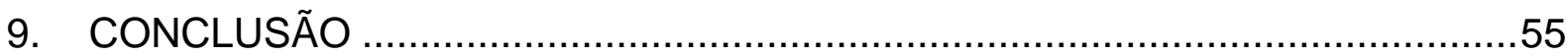

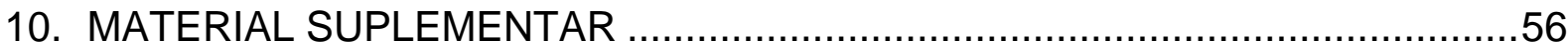

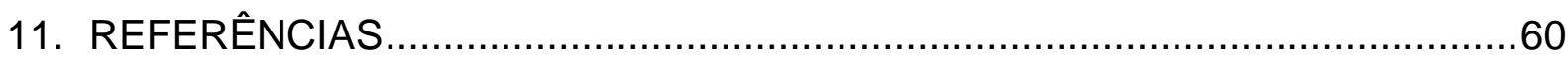




\section{INTRODUÇÃO}

O treinamento físico aeróbio é responsável por promover diversas adaptações cardiovasculares. Uma das respostas fenotípicas encontradas como resultado do treinamento físico realizado cronicamente é a hipertrofia cardíaca, sendo uma resposta adaptativa do miocárdio frente a uma sobrecarga hemodinâmica intermitente. Esta hipertrofia como resposta ao treinamento físico ocorre de uma forma intermitente, e é comumente conhecida como "coração de atleta". Nesta, há aumento da câmara cardíaca com aumento proporcional da parede, sem prejuízo ou até melhora da função cardíaca (MCMULLEN; JENNINGS, 2007). No entanto, há outro tipo de remodelamento cardíaco, quando causado por estímulos contínuos de sobrecarga, que resulta em hipertrofia cardíaca com fenótipo patológico e tem sido considerada um mau prognóstico, no qual o coração passa de um estado adaptativo para um modo descompensado e progride até a insuficiência cardíaca. No entanto, essas hipertrofias apresentam em comum a participação do sistema reninaangiotensina (SRA) (MEHTA; GRIENDLING, 2007).

Como revisado por Basso em 2001, o SRA clássico é um complexo sistema hormonal que vem sendo amplamente estudado desde a sua descoberta há mais de um século (BASSO; TERRAGNO, 2001). Desde então, muitos estudos mostram a participação deste sistema na homeostase do sistema cardiovascular, apresentando também ampla participação nas respostas metabólicas mediadas pelo exercício físico, o qual tem sido amplamente estudado como medida não farmacológica na prevenção de doenças crônicas como hipertensão, infarto do miocárdio, obesidade e diabetes, e até mesmo na reversão do fenótipo patológico da hipertrofia cardíaca (AUGUSTO et al., 2000; AVELAR et al., 2007; MCCOLLUM; GALLAGHER; ANN TALLANT, 2012; ARNOLD et al., 2014; MOTTA-SANTOS et al., 2016)

O SRA canônico tem início com a clivagem do angiotensinogênio (Agt) pela ação da enzima renina liberada pelas células justaglomerulares nos rins, formando então o decapeptídeo Angiotensina I (Ang-I) que por sua vez é convertida pela ação da ECA ao octapeptídeo Ang- II, o qual desempenha papel chave na homeostase cardiovascular quando ligada ao receptor de angiotensina 1 (AT1) e angiotensina 2 (AT2). O receptor AT1 é um receptor acoplado a proteína G e é responsável pela 
maioria das ações conhecidas de Ang-II, quando ligada ao receptor AT1 causa vasoconstrição, retenção hídrica e ação pró-hipertrófica pela ativação da via de MAPK/ERK1/2 (AUGUSTO et al., 2000; BASSO; TERRAGNO, 2001; FERREIRA et al., 2011b). No entanto, quando Ang-II é ligada ao receptor AT2, esta desempenha um papel antagônico ao de AT1, tendo um efeito cardioprotetor (PORRELLO; DELBRIDGE; THOMAS, 2009). O receptor de AT2 também é acoplado a proteína G e apresenta 34\% de homologia com AT1 embora suas ações sejam distintas (PORRELLO; DELBRIDGE; THOMAS, 2009). Sua expressão é relativamente alta durante o desenvolvimento e declina no período pós-natal. Sendo ainda que no miocárdio sua expressão é quase indetectável, mo entanto, diante de injurias cardiovasculares como infarto sua expressão é aumentada (STECKELINGS et al., 2010). Nas últimas décadas vem sendo amplamente estudada uma via alternativa do SRA, que tem como produto biológico ativo a Ang- (1-7), essa formada principalmente pela degradação da Ang-II pela ação da ECA2. Quando a Ang-(1-7) liga-se ao seu receptor MAS acoplado a proteína $\mathrm{G}$, desempenha um papel contra-regulatório ao do eixo canônico de Ang-II (CRACKOWER et al., 2002; CHAPPELL, 2007; PEDERSEN et al., 2011; PATEL et al., 2014).

Os componentes do SRA clássico e os de sua via alternativa já foram detectados em diversos tecidos (PAUL; POYAN MEHR; KREUTZ, 2006). No tecido cardíaco, estudos mostram que há ação deste sistema no processo de remodelamento cardíaco, tanto para o fenótipo de hipertrofia cardíaca patológico como fisiológico (PAUL; POYAN MEHR; KREUTZ, 2006; CHAPPELL, 2007; OLIVEIRA et al., 2009). Estudo in vitro demonstrou que miócitos tratados com Ang-II apresentaram fenótipo de hipertrofia e não miócitos (fibroblastos) apresentaram aumento no número de células, além disso, foi demonstrado que a administração de bloqueadores do receptor AT1 foram capazes de cessar estes efeitos deletérios (SADOSHIMA; IZUMO, 1993). Por outro lado, estudos com modelos animais vêm mostrando que a administração ou até mesmo a superexpressão de Ang- (1-7) resultam em efeito cardioprotetor (GIANI et al., 2010; MCCOLLUM; GALLAGHER; ANN TALLANT, 2012) MACHADO-SILVA et al., 2016; DARTORA DR, IRIGOYEN MC, CASALI KR, MORAES-SILVA IC, BERTAGNOLLI M, BADER M, 2017).

Ainda, estudos mostram que o treinamento físico aeróbio e resistido é capaz de modular os componentes tanto da via canônica quanto da via não canônica deste 
sistema, servindo como uma importante ferramenta, inclusive no controle do processo hipertrófico cardíaco (BARAUNA et al., 2008; OLIVEIRA et al., 2009; FERNANDES; SOCI; OLIVEIRA, 2011; ZAMO et al., 2011). Além disso, estudos recentes têm sugerido que o exercício pode regular a expressão de reguladores da expressão gênica, os microRNAs, que tem como alvo componentes do SRA (FERNANDES et al., 2015).

Os microRNAs são pequenos RNAs com aproximadamente 22 nucleotídeos, que regulam negativamente a expressão de seus genes alvos (LEE et al., 2003). Eles vêm sendo amplamente estudados por desempenhar importante papel na regulação de processos patológicos e fisiológicos, inclusive no remodelamento cardíaco. Já é bem descrito na literatura que o exercício físico é capaz de modular a expressão de diversos microRNAs (FERNANDES et al., 2011; SOCl et al., 2011; GU et al., 2014). Um estudo anterior de nosso grupo, demonstrou que a expressão de microRNAs modulados com o treinamento físico regulam a expressão da ECA e ECA2, mostrando que os microRNAs tem um papel fundamental na manutenção deste sistema e que treinamento físico aeróbio pode ser uma terapia não farmacológica à normalização do SRA (FERNANDES et al., 2011).

Desta forma, nossos objetivos no presente estudo são compreender quais os mecanismos moleculares envolvidos na via do SRA não canônico no tecido cardíaco em resposta ao exercício físico e também em animais transgênicos com superexpressão de ECA2, uma vez que está enzima é um ponto chave para o eixo não canônico. $E$ assim, buscar microRNAs terapêuticos que tenham como alvo este sistema ou que modulem sua resposta em outras vias de sinalização.

\section{REVISÃO DE LITERATURA}

\subsection{Efeito Cardioprotetor do Treinamento Físico}

O treinamento físico, tanto aeróbio como resistido é responsável por desencadear diversas adaptações que influenciam diretamente no sistema cardiovascular (DE ANGELIS et al., 2004). Em estudos clássicos de Morris com trabalhadores londrinos em 1953 foi mostrado que motoristas de ônibus de dois 
andares tinham maior propensão à "trombose coronariana" se comparados aos cobradores que necessitavam percorrer os dois andares do ônibus, sendo assim, mais ativos. Estes achados demonstram que atividade física apresenta importante papel cardioprotetivo (MORRIS; CRAWFORD, 1958). Assim, o exercício tem sido importante ferramenta não farmacológica tanto na prevenção como na reversão de fatores de risco para doenças cardiovasculares que resultam em fenótipo de insuficiência cardíaca como a obesidade, hipertensão, infarto de miocárdio e diabetes (FRISBEE et al., 2006; BUENO et al., 2010; BARRETTI et al., 2012; SHAH et al., 2012).

Dentre as adaptações cardíacas ocorridas com o treinamento físico aeróbio a ocorrência de bradicardia de repouso, em resposta ao aumento do tono vagal, de diminuição da atividade nervosa simpática ou da diminuição da atividade intrínseca cardíaca, é bem demonstrada e funciona como importante marcador de eficiência do treinamento e melhora da função cardiovascular (DE ANGELIS et al., 2004; MEDEIROS et al., 2004).

Outra adaptação recorrente do treinamento físico é o fenótipo conhecido como "coração de atleta", causado por um conjunto de alterações eletrocardiográficas e ecocardiográficas que resultam de treinamento físico intenso ou prolongado, que levam a hipertrofia dos cardiomiócitos, sem alteração ou com melhora na função cardíaca (SHARMA, 2012).

Como apresentado em revisão de Vega RB e colaboradores, o coração tem uma capacidade inata de identificar e distinguir os tipos de estresse a que é submetido, sendo este dinâmico ou estático e se é patológico ou fisiológico (VEGA et al., 2017). Assim, é bem demonstrado que o treinamento modula vias de sinalização celular preferenciais levando a uma adaptação benéfica (MCMULLEN et al., 2004). Além disso, vias ligadas ao metabolismo celular são atividas de formas distintas na hipertrofia fisiológica e patológica, como revisado por Vega RB, é demonstrado um importante papel do exercício na biogenese mitocondrial, sendo está correlacioanado a melhora na capacidade oxidativa do coração, enquanto o coração com fenótipo patológico apresenta um metabolismo glicolitico (VEGA et al., 2017).

Nas últimas décadas, vem sendo bem demonstrada a participação de pequenas moléculas reguladoras negativas de expressão gênica, os microRNAs, nas 
adaptações causadas pelo exercício no sistema cardiovascular (FERNANDES et al., 2011; SOCI et al., 2011; EULALIO et al., 2012; BERNARDO et al., 2014; LIU et al., 2015).

\subsection{Hipertrofia Cardíaca}

O coração apresenta alta plasticidade, podendo se remodelar em resposta a diferentes demandas a ele imposta. Esta adaptabilidade é resultante de um mecanismo protetor, onde o coração tenta reduzir o stress causado frente a uma sobrecarga. Dependendo da intensidade e da continuidade deste estímulo, serão geradas diferentes adaptações, sendo que a principal é uma resposta hipertrófica, que leva a mudança no fenótipo cardíaco. Essa mudança no fenótipo é dependente da natureza do estímulo, podendo gerar uma hipertrofia cardíaca fisiológica ou patológica. A diferença destas hipertrofias está nas respostas moleculares e também funcionais do miocárdio (HILL; OLSON, 2008).

A hipertrofia patológica resulta comumente de um mecanismo compensatório, quando há uma sobrecarga crônica de trabalho imposta ao miocárdio. É bem descrito na literatura que neste fenótipo de hipertrofia leva a passagem de um mecanismo adaptativo compensatório para um estado descompensado que progride para insuficiência cardíaca (GROSSMAN; JONES; MCLAURIN, 1975; ROTHERMEL et al., 2005; WARING et al., 2014). Isto ocorre, por exemplo, em doenças crônicas como hipertensão arterial, que leva há uma contínua e excessiva sobrecarga mecânica no coração, ativando vias de sinalizações preferenciais, que resultam no remodelamento cardíaco patológico (AVELAR et al., 2007). Este remodelamento é caracterizado pelo aumento de componentes da matriz-extracelular e reprogramação da carga genética fetal, ou seja, está associada a um aumento na expressão de genes que seriam expressos em abundância no coração apenas durante o período embrionário: betamiosina de cadeia pesada ( $\beta$ - MCP), $\alpha$ - actina esquelética, além do fator natriurético atrial (ANF), sendo assim, estes são considerados os principais marcadores moleculares de hipertrofia cardíaca patológica (DE SIMONE et al., 1994; FERNANDES et al., 2011; HASHIMOTO; FERNANDES; OLIVEIRA, 2011).

O estudo de Framingham, sobre coração, é o mais clássico estudo epidemiológico, que busca compreender os maiores fatores de risco para o 
desenvolvimento de doenças cardiovasculares (OPPENHEIMER, 2010). Este estudo que teve início em 1948 e que atualmente está em sua terceira geração, continua apontando que um dos principais fatores de risco cardiovascular é a inatividade física. Em estudo de Levy e colaboradores foi analisado o coração por ecocardiografia de 4976 pacientes deste estudo de Framingham (LEVY et al., 1988). Eles observaram que o fenótipo de hipertrofia é mais frequente com o envelhecimento e aponta que redução da pressão arterial e redução do peso corporal ajudam na prevenção e regressão deste fenótipo (LEVY et al., 1988). Assim, o exercício físico surge como uma forte terapia não farmacológica para esta patologia.

Conforme mencionado anteriormente, a hipertrofia cardíaca fisiológica por sua vez, se mostra dependente do tipo de treinamento. Diante de diferentes intensidades e/ou volumes de treinamento pode apresentar um padrão concêntrico ou excêntrico. A concêntrica é geralmente causada por exercícios resistidos em que é exigida maior sobrecarga pressórica levando a um elevado pico de tensão sistólica, ocasionando o aumento da parede do ventrículo esquerdo (VE) com a adição de sarcômeros em paralelo, entretanto, diferente da patológica a cavidade ventricular é preservada (PLUIM et al., 2000). Já a hipertrofia fisiológica excêntrica, adiciona sarcômeros em série, e consequente aumento no comprimento das miofibrilas. Esta é relacionada a exercícios aeróbicos, como a corrida onde é exigida uma maior sobrecarga volumétrica (BYE et al., 2008). Interessantemente, em estudo publicado em 2011 por Boström e colaboradores é mostrado um importante papel do treinamento físico sobre a plasticidade cardíaca, no qual a hipertrofia cardíaca fisiológica induzida pelo treinamento físico leva a aumento de novos cardiomiócitos, sendo este mecanismo regulado pelo fator de transcrição CEBPß (CCAAT/ enhancer- binding protein beta) (BOSTRÖM et al., 2011). Estes achados são de grande importância, uma vez que era pensado que a capacidade proliferativa do coração era cessada no período pós-natal.

Um importante entreposto nas duas formas de hipertrofia é a participação do SRA. Este possui grande importância neste processo de remodelamento cardíaco por ativar vias de sinalização preferencias. Sendo que diversas terapias, inclusive o treinamento físico mostram eficiência na modulação deste sistema para a prevenção e até mesmo reversão do processo hipertrófico cardíaco patológico (MEHTA; GRIENDLING, 2007). 


\subsection{Sistema Renina Angiotensina}

O SRA é um complexo sistema hormonal que desempenha importante papel para fisiologia cardiovascular, principalmente pela sua regulação na pressão arterial e volume homeostático (DZAU; BURT; PRATT, 1988).

No SRA canônico, a enzima renina é liberada pelas células justaglomerulares nos rins. Esta enzima foi descrita pela primeira vez em 1898 quando Tigerstedt e seu aluno, Bergman, analisando a influência do extrato renal de coelhos sobre a pressão arterial, conseguiram detectar a presença de um componente pressórico que denominaram de "renina" (MARKS; MAXWELL, 1898). Esta enzima é responsável por hidrolizar o Agt, liberando a Ang-I, que por sua vez sofre a ação da ECA, convertendoa em um octapeptídeo biologicamente ativo conhecido como Ang-II, que se liga ao receptor AT1, como foi descrito por Inagami e colaboradores (DE GASPARO, M., CATT, K. J., INAGAMI, T, WRIGHT, J. W. AND UNGER, 2000) e desencadeia assim diversos efeitos como retenção de sódio, hídrica e vasoconstrição (AUGUSTO et al., 2000). Ou ainda, pode ligar-se aos receptores AT2 acarretando em efeitos antagônicos ao de AT1 (STECKELINGS et al., 2010).

A ECA foi descrita por Skeegs e colaboradores em estudo onde eles apresentaram que neste sistema havia uma enzima além da renina, e que esta seria capaz de converter "hypertensin I" em "hypertensin II" (SKEGGS; KAHN; SHUMWAY, 1956). Esta enzima foi denominada de ECA, tendo papel chave no SRA sendo a responsável por formar seu produto biológico ativo. Após isso, começou uma grande busca por terapias farmacológicas a fim de inibi-la para o controle da pressão arterial, como revisado por Basso e Terragno em 2001 (BASSO; TERRAGNO, 2001).

Curiosamente, com o avanço das técnicas de biologia molecular e genética, foi possível identificar polimorfismos no gene da ECA. O polimorfismo II/DD é caracterizado pela inserção (alelo I) ou pela delação (alelo D) de 287 pares de base. Indivíduos que apresentam no seu genótipo o alelo $D$ apresentam maior quantidade de ECA circulante, sendo que esta condição foi relacionada à maior propensão de desenvolver hipertrofia cardíaca patológica (SAYED-TABATABAEI et al., 2006). No entanto, Montgomery em editorial publicado na Heart em 1997 cita que os fatores ambientais influenciam mais do que o genótipo para este fenótipo (MONTGOMERY, 
1997). Este polimorfismo também apresenta grande importância na resposta ao treinamento físico. No fenótipo de hipertrofia cardíaca fisiológica, os indivíduos homozigotos DD são mais responsivos aos estímulos hipertróficos fisiológicos e apresentam melhor desempenho para esporte de força e potência, enquanto os homozigotos II apresentam melhor desempenho aeróbio (MONTGOMERY et al., 1997, 1998).

Outro componente deste sistema que gerou inúmeros estudos a fim de buscar tratamentos farmacológicos foram os receptores de Ang-II, sendo que terapias inibitórias para o receptor AT1 já existem há mais de 20 anos (TIMMERMANS et al., 1995, KASCHINA UNGER, 2003). Estes receptores de angiotensina apresentam importante papel em diversos processos patológicos e fisiológicos. As maiores ações de Ang-II são mediadas por dois subtipos de receptores de angiotensina, os receptores AT1 e AT2. Estes são receptores acoplados à proteína-G com sete domínios transmembrânicos e desempenham papeis independentes(TIMMERMANS et al., 1995). O receptor AT1 é acoplado à proteína $G q$, sendo assim, preferencialmente ativa a fosfolipase $C$ (FLPC) que desencadeia os principais efeitos gerados pelo componente biológico ativo de SRA canônico, a Ang-II. Na literatura é bem demonstrado que um destes efeitos é o processo hipertrófico, que comumente é gerado pela ativação da via de sinalização da MAPK/ERK1/2 (mitogen-activated protein kinase) responsável por efeitos como proliferação e crescimento celular (LUZARDO et al., 2014). A ligação de Ang-ll ao receptor AT1 também é responsável por ativar fibroblastos aumentando assim componentes da matriz extracelular (SADOSHIMA; IZUMO, 1993). Por outro lado, o receptor AT2 desempenha efeitos antagônicos e independentes do AT1 (KASCHINA; UNGER, 2003). O receptor AT2 tem sua expressão relativamente alta durante o desenvolvimento e declina no período pós-natal (PORRELLO; DELBRIDGE; THOMAS, 2009). Sendo ainda que no miocárdio sua expressão é quase indetectável. No entanto, diante de injurias cardiovasculares como infarto sua expressão é aumentada. Como revisado em 2015 por Mendoza- Torres, o receptor AT2 também pode ter a Angiotensina A e Angiotensina- (1-9) como ligantes, não apenas a Ang-II.

$\mathrm{Na}$ hipertrofia cardíaca fisiológica, o receptor AT1 parece exercer um papel chave, em trabalho de Barauna e colaboradores (2008) foi demonstrado que a inibição deste receptor cessou o remodelamento cardíaco induzido por treinamento resistido 
(BARAUNA et al., 2008), ativado B-arrestina e a via de sinalização da PI3K-AKTmTOR e ERK 1/2, independente da ação sobre receptores de IGF-1 (MELO et al., 2017).

Com os avanços nas técnicas de bioquímica e biologia molecular se tornou possível à identificação de um novo eixo deste sistema, tendo uma ação antagônica ao SRA canônico. Este SRA não-canônico tem como principal produto biológico ativo a Ang-(1-7), que é formada pela ação da ECA2 (PAUL; POYAN MEHR; KREUTZ, 2006; CHAPPELL, 2007; PHYSIOLOGICAL; OF; RENIN, 2011; MCCOLLUM; GALLAGHER; ANN TALLANT, 2012). Está enzima apresenta uma sequência de 40\% dos aminoácidos homólogos à ECA e é responsável principalmente em metabolizar Ang-Il para formação do heptapeptídeo Ang-(1-7), no entanto, há outro mecanismo onde ela é capaz de remover o resíduo (Leu) da Ang-I convertendo-a em Angiotensina-(1-9) (Ang-[1-9]) que é clivada à Ang-(1-7) (TIPNIS et al., 2000; MENDOZA-TORRES et al., 2015). Ang-(1-7) quando ligada ao receptor MAS desencadeia vias de sinalização com um papel chave em contra-regular os efeitos do SRA canônico, levando à vasodilatação, efeito anti-fibrótico e anti-hipertrófico. A ECA2 se mostra um ponto chave neste sistema, uma vez que é necessária sua ação para a formação dos produtos biológicos ativos. Está enzima foi descrita por Tipinis e colaboradores em 2000. Porém, o mecanismo de ação foi descrito por Donoghue e colaboradores. Nesta publicação ele demonstra que ECA2 é responsável por hidrolisar a Leucina carboxi-terminal da Ang-I gerando assim Ang-(1-9) (DONOGHUE et al., 2000).

Recentemente, estudos vêm demonstrando que a Ang-(1-9) desempenha um papel cardioprotetor quando ligada ao receptor AT2 (OCARANZA et al., 2014). Esta até então era descrita como um produto biológico inativo deste sistema. No entanto, Ocaranza e colaboradores demonstraram que animais que foram infundidos com Ang-II combinada com Ang-(1-9) e com inibição do receptor AT1 apresentaram efeitos anti-hipertrófico e anti-fibrótico independente de Ang-(1-7) (OCARANZA et al., 2014; MENDOZA-TORRES et al., 2015).

Aumentando ainda mais o conhecimento sobre esta nova via, Lautner e colaboradores (2013) publicaram a descoberta de mais um novo componente ativo para SRA, a alamandina, detectada por espectrometria de massa. Esta possui papel 
similar à ação de Ang-(1-7) e é sintetizada pela ação de ECA2 clivando Angiotensina A ou pela descarboxilação de Ang-(1-7) e tem suas ações mediadas pelo receptor Mas-related GPCR, member D (MrgD) (LAUTNER et al., 2013).

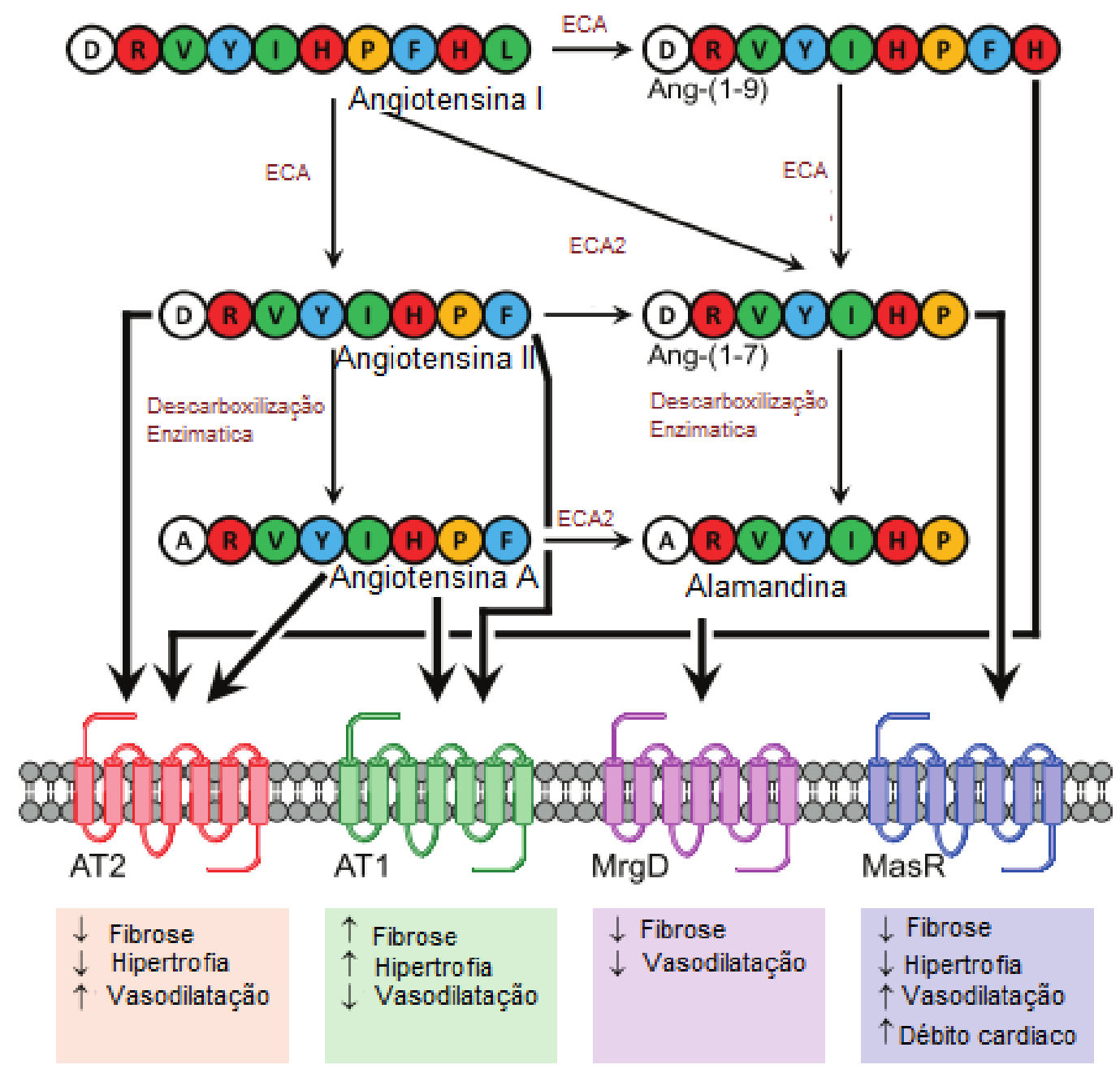

Figura 1. Vias do SRA: ECA2 e peptídeos vasoativos. ECA, Enzima conversora de Angiotensina; ECA2, Enzima conversora de angiotensina 2; AT2R, Receptor de angiotensina 2; MasR, Mas receptor; MrgD, Mas-related G protein- coupled receptor member $D$. Adaptado de (MENDOZA-TORRES et al., 2015).

\subsection{Sistema Renina Angiotensina e Coração}

Com o avanço das técnicas experimentais foi possível identificar RNAm dos componentes de SRA em diversos tecidos, entre eles no coração. Em estudo de Campbell em 1986, ele buscou em 17 tecidos diferentes à expressão de Agt, a fim de determinar se havia um sistema local, uma vez que seria necessário Agt para 
formação de Ang-II (CAMPBELL; HABENER, 1986). Assim, foi possível identificar em 12 destes tecidos, dentre eles no átrio, embora não em altas concentrações. Em estudo posterior ao de Campbell, de Dzau e colaboradores demonstraram que há expressão de renina no cérebro e no coração, embora a concentração de Agt seja muito superior a de renina (CAMPBELL; HABENER, 1986; DZAU et al., 1987). No entanto, é consenso de que a síntese de renina é baixa e praticamente indetectável no coração e que para viabilidade do SRA local, há um processo de captação de renina circulante para o coração por difusão e através da ligação de receptores (DE MELLO; DANSER, 2000).

Porém, em estudo de Pieruzzi (1995) foi demonstrado um aumento significante de renina cardíaca em resposta a diferentes graus de insuficiência cardíaca, mostrando assim que o desenvolvimento de insuficiência está correlacionado ao aumento da atividade de SRA local (PIERUZZI; ABASSI; KEISER, 1995).

Ang-II, por sua vez, apresenta baixas concentrações no coração em condições fisiológicas se comparado ao plasma. No entanto, estudos mostram a relação da AngII local desempenhando efeitos tróficos no coração, como a hipertrofia de cardiomiócitos e aumento de fibrose (DE MELLO; DANSER, 2000).

Os receptores do SRA também desempenham papel importante na fisiologia cardiovascular. Samyn (1998) demonstrou que a expressão cardíaca de AT1 é inalterada durante o período fetal e neonatal, no entanto, o receptor AT2 apresenta uma alta expressão no período fetal e tem sua expressão diminuída logo após 0 nascimento, mostrando assim importante papel deste receptor no desenvolvimento embrionário (SAMYN et al., 1998). Ainda, corroborando com a importância destes receptores, estudos com animais knockout (KO) para o receptor AT1 demonstram que frente a um estímulo patológico como infarto do miocárdio, estes animais possuem menor desenvolvimento de hipertrofia cardíaca e aumento de sobrevida (HARADA et al., 1999). Assim, vista a relação do SRA com o processo trófico no miocárdio, diversos estudos mostram que a inibição da ECA e do receptor AT1 com uso de fármacos é capaz de cessar o processo de remodelamento cardíaco (SADOSHIMA; IZUMO, 1993; BARAUNA et al., 2008; OLIVEIRA et al., 2009).

O SRA não- canônico também tem seus principais componentes (Ang- (1-7)/ ECA2/MAS) detectados localmente no coração (BADER, 2010). Muitos estudos vêm 
mostrando que Ang-(1-7) via seu receptor desempenha uma ação local cardioprotetora, melhorando a função cardíaca com diminuição do conteúdo fibrótico e prevenindo hipertrofia cardíaca patológica, além disso, também é demonstrado que a deleção do receptor MAS causa aumento de fibrose cardíaca (SANTOS et al., 2003; PAUL; POYAN MEHR; KREUTZ, 2006; MERCURE et al., 2008; IWAI; HORIUCHI, 2009; OLIVEIRA et al., 2009; BADER, 2010; DIAS-PEIXOTO et al., 2012; GAVA et al., 2012).

Uma vez que há um componente biológico com expressão local capaz de contra regular os efeitos prejudiciais do SRA canônico, o qual já foi demonstrado ter participação local na progressão de insuficiência cardíaca, abre-se uma nova busca por terapias (PIERUZZI; ABASSI; KEISER, 1995). No entanto, a administração de componentes deste SRA não canônico, como a Ang-(1-7) como terapia ainda causa algumas controvérsias (MERCURE et al., 2008). A literatura lista diversos efeitos da Ang-(1-7) na prevenção do processo de remodelamento cardíaco patológico, como em estudo de Giani e colaboradores (2010), que mostrou que a administração crônica de Ang-(1-7) preveniu o processo de hipertrofia cardíaca e aumento da fibrose cardíaca em ratos submetidos a uma sobrecarga de frutose (GIANI et al., 2010). Corroborando com estes achados, em estudo de McCollum LT e colaboradores (2011), mostraram que ratos infundidos com Ang-II com co-infusão de Ang-(1-7) tiveram atenuação no processo de remodelamento cardíaco patológico quando comparado ao grupo que foi tratado apenas com Ang-II (MCCOLLUM; GALLAGHER; ANN TALLANT, 2012). Porém, apesar dos diversos estudos que mostram a administração de Ang-(1-7) com seus efeitos cardioprotetores, também há estudos que mostram que a superexpressão de outros componentes deste eixo podem ter efeitos deletérios como arritmias e morte súbita, além disso, podendo levar ao aumento de NADPH oxidase, mostrando um possível aumento no estresse oxidativo (DONOGHUE et al., 2000; LO et al., 2013). Contrapondo-se e endossando o efeito cardioprotetor deste eixo não canônico, Ferreira AJ e colaboradores (2011) demonstraram que este eixo (ACE-2/ Ang-(1-7) /Mas) está presente no nó-sinoatrial de ratos saudáveis e que Ang-(1-7) desempenha importante papel arritmogênico em animais frente à isquemia (FERREIRA et al., 2011a).

A ECA2 possui papel chave neste eixo não canônico e é altamente expressa no coração. Estudos apontam que a superexpressão de ECA2, feita por meio de 
adenovírus, foi responsável por prevenir a hipertrofia cardíaca patológica induzida por hipertensão e diminuir a fibrose cardíaca (CRACKOWER et al., 2002; DÍEZ-FREIRE et al., 2006) e inibir a via de sinalização de MAPK/ERK1/2, cessando o processo hipertrófico ativado pela interação de Ang-II com o seu receptor AT1(FERREIRA et al., 2011b).

\subsection{Sistema Renina Angiotensina e Exercício Físico}

Muitos estudos mostram a participação do SRA na homeostase do sistema cardiovascular, prevenindo o remodelamento cardíaco em diversas patologias. Ao mesmo tempo, o exercício físico tem sido amplamente estudado como medida não farmacológica na prevenção e reversão deste remodelamento em diversas patologias, como hipertensão, obesidade, infarto do miocárdio e insuficiência cardíaca (FERNANDES; SOCI; OLIVEIRA, 2011; SILVA et al., 2011; DIAS-PEIXOTO et al., 2012).

Nosso grupo já demonstrou que o treinamento físico aeróbio, é capaz de modular os componentes do SRA em diferentes estágios da hipertensão controlando o remodelamento cardíaco patológico (ZAMO et al., 2011), o mesmo é visto em estudo com modelo de ratos Zucker Obeso, estes animais apresentaram um aumento de Ang-II cardíaca e o treinamento foi capaz de normalizar está expressão e prevenir a hipertrofia cardíaca patológica (BARRETTI et al., 2012). Ainda, já demonstramos que a hipertrofia cardíaca fisiológica, tanto por treinamento físico aeróbio como por treinamento resistido também é regulada por componentes do SRA (BARAUNA et al., 2008). Oliveira em estudo publicado em 2009, mostrou que animais com inibição de componentes do SRA (Enalapril [inibidor de ECA]) e Losartan (inibidor do receptor [AT1]), quando submetidos ao treinamento físico aeróbio de natação tinham atenuação do remodelamento cardíaco fisiológico se comparados ao grupo que apenas realizou treinamento físico aeróbio sem inibição de ECA ou do receptor AT1 (OLIVEIRA et al., 2009). Ainda, em estudo com treinamento resistido, Barauna demonstrou que a expressão de Ang-II não apresentou nenhuma diferença significante, no entanto, o receptor AT1estava significantemente aumentado nos grupos treinados e sua inibição combinada com o preveniu o remodelamento cardíaco, indicando que este receptor pode desempenhar um papel chave no fenótipo 
de hipertrofia cardíaca fisiológica em decorrência do treinamento resistido (BARAUNA et al., 2005, 2008).

Recentemente, alguns estudos também têm investigado o papel do exercício físico na regulação do sistema não canônico (Ang- [1-7]/ECA2/MAS). Estudos com modelos animais demonstram que o treinamento físico é capaz de aumentar Ang-(17) assim como, a atividade de ECA2 e do receptor MAS, proporcionando melhora na complacência vascular e prevenção no remodelamento cardíaco patológico, mostrando o papel fundamental desta via alternativa do SRA para manutenção do funcionamento fisiológico do miocárdio (DÍEZ-FREIRE et al., 2006; FILHO et al., 2008; FERNANDES et al., 2011; DIAS-PEIXOTO et al., 2012; PATEL et al., 2014; SILVA et al., 2015). Em 2014, estudo de Bertagnolli M demonstrou que a administração oral de Ang-(1-7) produziu efeitos benéficos em ratos SHR, semelhantes aos benefícios causados pelo treinamento físico (BERTAGNOLLI et al., 2014).

Em recente estudo de Motta-Santos e colaboradores, foi demonstrado que animais KO para ECA2 apresentavam deficiência nas respostas causadas pela atividade física voluntária em camundongos (MOTTA-SANTOS et al., 2016). Ainda, o treinamento físico aeróbio de natação, em ratos, aumentou a expressão da ECA2 e a concentração de Ang-(1-7) e diminuição de Ang-Il local, no coração. Este estudo também foi o primeiro a demonstrar a participação dos microRNAs na regulação da expressão destes componentes do SRA com o treinamento físico (FERNANDES et al., 2011).

\section{5 microRNAs}

Os microRNAs, são pequenos RNAs com uma sequência de aproximadamente 22 nucleotídeos, que regulam a expressão de seus genes alvo, inibindo a tradução do RNAm ou degradando-o (LEE et al., 2003). Os microRNAs são transcritos endogenamente pela ação da enzima RNA-Polimerase II, originando um transcrito primário chamado pri-microRNA, este pri-microRNA apresenta uma longa sequência de nucleotídeos até ser clivado pela Ribonuclease III conhecida como DROSHA (LEE et al., 2003). Após essa clivagem é formado um pré-microRNA, com aproximadamente 60-70 nucleotídeos, que é exportado do núcleo para o citoplasma pela Exportina-5 (LEE et al., 2003). No citoplasma o pré-microRNA sofre ação da enzima Dicer, clivando-o à 19-22 nucleotídeos (LEE et al., 2003). A enzima Dicer ainda carreia o 
pré-microRNA ao complexo RISC (RNA induced silence complex), onde uma das fitas do microRNA se liga ao complexo RISC (LEE et al., 2003). Como parte do complexo RISC, os microRNAs regulam negativamente a expressão gênica por meio de dois mecanismos, a repressão translacional e clivagem do RNAm, que dependem do grau de complementaridade entre o microRNA e seu RNAm alvo ( LEE et al., 2003; GRUETER et al., 2012; van ROOJI et al. 2012).

Os microRNAs vem sendo amplamente estudados por apresentar importante papel regulatório em diversos processos patológicos e fisiológicos (GRUETER et al., 2012). No entanto, ainda são pouco elucidativos os estudos que mostram a participação de microRNAs atuando especificamente sobre componentes da via nãocanônica do SRA e doenças cardiovasculares.

Por fim, muitos estudos têm demonstrado a eficácia do treinamento físico em modular a expressão de diversos microRNAs, regulando seus genes alvos em processos patológicos e fisiológicos, como angiogênese, hipertensão, hipertrofia cardíaca, obesidade e infarto do miocárdio. Portanto, o treinamento físico é um importante agente terapêutico não farmacológico para prevenção e reversão de processos patológicos (MCMULLEN; JENNINGS, 2007; FERNANDES; SOCl; OLIVEIRA, 2011; SOCl et al., 2011; MELO et al., 2014).

\subsection{Sistema Renina Angiotensina e microRNAs}

Diversas terapias farmacológicas visando modular componentes do SRA vêm sendo descritas há décadas, por exemplo, inibição dos seus receptores (TIMMERMANS et al., 1995). Com a descoberta dos microRNAs abre-se um novo campo de busca para terapias do controle deste sistema.

Recentemente, Diniz e colaboradores (2015) demonstraram que a hipertrofia cardíaca causada por hipertireoidismo em ratos é induzida via receptor AT1, uma vez que a inibição deste com o uso de fármaco Losartan preveniu este fenótipo hipertrófico (DINIZ et al., 2015). Ainda, neste estudo foi demonstrado que este mecanismo hipertrófico está relacionado com a expressão do microRNA-133a (DINIZ et al., 2015). Este mesmo microRNA também é mostrado, no estudo de Rana e colaboradores (2015)(RANA et al., 2015), que este junto com os microRNAs -1, -212 e -132 seriam 
possíveis candidatos há um efeito cardioprotetor em animais que apresentavam doença renal.

Nosso grupo vem mostrando que o treinamento físico também é capaz de modular a expressão de diversos microRNAs, que participam do processo de remodelamento cardíaco (FERNANDES et al., 2015).

O efeito do treinamento físico e a expressão de microRNAs ligados ao SRA cardíaco foi visto em estudo de Fernandes (FERNANDES et al., 2011), no qual os autores mostraram que o treinamento físico aeróbio de natação em animais normotensos causa modulação na expressão de de microRNAs que tem como alvo componentes do SRA. A expressão dos microRNAs-27a e -27b foi aumentada nos grupos treinados quando comparado ao grupo sedentário, enquanto a expressão de seu alvo, a ECA, foi diminuída nestes grupos treinados (FERNANDES et al., 2011). O mesmo foi observado para a expressão do microRNA-143, que foi diminuído nos animais treinados, se opondo a expressão do seu alvo direto, a ECA2, que estava aumentada nos grupos treinados em relação ao grupo sedentário. Este estudo de Fernandes e colaboradores foi o primeiro estudo que demonstrou a participação dos microRNAs e treinamento físico na regulação dos componentes do SRA canônico e do não- canônico SRA [eixo ECA2/Ang-(1-7)] (FERNANDES et al., 2011).

\section{JUSTIFICATIVA}

A descoberta da ECA2 no ano 2000 abriu um novo capítulo na história do SRA, o que claramente configura uma segunda via do sistema, do qual emergem a Ang-(17), ECA2 e o receptor MAS. A ECA2 desempenha papel chave neste eixo por gerar um potente produto biológico ativo com função vasodilatadora e anti-fibrótica, a Ang (1-7), por metabolizar a Ang-II. Desta forma, contrabalançando os efeitos vasopressores da ECA mediados pela Ang-II.

Em 2011, nosso grupo demonstrou que os genes da ECA e ECA2 podem ser regulados pelos microRNA-27a e -27b e pelo microRNA-143 (FERNANDES ET AL., 2011), porém pouco se sabe sobre o efeito do treinamento físico na regulação de outros microRNAs que interagem com o SRA. Estes resultados do nosso laboratório 
mostraram que estes microRNAs podem promover um balanço positivo na via de formação do vasodilatador Ang-(1-7) em detrimento de uma via de vasoconstrição da Ang-II. Diante das informações científicas disponíveis até o momento, é evidente que a ECA2 é uma enzima chave para o remodelamento benéfico cardíaco, entretanto ainda não existem estudos que mostrem o perfil de expressão dos microRNAs no coração de animais que superexpressam ECA2.

Uma vez que o treinamento físico aeróbio promove aumento da ECA2 e diversas outras moléculas no coração, comparar o perfil de microRNAs expressos nesta condição com o perfil expresso em animais que superexpressam ECA2 no coração pode possibilitar identificarmos um perfil de microRNAs terapêuticos para doenças cardíacas.

\section{HIPÓTESE}

Uma vez que o treinamento físico aumenta os níveis de ECA2 e Ang-(1-7) cardíaca e que este aumento parece estar relacionado ao fenótipo de hipertrofia cardíaca, será investigado se a superexpressão de ECA2 cardíaca apresenta adaptações cardíacas semelhantes as geradas pelo treinamento físico.

\section{OBJETIVOS}

\subsection{Objetivo Geral}

Traçar o perfil de expressão dos microRNAs em camundongos que superexpressam ECA2 cardíaca e comparar com o perfil de microRNAs expressos no coração de camundongos submetidos ao treinamento físico aeróbio em esteira.

\subsection{Objetivos Específicos}

- Determinar e comparar o perfil de microRNAs expressos no coração dos animais treinados com animais que super-expressam ECA2 cardíaca. 
- Confirmar por RT- qPCR os microRNAs diferencialmente expressos.

- Buscar por análise in silico possíveis alvos dos microRNAs diferencialmente expressos selecionados e confirmados.

- Determinar a concentração cardíaca de componentes do SRA, por HPLC 


\section{MATERIAIS E MÉTODOS}

\subsection{Grupos Experimentais}

Foram utilizados para este estudo camundongos da linhagem C57BL/6 com a idade em torno de 100 a 120 dias. Os animais foram divididos em 3 grupos, cada um com $n=6$ : 1) grupo sedentário (SD); 2) grupo treinado (TR); 3) grupo com superexpressão de ECA2 $\left(\mathrm{ECA}^{+/+}\right)$. Os animais foram identificados com marcação na cauda e pesados semanalmente. Os animais submetidos ao treinamento em esteira foram sacrificados 24 horas após a última sessão de exercício físico e todos os procedimentos foram aprovados pelo Comitê de Ética da EEFEUSP sob o número CEUA 01/2015.

Os corações dos animais com superexpressão de ECA2 foram provenientes, do Laboratório do Prof. Dr. Eric Lazartigues, da School of Medicine do Health Science Center da Louisiana State University, de New Orleans. Nós tivemos acesso somente ao tecido cardíaco, cérebro e plasma desses animais. Nós não tivemos acesso à esses tecidos preparados para realização de técnicas histológicas.

\subsection{Protocolo de Treinamento}

O treinamento do grupo TR foi realizado segundo o protocolo desenvolvido por Ferreira e seus colaboradores (2007) em sistema de esteira. O treinamento teve duração de 8 semanas sendo 5 sessões semanais com aumento progressivo do tempo, chegando a 60 minutos, e aumento progressivo de sobrecarga de trabalho, chegando a $60 \%$ da velocidade máxima conseguida no teste de exaustão que corresponde a intensidade de máxima fase estável de lactato. Esse trabalho é caracterizado como de moderada intensidade com predomínio de metabolismo aeróbio (FERREIRA et al., 2007).

\subsection{Avaliações das Respostas Hemodinâmicas}

A pressão arterial sistólica (PA) e a frequência cardíaca foram aferidas após período de treinamento físico, por pletismografia de cauda (sistema da KENT 
SCIENTIFIC RTBP1001 para ratos e camundongos, Litchfield, USA) nos grupos de animais.

Para que fossem realizadas estas medidas os animais passaram uma semana de ambientação com a técnica de medida. Durante as medidas os animais estavam acordados, em repouso e com restrição de movimentos.

O equipamento de registro da PAS de cauda consiste em um manguito de borracha que é adaptado a região proximal da cauda, que está ligado ao pletismógrafo para insuflar e desinflar gradualmente o manguito de 1 a 250/300mmHg. Numa região mais proximal da cauda é acoplado um transdutor de pulso pneumático para detecção dos sinais de passagem da onda de pulso de PA na artéria caudal e registrado no sistema de aquisição de sinais. Os resultados foram expressos em $\mathrm{mmHg}$.

\subsection{Análise Histológica}

Durante o sacrifício dos animais, parte do VE foi congelada em tissue tek e armazenada em nitrogênio líquido para confecção de lâminas histológicas. Para confecção destas, foram realizados cortes histológicos de $5 \mu \mathrm{m}$. Os cortes foram posteriormente corados com hematoxilina e eosina (HE). A imagem foi amplificada em 400x e os miócitos cardíacos com núcleos visíveis e membrana celular intacta foram escolhidos para análise. Foi traçada uma reta entre uma membrana e outra passando pelo núcleo da célula, sendo utilizada a distância em $\mu \mathrm{m}$ para quantificação. A análise foi realizada por microscópio óptico associado a um sistema de análise de imagens QuantimetLeica® (Leica, UK). No mínimo 10 campos visuais foram analisados por animal.

\subsection{Análises Bioquímicas e Moleculares}

\subsubsection{Obtenção do Plasma e Coleta do Tecido Cardíaco}

Finalizado o prazo dos protocolos experimentais os animais foram sacrificados por excesso de anestésico inalatório (isoflurano). Neste momento, amostras de sangue foram coletadas para quantificar os peptídeos de angiotensina (angiotensina I, angiotensina II, angiotensina 1-7) no plasma e coração, por HPLC e a atividade da ECA e ECA2 no coração por fluorometria. Para quantificação dos peptídeos de angiotensina no plasma, o sangue foi rapidamente coletado em micro tubos 
refrigerados contendo uma mistura de inibidores de protease $(25 \mathrm{mmol}$ EDTA potássio; 0,44 mmol o-fenantrolina; $0,12 \mathrm{mmol}$ pepstatin $A ; 1 \mathrm{mmol}$ ácido 4cloromercuribenzoato), que previne in vitro a produção e a degradação de peptídeos de angiotensina. $O$ coração foi removido da cavidade torácica e dissecado para separar o VE e ventrículo direito (VD) e congelados em freezer $-80^{\circ} \mathrm{C}$. A hipertrofia cardíaca foi avaliada pesando-se o coração (peso úmido) e os resultados foram expressos pela relação entre o peso da massa total cardíaca pelo peso corporal $(\mathrm{mg} / \mathrm{g})$ e pelo comprimento da tíbia do animal $(\mathrm{g} / \mathrm{mm})$.

O sangue, mantido em gelo, foi centrifugado a $1.500 \mathrm{~g}$ durante 10 minutos a uma temperatura de $4^{\circ} \mathrm{C}$. Após centrifugação, os sobrenadantes foram armazenados a $-80^{\circ} \mathrm{C}$ até a sua utilização, para determinação da atividade da ECA e ECA2, por método fluorimétrico.

\subsubsection{Determinação das Concentrações de Angiotensinas no plasma}

A técnica de cromatografia líquida de alta eficiência (HPLC) (BIRD, 1989) foi realizada em colaboração com a Prof ${ }^{\underline{a}} \mathrm{Dr}^{\underline{a}}$ Dulce Elena Casarini, coordenadora do Laboratório de Rim e Hormônios.

A extração das angiotensinas plasmáticas foi realizada através de colunas Oasis $\mathrm{C}_{18}$ (Waters, MA, USA), previamente ativadas com metanol $(5 \mathrm{ml})$, hexano $(5 \mathrm{ml})$, metanol $(5 \mathrm{ml})$ e água $(10 \mathrm{ml})$. Após ativação, as amostras foram aplicadas nas colunas, lavadas com água e eluídas em etanol/ ácido acético/ água na proporção $90 \% / 4 \% / 6 \%$. As frações eluídas foram liofilizadas e redissolvidas em $500 \mu \mathrm{L}$ de veículo em fase $\mathrm{A}$ ( $5 \%$ acetonitrila em $0,1 \%$ ácido fosfórico) e filtradas em membranas de 0,22mm para análise de cromatógrafo (HPLC, SHIMADZUSYSTEM, Japão). As angiotensinas de cada amostra foram separadas em coluna de fase reversa ODS Aquapor 300 (240x4,6mm), $7 \mu \mathrm{L}$ (Colunas Browlee, Perkin Elmer), usando um gradiente de 5 a 35\% de fase móvel B (95\% de acetonitrila em 0,1\% de ácido fosfórico) sob um fluxo de $1,5 \mathrm{ml} \cdot \mathrm{min}^{-1}$ por $40 \mathrm{~min}$. As angiotensinas foram identificadas por comparação com o tempo de retenção das amostras padrão de angiotensinas, e os resultados expressos em pmol. $\mathrm{ml}^{-1}$ de plasma. 


\subsubsection{Atividade da Enzima Citrato Sintase}

A atividade da citrato sintase (CS) foi determinada por espectrofotômetro, no sóleo, segundo ALP e colaboradores (ALP; NEWSHOLME; ZAMMIT, 1976). Está enzima é usada como um marcador de atividade oxidativa no músculo para mostrar a eficácia do protocolo de treinamento físico aeróbio através de parâmetros bioquímicos. A atividade da enzima foi medida em homogeneizado de músculos inteiros e a quantidade do complexo resultante de acetil-coA e oxaloacetato será determinada em $412 \mathrm{~nm}$ e $25^{\circ} \mathrm{C}$, em um intervalo de $10 \mathrm{~min}$. Atividade de $\mathrm{CS}$ foi expressa em as $\mu \mathrm{mol} \cdot \mathrm{ml}-1 \cdot \mathrm{mg}-1$ de proteína.

\subsection{4 microRNA Microarray}

O VE (20-35 mg de tecido) foi homogeneizado em $1 \mathrm{~mL}$ de Trizol (Invitrogen) em tubo de ensaio e transferido para micro tubo de $1,5 \mathrm{~mL}$ de volume. A extração do RNA total seguiu as instruções do fabricante (Thermo Fisher Scientific). O RNA precipitado foi lavado com etanol $70 \%$ para eliminar resíduos de fenol e sal, e solubilizado em $20 \mu \mathrm{l}$ de água tratada com dietil pirocarbonato livre de endonucleases (DEPC). A concentração das amostras de RNA total foi quantificada usando o espectrofotômetro NanoDrop (NanoDrop Technologies, USA), a qual variou entre 700 a $1000 \mathrm{ng} / \mu \mathrm{l}$.

A plataforma de microarray foi realizada baseado no sistema microRNABase Versão 17.0, com chip 3.0. O experimento foi realizado com os kits da companhia AFFYMETRIX (USA), possibilitando assim a determinação de um perfil de expressão dos microRNAs no coração dos três grupos experimentais.

Para a realização do microarray a amostra de RNA total extraída do VE foi purificada e foi realizado o isolamento dos pequenos RNAs (microRNAs). Ambos processos foram realizados por meio de um kit da Ambion (microRNAVana ${ }^{T M}$ microRNAisolation kit) seguindo as recomendações do fabricante. Devido a isso foi necessário a utilização de um pool ( 3 amostras de VE para $n=1$ amostra) para a realização do microarray. Após o processo de purificação e isolamento dos microRNAs, concentramos as amostras para que fosse possível obter valores que ficassem entre 130 a $400 \mathrm{ng}$ de microRNA presentes em um volume máximo de $8 \mu$ l (concentração e volume especificados pelo fabricante para realização 
do microarray). Para a realização do microarray utilizamos uma concentração de 185 ng de microRNAs em $8 \mu \mathrm{l}(\mathrm{n}=2$ por grupo experimental).

O microRNAarray foi realizado utilizando o kit FlashTag ${ }^{\text {TMBiotin } H S R ~ R N A ~}$ Labeling, que marca o RNA das amostras para a análise através do Affymetrix Gene Chip microRNA Arrays. Inicialmente, foi feito o anelamento da cauda poli-a no RNA total seguido da ligação com DNA marcado com biotina. Após essa primeira parte do experimento, testamos através do ensaio de ELOSA se esse anelamento e a ligação da biotina foram efetivos.

Após esses testes nas amostras de RNA, a hibridização foi realizada por incubação dos chips, overnight, a $48^{\circ} \mathrm{C}$, sob agitação. No chip, cada probe consiste de um nucleotídeo modificado quimicamente que codifica segmentos complementares ao microRNA alvo e um segmento espaçador de propilenglicol para estender o segmento codificante a partir do substrato. Após a hibridização, os chips foram submetidos a estação de lavagem para posterior detecção de fluoróforos específicos para cada amostra. As detecções das imagens foram feitas utilizando um scanner laser (Affimetrix, USA).

Os dados gerados foram analisados primeiramente subtraindo o background e então normalizando os sinais para balancear as intensidades dos fluoróforos, de forma que a razão da expressão diferencial pudesse ser calculada. Para isso foram utilizados os softwares Expression Console para o controle de qualidade e normalização dos chips e o Transcriptome Analysis Console (TAC) para obter os valores de expressão (expressos em Log2) disponibilizados pela Affymetrix. O tipo de análise utilizada pelo software TAC foi o Gene Level Differential Expression Analysis para arraymicroRNA-3.0.

\subsubsection{Análise da Expressão Gênica Utilizando qPCR após Transcrição Reversa}

Para extração do RNA total, aproximadamente $40 \mathrm{mg}$ de tecido foram homogeneizados com o reagente TRIZOL (Invitrogen, USA). O homogeneizado foi transferido para tubos de $1,5 \mathrm{~mL}$ e centrifugados por 5 minutos a $10.000 \mathrm{rpm}$ a $4^{\circ} \mathrm{C}$. O sobrenadante foi retirado e transferido para um novo tubo $1,5 \mathrm{~mL}$, onde foi adicionado $200 \mu \mathrm{L}$ de clorofórmio. Os tubos foram mantidos em temperatura ambiente por 10 minutos, e novamente centrifugados por $15 \mathrm{~min}$ a $12.000 \mathrm{rpm}$ à $4^{\circ} \mathrm{C}$. Após a 
centrifugação, observou-se 3 fases, que consistiam no RNA, DNA e proteína respectivamente. O RNA foi retirado e transferido para novos tubos. Em temperatura ambiente, foi acrescentado $1 \mathrm{~mL}$ de álcool isopropílico. Novamente, os tubos foram centrifugados por $10 \mathrm{~min}$ à $12.000 \mathrm{rpm}$ e $4^{\circ} \mathrm{C}$. Foi observada a formação de um precipitado. O sobrenadante foi retirado e a ele acrescentado $1 \mathrm{~mL}$ de etanol $75 \%$ para que o precipitado perdesse a aderência com o tubo. Os tubos foram centrifugados novamente por $5 \mathrm{~min}$ a $12.000 \mathrm{rpm}$ e $4^{\circ} \mathrm{C}$. O etanol foi retirado dos tubos e, uma vez seco, o precipitado foi ressuspenso em $\mathrm{H}_{2} \mathrm{O}$ DEPC, agitando os tubos para dissolvêlo. Para confirmação da qualidade do processo de extração, foi utilizada uma relação RNA/DNA, determinada em espectrofotômetro (NanoDrop 2000, Thermo Scientific, EUA), entre os comprimentos de onda de 260 e $280 \mathrm{~nm}$, sendo somente utilizadas amostras que atingissem o intervalo de 1,6 a 2,0nm. A partir disto, foi verificada a integridade do RNA em gel de agarose 1\% corado com Nancy- 520 (Sigma \#10171990).

A transcrição reversa (cDNA) foi confeccionada com RevertAidTM First Strand cDNA synthesis kit (Fermentas, EUA). Para isso, $2 \mu \mathrm{g}$ de RNA total foram adicionados num tubo contendo $0,5 \mu \mathrm{g}$ de oligo dT, 20uL de RiboLockTM RNAse inhibitor, $1 \mathrm{mM}$ de dNTP mix, 200 $\mu \mathrm{L}$ de RivertAidTM Reverse transcriptase, totalizando uma solução final de $20 \mu \mathrm{L}$ (Fermentas, EUA), que foi incubada a $42^{\circ} \mathrm{C}$ por uma hora e mais $10 \mathrm{~min}$ a $70^{\circ} \mathrm{C}$ para o término da transcrição reversa. A expressão do RNA mensageiro foi avaliada por polimerase chain reaction (PCR) em tempo real, utilizando uma alíquota de cDNA, primers específicos para os genes estudados e o marcador fluorescente SYBR Green qPCR (Fermentas, EUA), que se liga à dupla-fita amplificada. Para os microRNAs foi utilizada TaqMan MicroRNA Assays da Applied Biosystems (\#4373142).

Cada amostra foi analisada em duplicatas. Quantidades relativas da expressão dos genes alvos nos grupos foram comparadas após a normalização dos valores de ciclofilina para os genes e U6 para os microRNAs [mudança no limiar do ciclo( $\triangle C T)$ ]. As mudanças na expressão de microRNA foram calculadas usando as diferenças nos valores de $\Delta C T$ entre as duas amostras $(\Delta \Delta C T)$ e a equação $2^{-\Delta \Delta C T}$. Dados estão expressos em porcentagem relacionada ao grupo SED (controle). 


\begin{tabular}{|c|c|c|}
\hline Primer & & Sequência \\
\hline \multirow[t]{2}{*}{ Alpha- MCP } & Sense & AGATTTTCCCGGTGGAGAG \\
\hline & Anti-sense & GCTGGCTGGAAAAGAACAA \\
\hline \multirow[t]{2}{*}{ Beta- MCP } & Sense & TGCAAAGGCTCCAGGTCTGAGGGC \\
\hline & Anti-sense & GCCAACACCAACCTGTCCAAGTTC \\
\hline \multirow[t]{2}{*}{ Beta- Actina } & Sense & СCTTCTTGGGTATGGAATCCTGT \\
\hline & Anti-sense & GAGGTCTTTACGGATGTCAACG \\
\hline \multirow[t]{2}{*}{ ECA2 } & Sense & ATGTGGTAGGAGCAAGGAATAT \\
\hline & Anti-sense & GGGTGAGGTGACAAAGAAGTAG \\
\hline \multirow[t]{2}{*}{ MAS1 } & Sense & ACTGTCGGGCGGTCATCATC \\
\hline & Anti-sense & GGTGGAGAAAAGCAAGGAGA \\
\hline \multirow[t]{2}{*}{ COLIAI } & Sense & CCCTGGTCCCTCTGGAAATG \\
\hline & Anti-sense & GGACCTTTGCCCCCTTCTTT \\
\hline \multirow[t]{2}{*}{ COL3AI } & Sense & GGGCAGTGGCTACGAGTATG \\
\hline & Anti-sense & GCTGAAGGGGATAAAGGCGA \\
\hline \multirow[t]{2}{*}{ ECA } & Sense & GGGCAGTGGCTACGAGTATG \\
\hline & Anti-sense & GCTGAAGGGGATAAAGGCGA \\
\hline \multirow[t]{2}{*}{ AT2R } & Sense & AAACACTGGCAACTAAAAAGGTGT \\
\hline & Anti-sense & AAAGGACGGCTGCTGGTAAT \\
\hline \multirow[t]{2}{*}{ Nf1 } & Sense & TCAGGAGGCTATGGAGGCTT \\
\hline & Anti-sense & GGTGGCGGAAACAGGACATA \\
\hline \multirow[t]{2}{*}{ Nras } & Sense & TTCTCAGGTTGAAGTCCAAAAGC \\
\hline & Anti-sense & TTCAAAGTGTCTTACTACATCAGCA \\
\hline \multirow[t]{2}{*}{ Creb1 } & Sense & TGTACCACCGGTATCCATGC \\
\hline & Anti-sense & GCACTGCCACTCTGTTCTCT \\
\hline \multirow[t]{2}{*}{ Prkacb } & Sense & CAGCACTTGAGTCTCCGTGA \\
\hline & Anti-sense & CCCGAAATCTGTGACCTGGA \\
\hline \multirow[t]{2}{*}{ F2r } & Sense & CCAGCCAGAATCAGAGAGGAC \\
\hline & Anti-sense & AGACCCGAACTGCCAATCAG \\
\hline \multirow[t]{2}{*}{ Lpar3 } & Sense & GTCTTAGGCGCCTTCGTGG \\
\hline & Anti-sense & TTGCACGTTACACTGCTTGC \\
\hline \multirow[t]{2}{*}{ Lpar4 } & Sense & САCACTCTTTCTTGGGCACTCA \\
\hline & Anti-sense & AGACAAACAGGGAGGCACTG \\
\hline \multirow[t]{2}{*}{ Pik3r3 } & Sense & CCGTTGGAAACCCCCAAGTA \\
\hline & Anti-sense & TTTGGTGGAAGAGCTGGAGG \\
\hline \multirow[t]{2}{*}{ Pikracb } & Sense & GAAGGCAGCAAGAGACTGGG \\
\hline & Anti-sense & TAGAAGATGAACTGCCCCGC \\
\hline \multirow[t]{2}{*}{ Gng4 } & Sense & CCTAGGTGTCCCCAGGAGAA \\
\hline & Anti-sense & AGTAGGCCAGGAGGTCTGAG \\
\hline
\end{tabular}

Tabela 1. Sequência dos primers utilizados para expressão gênica por RT- qPCR.

\subsubsection{Quantificação da Expressão de Proteínas por Western Blot}

Para quantificação da expressão de proteínas do SRA foi utilizada a técnica de Eletroforese em Gel de Poliacrilamida (SDS-PAGE), que consiste na migração de moléculas com carga, numa solução tampão, decorrente da aplicação de um campo elétrico no aparelho minigel, sendo que foram colocados 30ug de proteína por poço 
do gel (Mini Protean, BioRad, EUA). As proteínas foram transferidas para uma membrana de nitrocelulose (American Biosciences, NJ, EUA). A membrana foi incubada em solução contendo albumina e incubada com o anticorpo primário para mouse anti-AT1 (ab9391- Abcam, USA), rabbit anti-AT2 (sc-9040, Santa Cruz, USA), mouse anti-ECA (ab11734- Abcam, USA) e rabbit anti-ECA2 (sc-20998, Santa Cruz, USA), os quais se ligam à proteína que se pretende detectar, formando um complexo anticorpo-proteína. Depois de lavar a membrana para remover o anticorpo não ligado, ela foi exposta ao anticorpo secundário, direcionado à porções espécies-específicas do anticorpo primário. As bandas existentes nas membranas incubadas foram visualizadas através do uso do Kit para detecção por quimioluminescência. Para se medir a intensidade das bandas nas auto-radiografias, as figuras obtidas por escaner foram analisadas utilizando o programa de análise de densitometria óptica ScionImage, fornecido gratuitamente pela NIH (USA) via internet. Os resultados foram expressos em unidades arbitrárias (U.A.).

\subsection{Predição Bioinformática para Análise in silico:}

A análise de bioinformática, foi realizada inicialmente com uma busca para cada microRNA através do programa microRNAWalk 2.0, afim de encontrar os genes preditos como alvo para cada um dos microRNAs. Dos 10 programas de identificação de alvos de microRNAs (sendo que obrigatoriamente este gene alvo deveria ser predito pelo Targetscan e mais 6 dos outros 10 programas de busca utilizados: microRNAWalk, Microt4, microRNAanda, microRNAbridge, microRNADB, microRNAMap, Pictar2, RNA22 e Targetscan). Essa lista de microRNAs foi submetida a base de dados biológicos do DAVID Bioinformatics resources 6.7 (Database for Annotation, Visualization and Integrated Discovery), que através de uma análise funcional (Functional Annotation Chart) utilizando a base de dados KEGG (Kyoto Encyclopedia of Genes and Genomes) identificou os mais relevantes termos biológicos associados com a lista.

Para analisarmos as diferenças entre os grupos avaliamos primeiramente os microRNAs que tiveram sua expressão alterada no grupo controle (SED) quando comparado ao grupo treinado (TR) e posteriormente fizemos uma comparação entre o grupo SED vs. Grupo ECA2 ${ }^{+/+}$, afim de encontrar os microRNAs que tinham mesmo padrão 
de expressão entre TR vs. $E C A 2^{+/+}$. Utilizamos como parâmetro de análise após a realização da ANOVA (oneway) o valor de $p<0,05$ e excluímos o corte realizado pelo FoldChange $<-2$ ou $>2$ como parâmetro, uma vez que esse critério excluiu quase todos os microRNAs que foram encontrados diferencialmente expressos.

\subsection{Análise Estatística}

As variáveis dependentes foram analisadas por meio de ANOVA de 1 fator (grupo: sedentário $x$ treinado $x$ superexpressão da enzima ECA2). O nível de significância foi estabelecido com $p<0,05$. Comparações post-hoc foram realizadas por meio do teste de Tukey. Os dados estão apresentados como média e erro padrão. As análises foram feitas usando-se o programa GraphPad Prism6. 


\section{RESULTADOS}

\subsection{Parâmetros de Treinamento}

A Figura 2 mostra os parâmetros avaliados a partir dos testes máximos. O primeiro teste (Teste 1) foi realizado no início do protocolo afim de inferir a máxima fase estável de lactato para posterior realização do protocolo de treinamento físico (FERREIRA et al., 2007). Após 4 semanas realizamos um novo teste para que houvesse readequação da velocidade do treinamento, uma vez que os animais já estariam adaptados (Teste 2). Ao final da $8^{\underline{a}}$ semana foi realizado o terceiro e último teste máximo afim de comparar as adaptações ocorridas com o treinamento físico de corrida em esteira. Na Figura 2a temos uma representação da periodicidade em que foram realizadas as sessões destes testes máximos.

Nas Figuras 2b, 2c e 2d mostram que o treinamento físico resultou em aumento significante da distância percorrida, na velocidade e no tempo máximo de teste, respectivamente, quando comparados os resultados do grupo treinado no teste $2 \mathrm{e}$ teste 3 em relação aos demais. Na distância percorrida, também se observa diferença estatística significativa intragrupo quando comparamos teste 2 e teste 3 do grupo treinado. 


\section{FIGURA 2}

A)

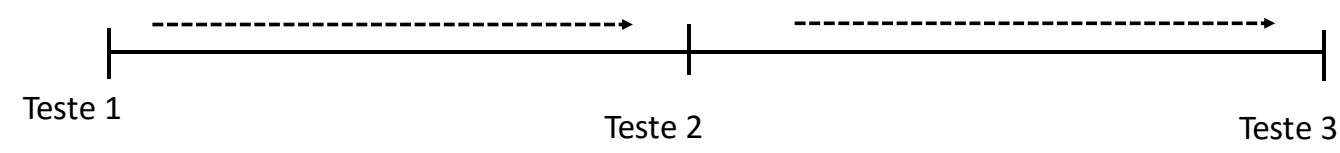

B)

C)
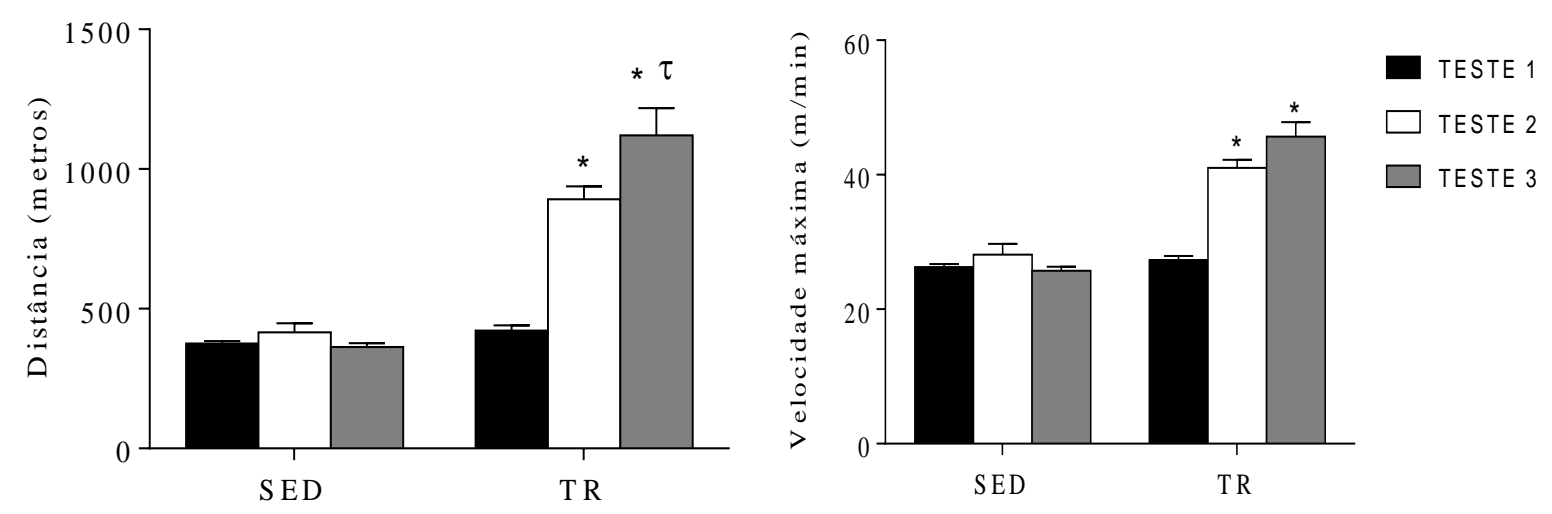

D)

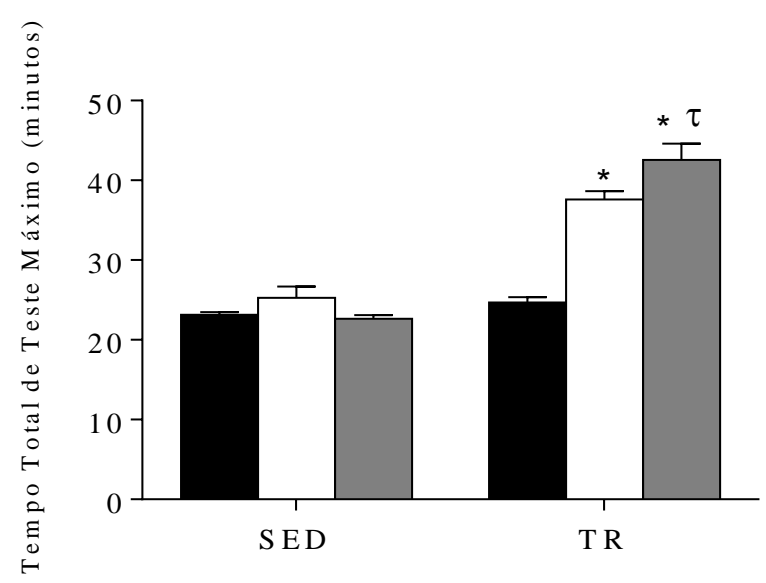

FIGURA 2. Parâmetros avaliados a partir do teste máximo em esteira. Figura 2a) representação esquemática da periodicidade da realização dos testes. Figura 2b) Distância percorrida durante o teste máximo comparando Grupo sedentário (SED) vs. Grupo treinado (TR). Figura 2c) Velocidade máxima atingida durante o teste máximo comparando Grupo sedentário (SED) vs. Grupo treinado (TR). Figura 2d) Tempo máximo do teste máximo comparando Grupo sedentário (SED) vs. Grupo treinado (TR). ${ }^{*} p<0,0001$ TR: Teste 2 e Teste 3 vs. SED: Teste 1, Teste 2, Teste 3. 'T $p<0,05$ TR: Teste 2 vs. Teste 3. 


\subsection{Medidas Morfométricas}

A massa corporal dos animais foi medida semanalmente desde o início do protocolo experimental. A figura 3 mostra os valores médios finais da massa corporal dos animais sedentários (SED), treinados (TR) e com superexpressão da enzima conversora de angiotensina $2\left(\mathrm{ECA}^{+/+}\right)$. Observar-se que não houve diferença estatística significativa entre os grupos.

\section{FIGURA 3}

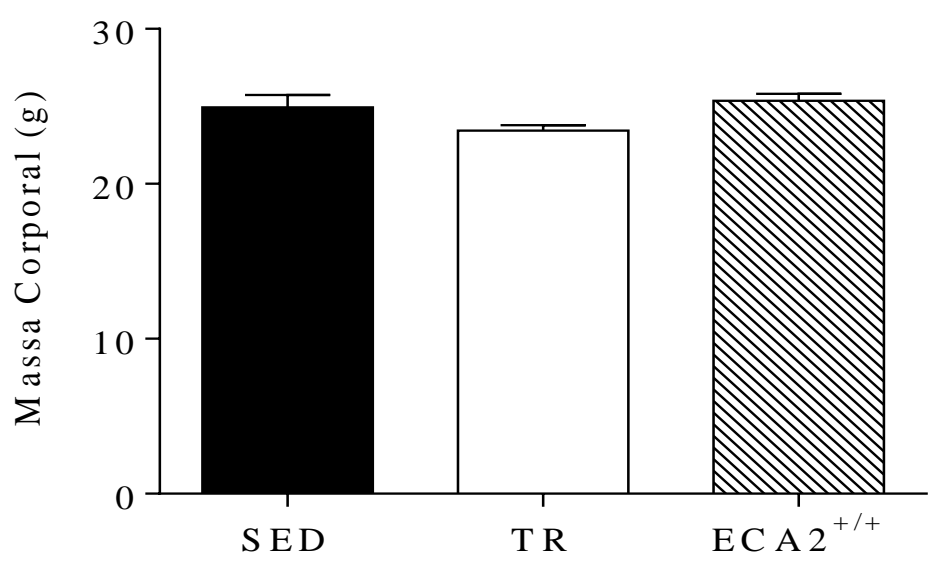

FIGURA 3. Massa corporal ao final do protocolo experimental. Grupos Sedentário (SED), Treinado (TR) e com superexpressão da enzima conversora de angiotensina $2\left(E C A 2^{+/+}\right)$.

\subsection{Medidas Hemodinâmicas}

Ao final do protocolo experimental, foram realizadas as medidas hemodinâmicas de pressão arterial e frequência cardíaca por pletismografia de cauda nos grupos SED e TR. A Figura 4a mostra os valores de pressão arterial sistólica, onde não obtivemos diferenças estatísticas significativas quando comparado o grupo treinado (TR) com o grupo sedentário (SED).

A frequência cardíaca foi avaliada a fim de demonstrar a eficácia do protocolo de treinamento aeróbio empregado, uma vez que a bradicardia é uma importante adaptação resultante do treinamento físico aeróbio. Na Figura 4b temos os valores obtidos, os quais mostram que o treinamento foi eficiente diminuir a frequência cardíaca de repouso. 


\section{FIGURA 4}

A)

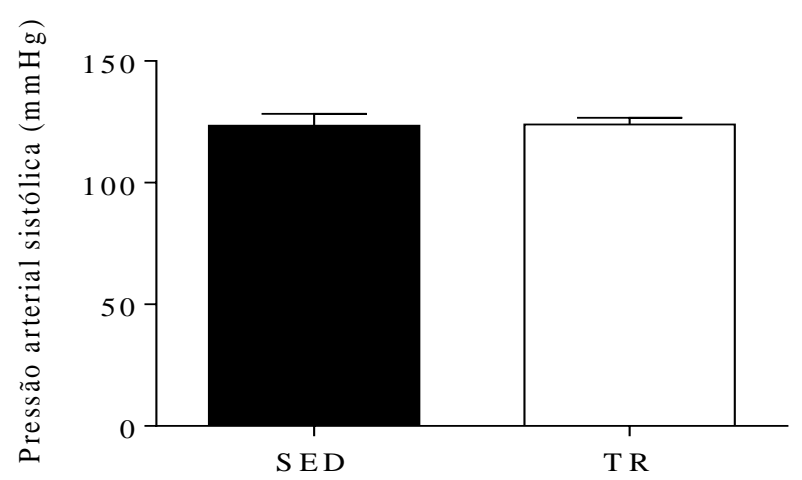

B)

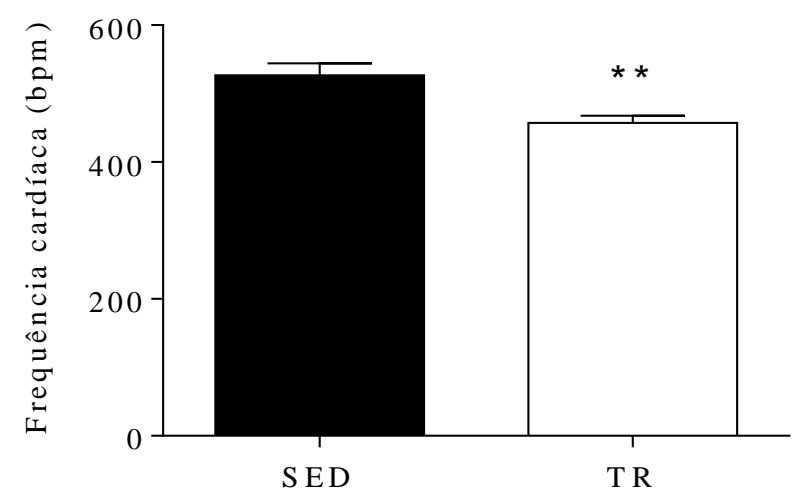

FIGURA 4. Parâmetros hemodinâmicos avaliados por pletismografia de cauda. Figura 4a) Valores de pressão arterial sistólica comparando o grupo Treinado (TR) e grupo Sedentário (SED). Figura 4b) Valores de frequência cardíaca de repouso comparando os grupos Treinado (TR) e Sedentário (SED) ${ }^{* *} p<0,0001$ vs. SED.

\subsection{Hipertrofia Cardíaca}

A hipertrofia cardíaca foi avaliada pela razão entre massa total do coração corrigida pelo comprimento da tíbia, como mostra a Figura 5a. Os resultados mostram aumento significante da massa do coração no grupo $\mathrm{ECA} 2^{+/+}$, quando comparado aos demais grupos (SED e TR). Na Figura 5b, observa-se a razão entre a massa total do coração corrigida pela massa corporal. Os resultados mostram que houve um aumento significante no grupo $\mathrm{ECA} 2^{+/+}$quando comparado aos grupos TR e SED. Ainda, foi realizada análise histológica, pela técnica de HE, para avaliar o diâmetro dos cardiomiócitos entre os grupos SED e TR, porém, não foram observadas diferenças nesta análise. $\mathrm{Na}$ análise histológica não contamos com o grupo $\mathrm{ECA} 2^{+/+}$ 
pois não foi possível o envio das amostras preparadas para que pudéssemos realizar as técnicas de confecção de lâminas histológicas.

\section{FIGURA 5}

A)

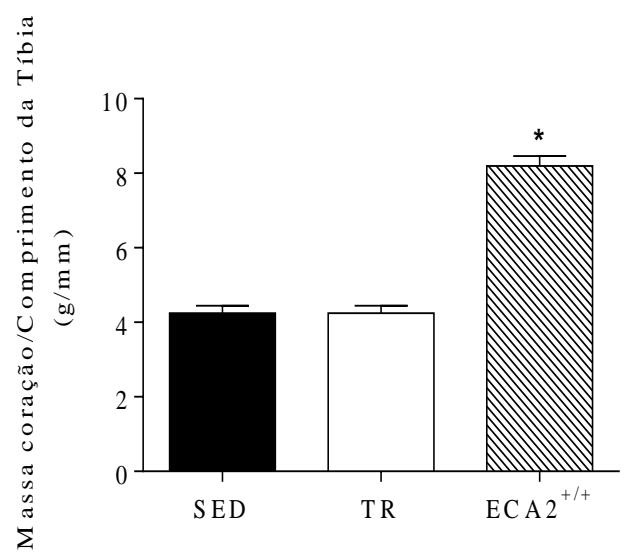

C)

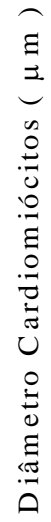

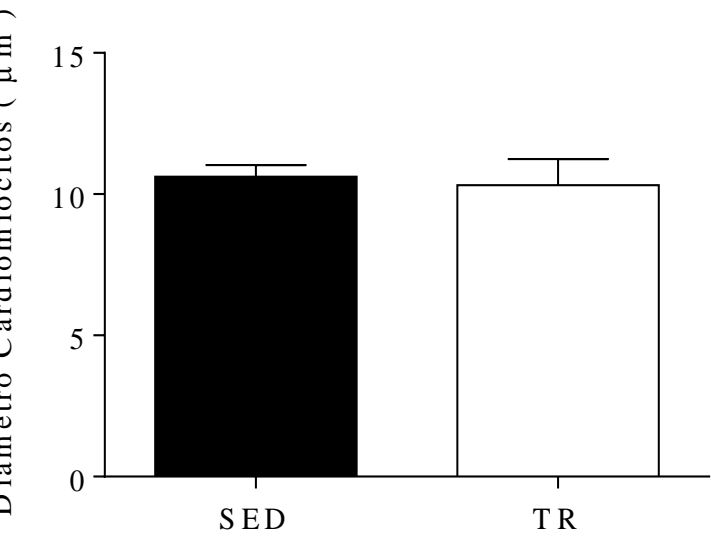

B)

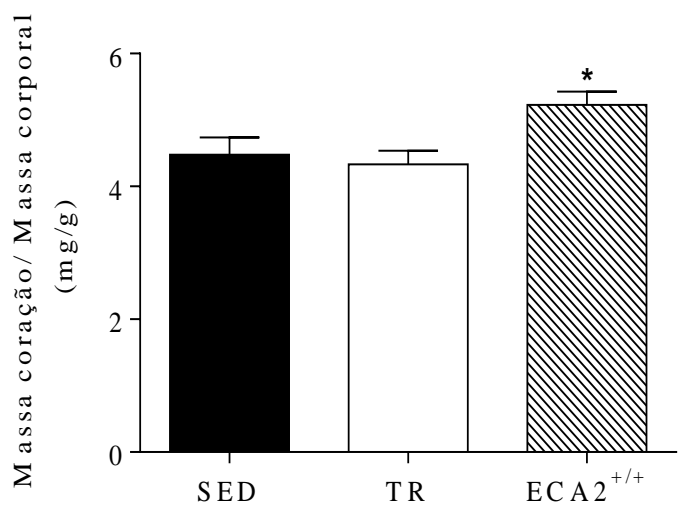

D)

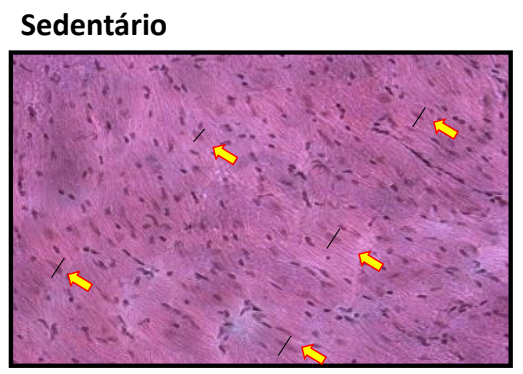

Treinado

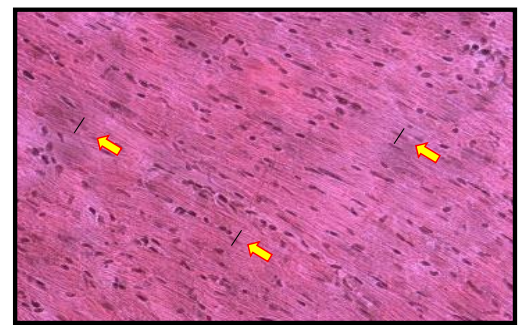

FIGURA 5. Análise da morfologia cardíaca dos animais sedentários (SED), treinados (TR) e com superexpressão da enzima conversora de angiotensina $2\left(E C A 2^{+/+}\right.$.). Figura 5a) Razão entre a massa total do coração corrigido pelo comprimento da tíbia. Figura 5b) Razão entre a massa total do coração corrigido pela massa corporal. Figura 5c) Diâmetro dos cardiomiócitos avaliados pela técnica histológica de Hematoxilina e Eosina (HE). Figura 5d) Imagem representativa dos cortes histológicos corados com HE aumento de 200x, flechas em amarelo indicando cardiomiócitos. ${ }^{*} \mathrm{p}<0,0001 \mathrm{ECA} 2^{+/+}$vs. SED e TR.

\subsection{Análises Bioquímicas e Moleculares}




\subsubsection{Citrato Sintase}

A enzima citrato sintase é responsável pela primeira reação do ciclo de Krebs, na qual há a condensação do Acetil-coA com Oxalacetato formando ácido cítrico (6C). Devido ao seu papel chave no metabolismo aeróbio, está enzima tem sido utilizada como importante marcador para demonstrar a adaptabilidade ao treinamento físico aeróbio (ALP; NEWSHOLME; ZAMMIT, 1976). Assim, ao fim do protocolo de treinamento físico aeróbio de corrida em esteira avaliamos a atividade desta enzima no sóleo dos animais dos grupos SED e TR. Esta apresentou um aumento significante de sua atividade no grupo submetido ao protocolo de treinamento, como pode ser observado na Figura 6.

\section{FIGURA 6}
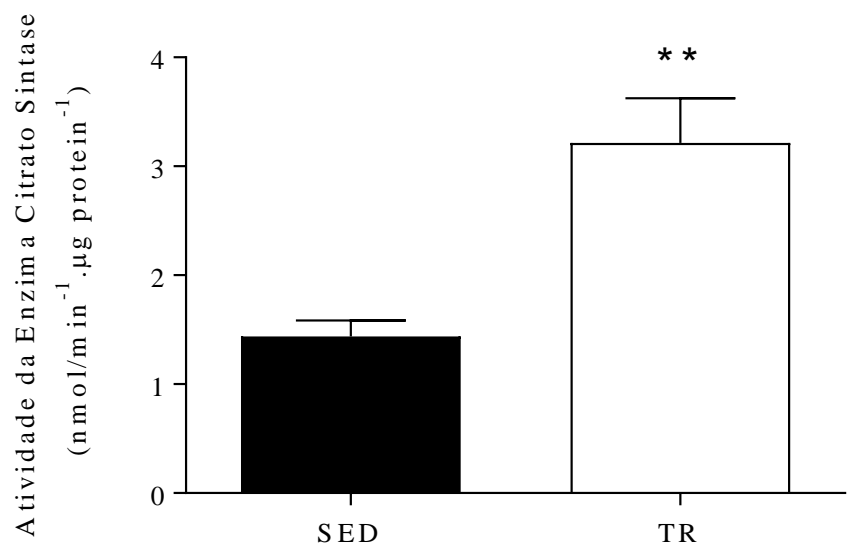

FIGURA 6. Avaliação da atividade da enzima citrato sintase no músculo sóleo dos grupos sedentário (SED) e treinado (TR). ${ }^{* *} p<0,01$ TR vs. SED.

\subsubsection{Marcadores de Hipertrofia Cardíaca}

Realizamos a expressão dos marcadores de hipertrofia cardíaca, afim de identificar qual o fenótipo de hipertrofia cardíaca encontrado. Observar-se na Figura 7a que os marcadores de hipertrofia cardíaca $\beta$-MCP estava significativamente diminuída no grupo ECA2 ${ }^{+/+}$em relação ao grupo SED e TR. Na figura $7 b$ observar-se que houve diminuição da $\alpha$-actina esquelética no grupo $\mathrm{ECA}^{+/+}$comparado ao grupo SED e não foram encontradas diferenças significantes em relação ao ANF. Ainda, podemos ver na Figura $7 \mathrm{~d}$, que o treinamento físico foi capaz de aumentar a expressão gênica de $\alpha-M C P$ comparado aos grupos SED e ECA2 ${ }^{+/+}$. 


\section{FIGURA 7}

A)

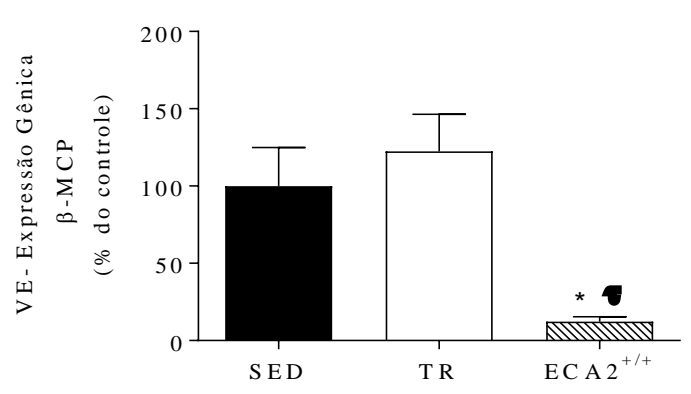

C)

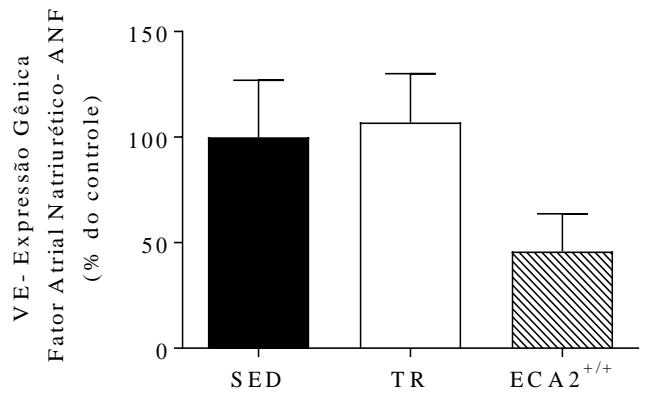

B)

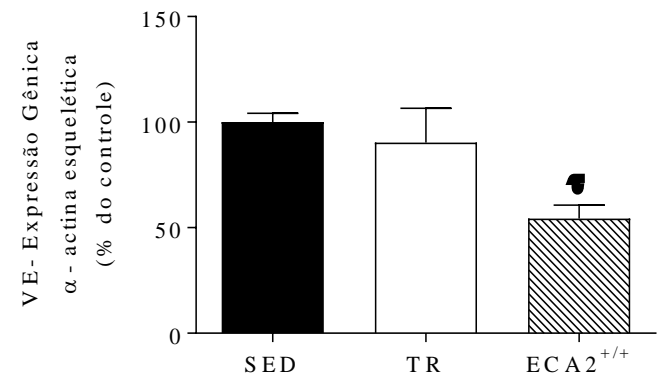

D)

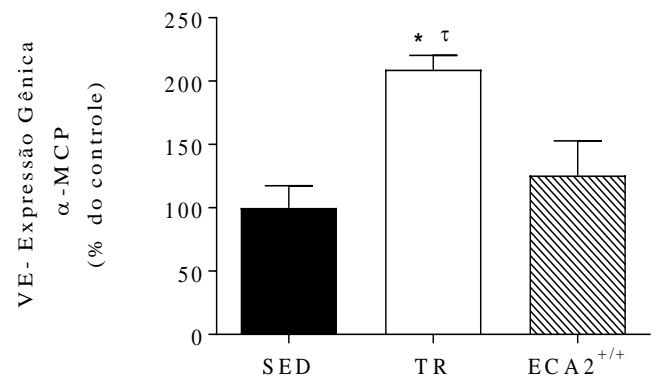

FIGURA 7. Expressão gênica dos marcadores de hipertrofia cardíaca. Figura 7a) expressão gênica da beta-miosina de cadeia pesada ( $\beta$-MCP) nos grupos sedentários (SED), treinados (TR) e com superexpressão da enzima conversora de angiotensina $2\left(E C A 2^{+++}\right)$. Figura $\left.7 b\right)$ Expressão gênica da alfa-actina esquelética ( $\alpha$-actina esquelética). Figura $7 \mathrm{c}$ ) Expressão gênica do fator natriurético atrial (ANF) Expressão gênica da alfa-miosina de cadeia pesada ( $\alpha-M C P) .{ }^{*} p<0,01$ TR vs. ECA2+. ${ }^{\top} p<0,05$ TR vs. SED.

\subsubsection{Expressão Gênica do Colágeno IAI e Colágeno 3AI}

A expressão dos genes de colágeno IAI e 3AI não foi alterada nos 3 grupos experimentais, embora houvesse uma tendência estatística $(p=0,09)$ para o aumento de colágeno 3AI (Figura 8b) no grupo $\mathrm{ECA}^{+/+}$comparado ao grupo SED. 


\section{FIGURA 8}

A)

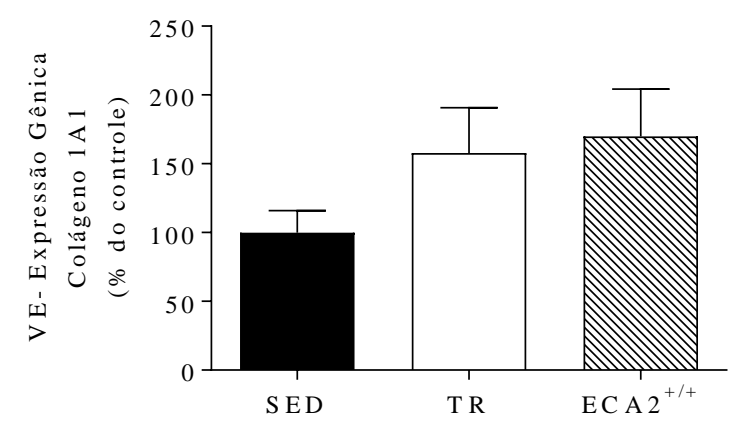

B)

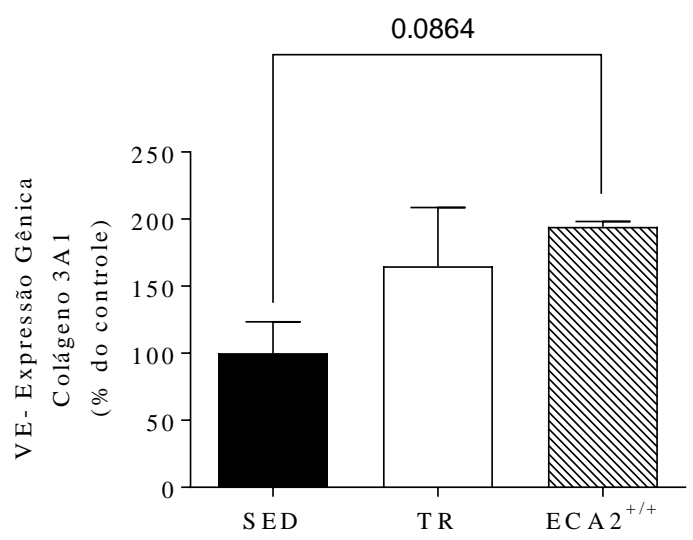

FIGURA 8. A) Expressão gênica do colágeno IAI e B) Expressão gênica do colágeno 3AI dos animais sedentários (SED), treinados (TR) e com superexpressão da enzima conversora de angiotensina $2\left(\mathrm{ECA}^{+/+}\right)$.

7.5.4 Expressão Gênica, Proteica e Atividade da enzima Conversora de Angiotensina I (ECA)

A enzima conversora de angiotensina é responsável por clivar Ang-I à Ang-II. A Figura 9a apresenta os valores obtidos da atividade da ECA no plasma, observa-se que houve uma redução significante da atividade desta enzima no grupo treinado quando comparado aos demais grupo (SED e ECA2 ${ }^{+/+}$). Entretanto, não encontramos diferenças significantes na expressão proteica, como mostrado na figura 9B, porém, há um aumento estatisticamente significante na expressão gênica de ECA no grupo treinado em relação à $\mathrm{ECA} 2^{+/+}$. 


\section{FIGURA 9}

A)

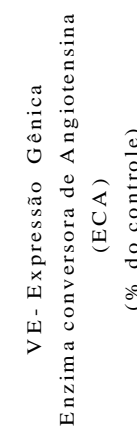

C)

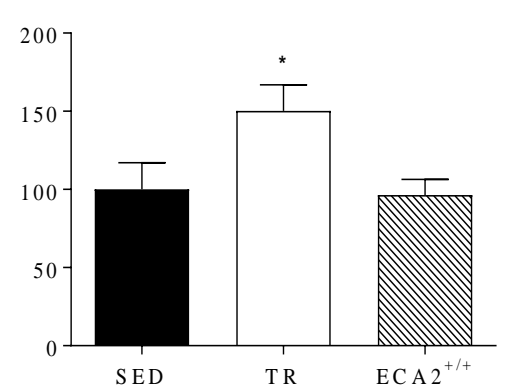

B)

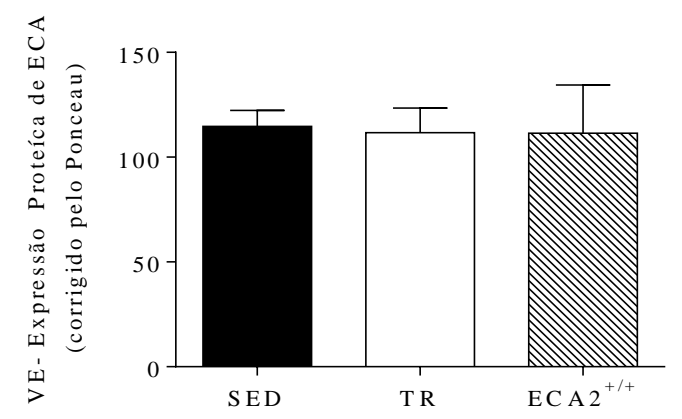

D)

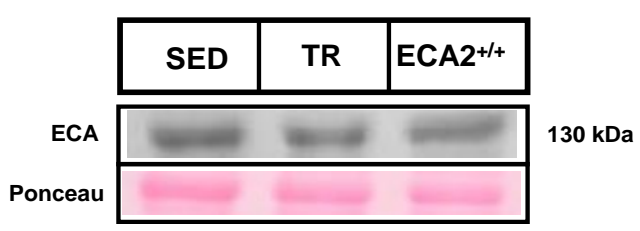

FIGURA 9. Expressão Gênica da Enzima Conversora de Angiotensina (ECA) (A). Expressão Proteíca de ECA (B). Atividade da enzima ECA no plasma (C). Blots representativos da ECA (D) dos animais sedentários (SED), treinados (TR) e com superexpressão da enzima conversora de angiotensina $2\left(\mathrm{ECA}^{+/+}\right){ }^{\Phi} \mathrm{p}<0,001 \mathrm{TR}$ vs. $\mathrm{ECA} 2^{+/+} .{ }^{\mathrm{T}} \mathrm{p}<0,05 \mathrm{TR}$ vs. SED ; ${ }^{*} \mathrm{p}<0,01 \mathrm{TR}$ vs. ECA2+.

7.5.5 Expressão Gênica, Proteica e Atividade da Enzima Conversora de Angiotensina II (ECA2)

A enzima ECA2 tem papel chave no eixo (Ang-(1-7)/ECA2/Mas) contrabalanceando os efeitos do eixo clássico (Ang-II/ECA/AT1) do sistema renina angiotensina clássico.

A Figura 10a mostra aumento estatisticamente significativo na expressão gênica de ECA2 no grupo ECA2 ${ }^{+/+}$quando comparado a SED e TR. No entanto, não tivemos diferenças estaticamente significativas na expressão proteica de ECA2 no coração e nem atividade da ECA2 medida no plasma (Figura 10b, c e d). 


\section{FIGURA 10}

A)
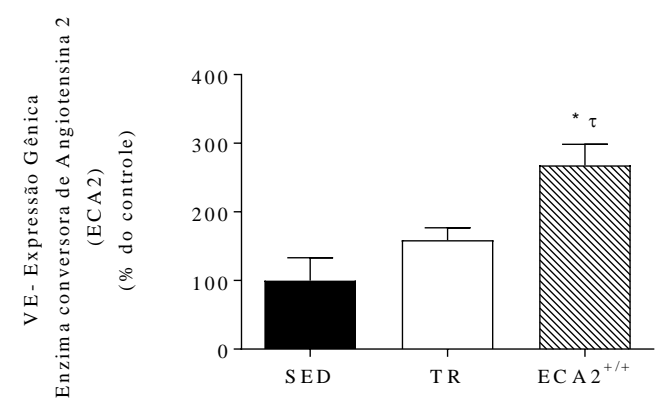

C)

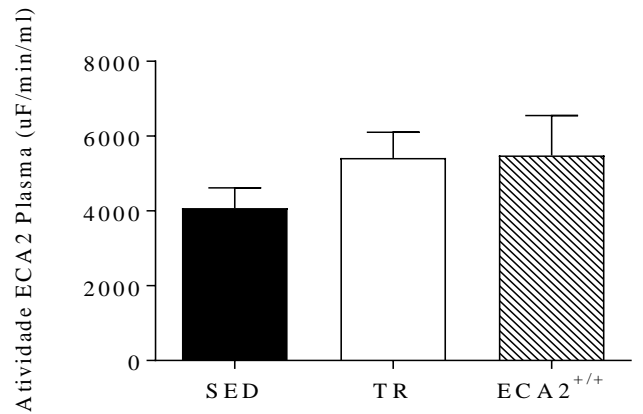

B)

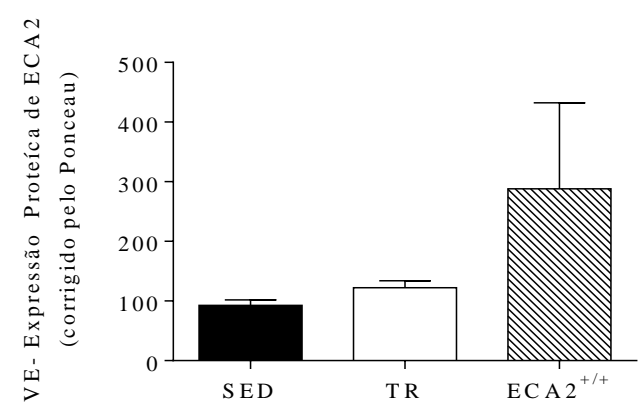

D)

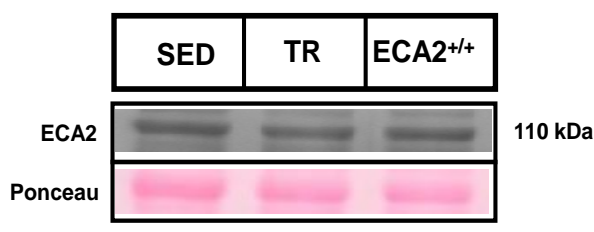

FIGURA 10. Expressão Gênica da Enzima Conversora de Angiotensina 2 (ECA2) (A). Expressão Proteíca de ECA2 (B). Atividade da enzima ECA2 no plasma (C). Blots representativos da ECA2 (D) dos animais sedentários (SED), treinados (TR) e com superexpressão da enzima conversora de angiotensina $2\left(E C A 2^{+/+}\right)^{\top} p<0,05 E C A 2^{+/+}$vs. TR ; ${ }^{*} \mathrm{p}<0,01 \mathrm{ECA}^{+/+}$vs. SED.

\subsubsection{High Performance Liquid Chromatography (HPLC) no Plasma.}

A figura 11 mostra a quantificação dos peptídeos Ang- I, Ang-II, Ang-(1-7) e a relação entre os níveis de Ang-II e Ang-(1-7) no plasma.

Os níveis de Ang-Il diminuíram significativamente no grupo TR quando comparado ao grupo SED (figura 11b). Na figura 11c mostra aumento estatisticamente significativo de Ang- (1-7) no grupo ECA2 $2^{+/+}$em relação aos grupos SED e TR. Ainda, a razão entre os níveis de Ang-II/ Ang- (1-7) foram diminuídos significativamente para os grupos $\mathrm{ECA}^{+/+}$e TR comparados ao grupo sedentário. 


\section{FIGURA 11}

A)

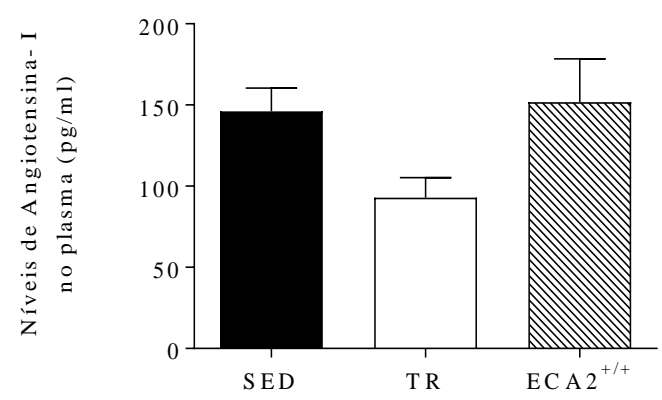

C)

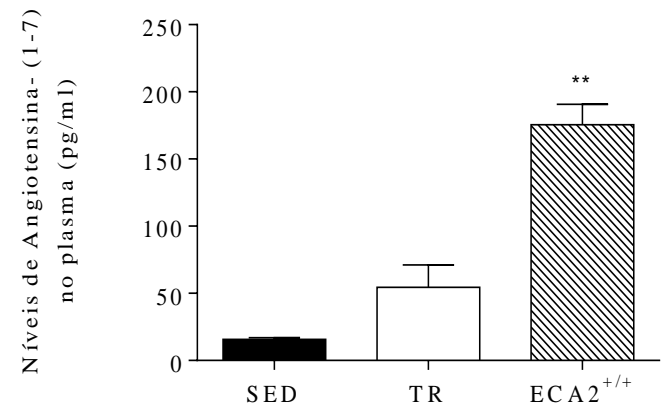

B)

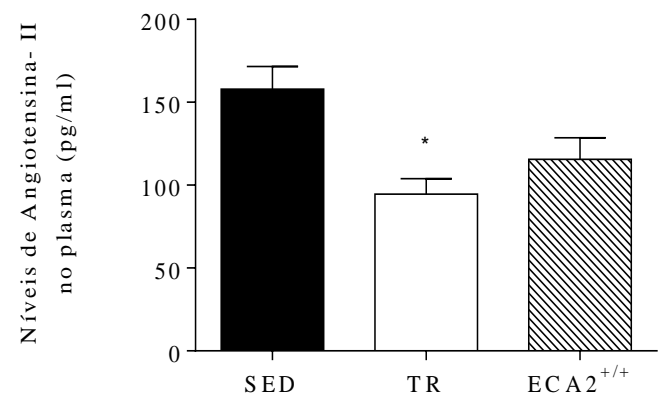

D)

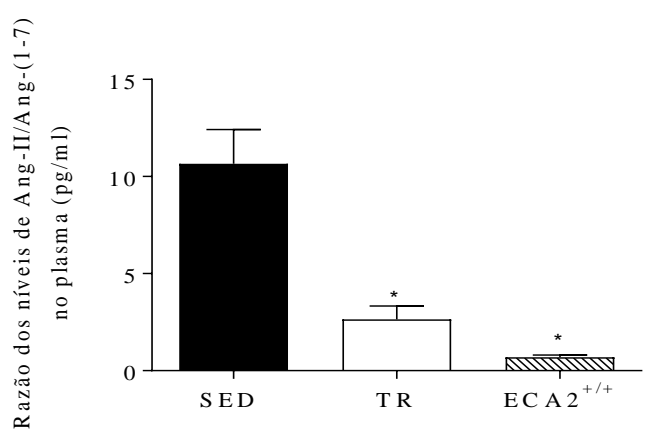

FIGURA 11. Quantificação dos peptídeos Ang- I, Ang-II, Ang-(1-7) e a relação entre os níveis de Ang-Il e Ang-(1-7) no plasma pela técnica de HPLC. Sedentários (SED), treinados (TR) e com superexpressão da enzima conversora de angiotensina $2\left(E C A 2^{+/+}\right) .{ }^{*} p<0,01$ TR vs. SED; ${ }^{* *} p<0,01 \mathrm{ECA} 2+$ vs. SED e TR.

\subsubsection{Receptores do Sistema Renina Angiotensina.}

A Figura 12a e b mostra a expressão gênica do receptor e expressão proteica do receptor MAS1, respectivamente. No grupo $\mathrm{ECA}^{+/+}$temos um aumento da expressão gênica quando comparado aos grupos SED e TR, porém, não foram encontradas diferenças estatisticamente significativas na expressão proteica deste receptor.

Nas figuras 12c e d, podemos observar que não foram encontradas diferenças estatisticamente significantes na expressão dos receptores AT2 e AT1, respectivamente. Ainda, temos a representação dos blots nas figuras $12 \mathrm{c}, \mathrm{f}$ e $\mathrm{g}$. 


\section{FIGURA 12}

A)

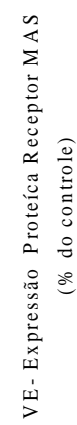

C)

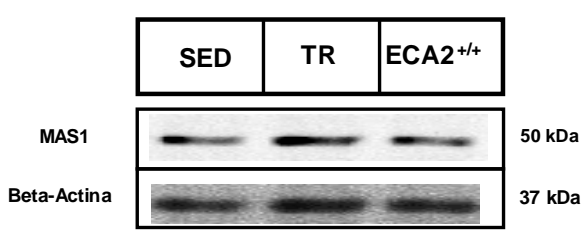

E)

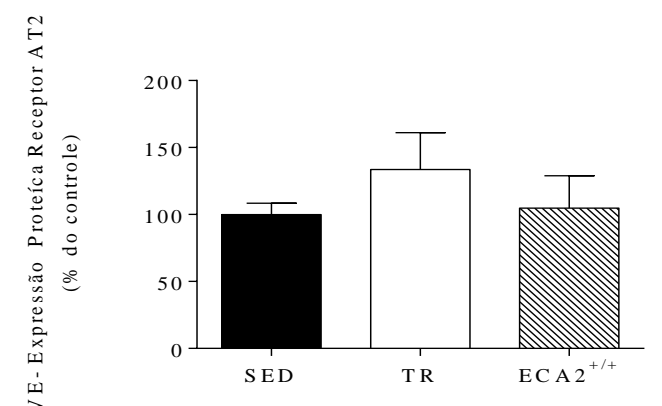

G)

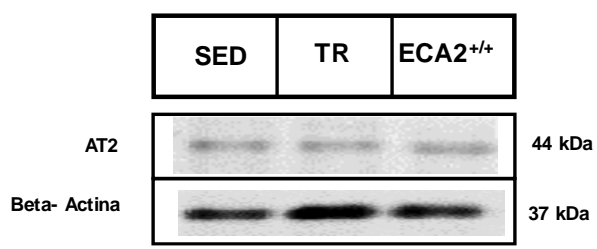

B)

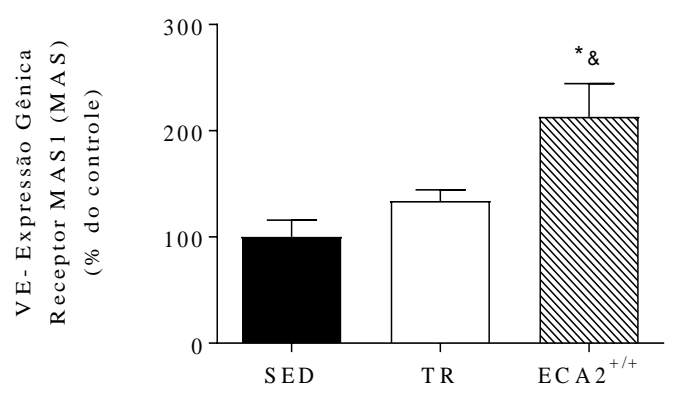

D)
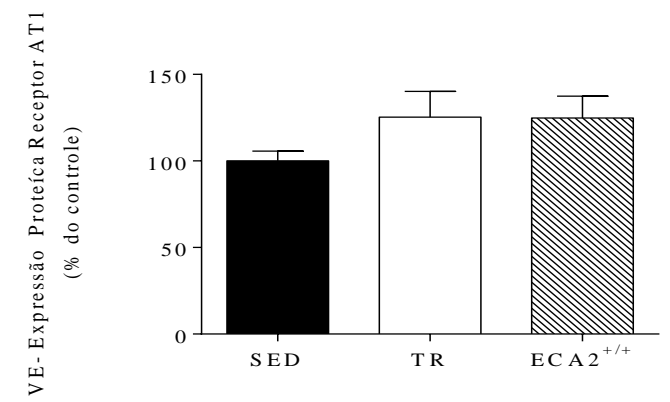

F)

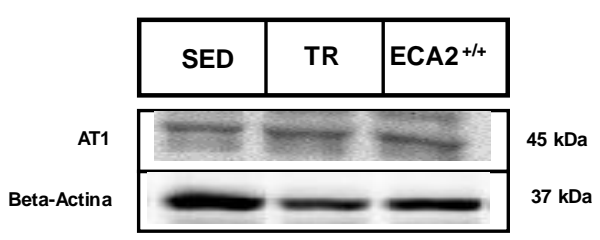

FIGURA 12. Expressão proteica por Western Blot do receptor MAS1 (A). Expressão gênica do receptor MAS1 por RT-qPCR (B). Representação dos blots analisados para quantificação protéica do receptor MAS1 (C). Expressão proteica do receptor AT1 (D). Expressão proteica do receptor AT2 (E) Representação dos blots analisados para quantificação protéica do receptor AT1 (F); Representação dos blots analisados para quantificação protéica do receptor AT2 (G). Grupos (ECA2) dos animais sedentários (SED), treinados (TR) e com superexpressão da enzima conversora de angiotensina $2\left(E C A 2^{+/+}\right) . \& p<0,001 E^{2} A 2^{+/+}$vs. SED ${ }^{*} \mathrm{p}<0,01 \mathrm{ECA}^{+/+}$vs. TR. 


\subsubsection{MicroArray}

A figura 13 mostra o Heat-Map hierárquico do microArray de microRNAs, o qual foi obtido da análise dos resultados do scanner laser (Affymetrix, USA). Para analisarmos as diferenças entre os grupos avaliamos primeiramente os microRNAs que tiveram sua expressão alterada no grupo TR quando comparado ao grupo SED, utilizando os parâmetros apresentados nos métodos. A partir desta análise, encontramos 4 microRNAs que estavam diferencialmente expressos quando comparados os perfis de expressão do grupo SED com o grupo TR.

Em seguida, realizamos a mesma análise para os animais $\mathrm{ECA}^{+/+} \mathrm{e}$ encontramos 14 microRNAs diferencialmente expressos, quando comparado o grupo SED com o ECA2 ${ }^{+/+}$.

$\mathrm{Na}$ Figura 14 temos um gráfico de VENN e gráfico em barras com os microRNAs aumentados e diminuídos para os grupos $E C A 2^{+/+}$e TR comparados com SED. 


\section{FIGURA 13}

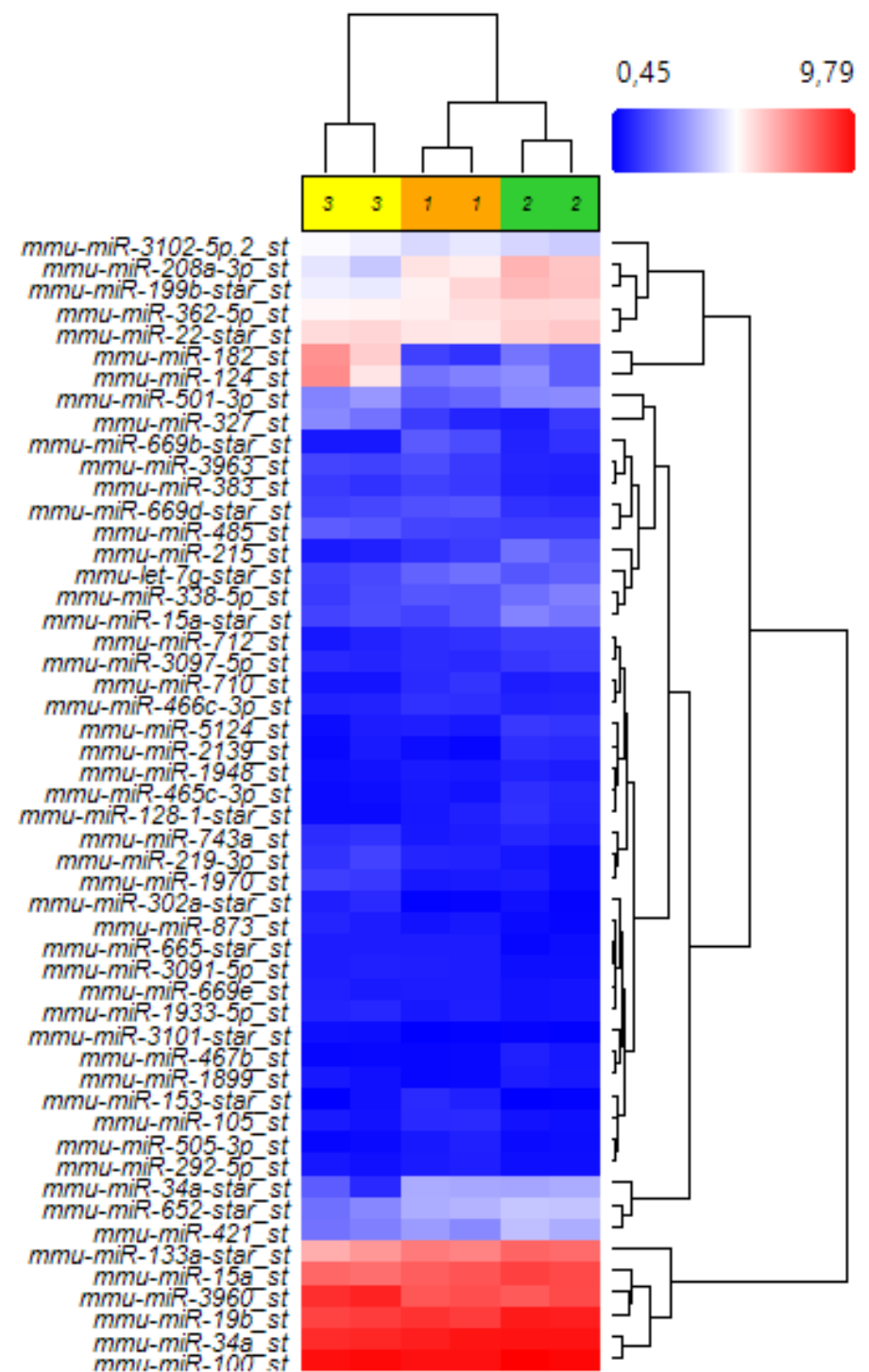

FIGURA 13. Heat-Map hierárquico do microArray dos animais sedentários (SED), treinados (TR) e com superexpressão da enzima conversora de angiotensina $2\left(E C A 2^{+/+}\right) \operatorname{com} p<0,05$, FDR $<0,01$ e Fold-Change $=>2$ e $<-2$. 


\section{FIGURA 14}

A)

$\mathrm{ECA}^{+/+}$

\section{TR}

\section{DOWN}

mmu-miR-199b-5p

mmu-miR-208b-3p

mmu-miR-34c-5p

mmu-miR-652-5p

mmu-miR-411-5p

mmu-miR-208a-3p

mmu-miR-215-5p

mmu-miR-421-3p

mmu-miR-133a-5p

mmu-miR-182-5p

UP

mmu-miR-182-5p

mmu-miR-327

B)

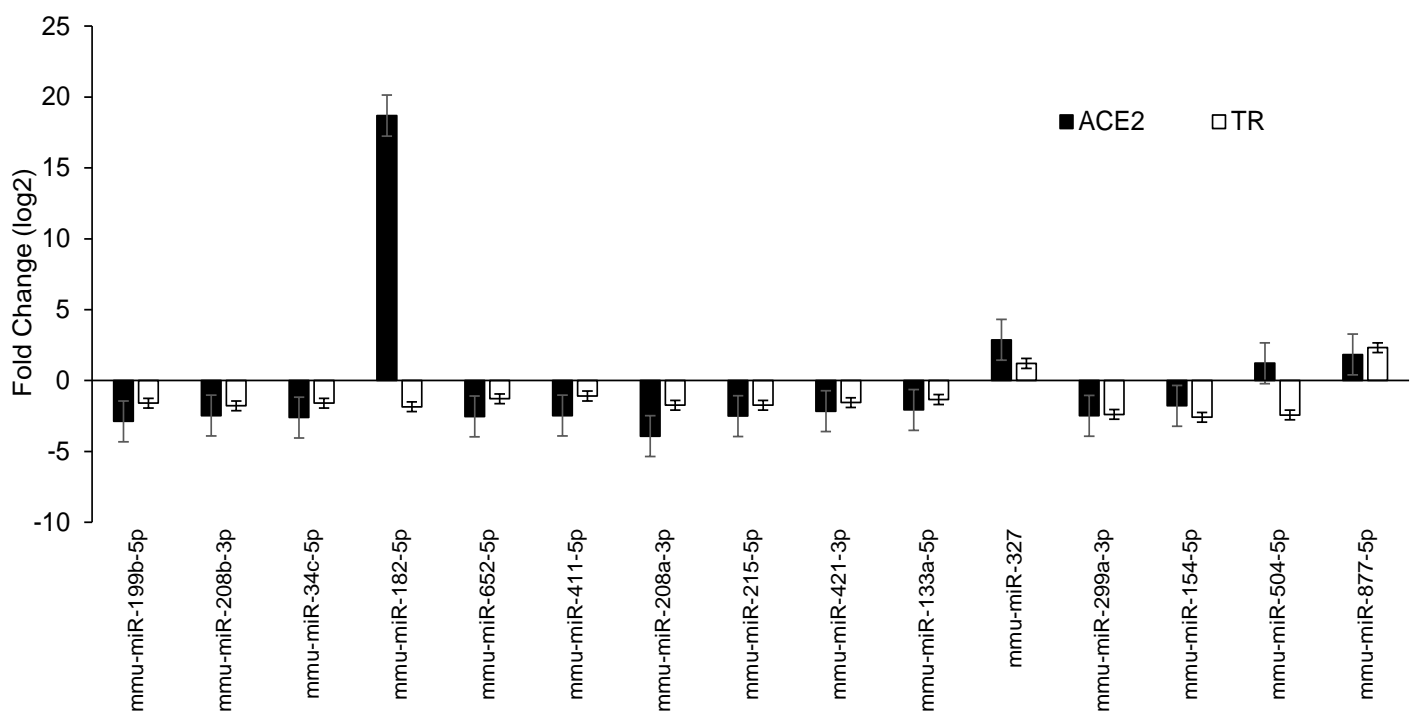

FIGURA 14. MicroRNAs diferencialmente expressos nos grupos experimentais treinado (TR) e com superexpressão da enzima conversora de angiotensina II $\left(\mathrm{ECA}^{+/+}\right)$em relação ao controle sedentário (SED). Figura 11a) MicroRNAs aumentados nos grupos experimentais treinado (TR) e com superexpressão da enzima conversora de angiotensina II $\left(E C A 2^{+/+}\right)$em relação ao controle sedentário (SED). Figura 11b) MicroRNAs diminuídos nos grupos experimentais treinado (TR) e com superexpressão da enzima conversora de angiotensina II $\left(\mathrm{ECA}^{+/+}\right)$em relação ao controle sedentário (SED). 


\subsection{RT- qPCR- Confirmação dos microRNas do Array}

Após a análise do perfil de microRNAs encontrados pelo microArray no ventrículo destes animais, foram selecionados para confirmação por RT-qPCR 15 microRNAs. Conforme verificado no microArray três microRNAs apresentaram diminuição estatisticamente significativa (microRNAs -133a-5p, -215-5p e -208a-3p) apresentados na figura 15.

O microRNA-34c-5p não foi utilizado por apresentar uma expressão muito baixa ao ser analisado o resultado da confirmação por RT-qPCR.

\section{FIGURA 15}

A)

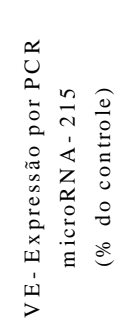

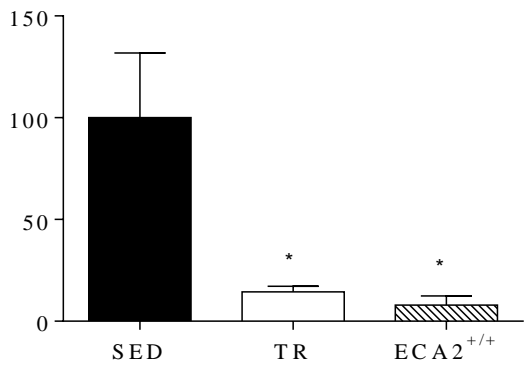

C)
B)

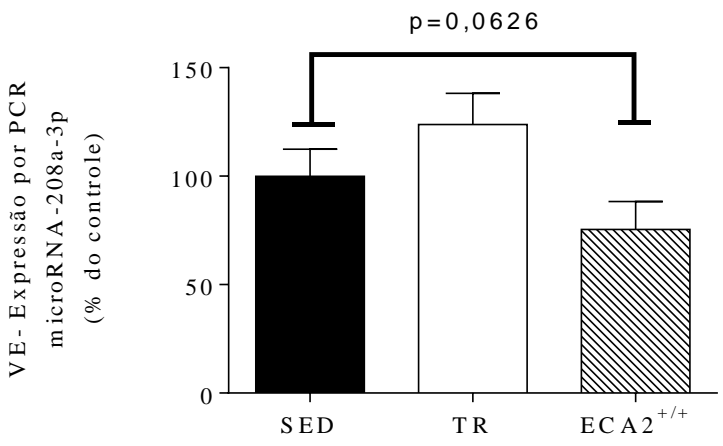

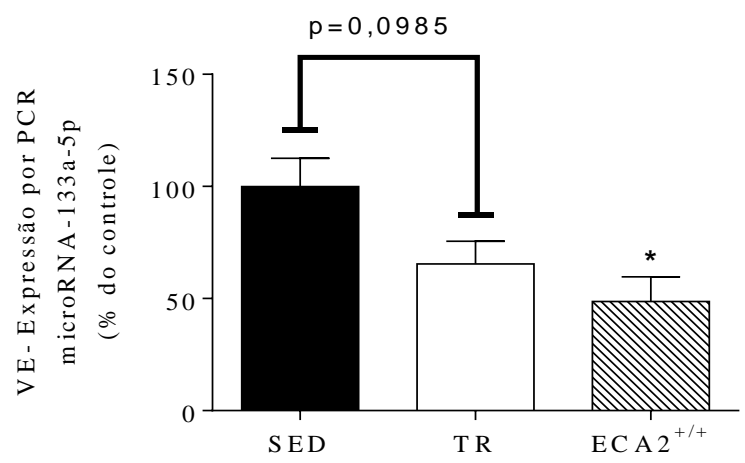

Figura 15. Expressão gênica dos microRNAs- 215-5p (A), -208a-3p (B) e -133a-5p (C) pela técnica de RT- qPCR nos grupos: sedentário (SED), treinado (TR) e com superexpressão da enzima conversora de angiotensina $2\left(\mathrm{ECA}^{+/+}\right){ }^{*} \mathrm{p}<0,01 \mathrm{ECA} 2^{+/+} \mathrm{vs}$.SED. 
7.7 MicroRNAs para análise de bioinformática

Após a confirmação dos microRNAs encontrados no microarray pela técnica de RT- qPCR, 3 microRNAs foram confirmados, os mesmos estão demonstrados na figura 15. Os demais microRNAs estão representados na Figura 1 e 1.1 dos suplementos. Estes foram submetidos a uma análise funcional de bioinformática, onde inicialmente foi feita uma busca para cada microRNA através do programa microRNAWalk 2.0, afim de encontrar os genes preditos como alvo para cada um dos microRNAs. Nesta busca foram estabelecidos alguns critérios que geraram um total de 418 genes alvos preditos para os 3 microRNAs investigados nesse estudo, e que estavam presentes em pelo menos 8 dos 10 programas de identificação de alvos de microRNAs (sendo que obrigatoriamente este gene alvo deveria ser predito pelo Targetscan e mais 7 dos outros 10 programas de busca utilizados: microRNAWalk, Microt4, microRNAanda, microRNAbridge, microRNADB, microRNAMap, Pictar2, RNA22 e Targetscan). Essa lista de genes alvo preditos para os três microRNAs escolhidos foi então submetida a base de dados biológicos do DAVID Bioinformatics resources 6.7 (Database for Annotation, Visualization and Integrated Discovery), que através de uma análise funcional (Functiona IAnnotation Chart) utilizando a base de dados KEGG (Kyoto Encyclopedia of Genes and Genomes) identificou os mais relevantes termos biológicos associados com a lista.

Após esta busca, obtivemos 24 vias enriquecidas para nossa lista de genes, todas as vias estão apresentadas na Tabela 2 na sessão suplementar. Na figura 16 apresentamos as duas vias de sinalização ligadas ao fenótipo de hipertrofia que selecionamos para analisar os possíveis genes alvos para os microRNAs: -133a-5p, 208a-3p e -215-5p.

Ainda, submetemos estas vias de sinalização na plataforma online STRING Protein-Protein Interaction Networks, onde podemos identificar a interação destes genes dentro da lista. Utilizando o High confidence de minimum required interaction score para identificar as interações que estão apresentadas na Imagem 1 e Imagem 2 e relacionadas aos respectivos microRNAs. 


\section{FIGURA 16}

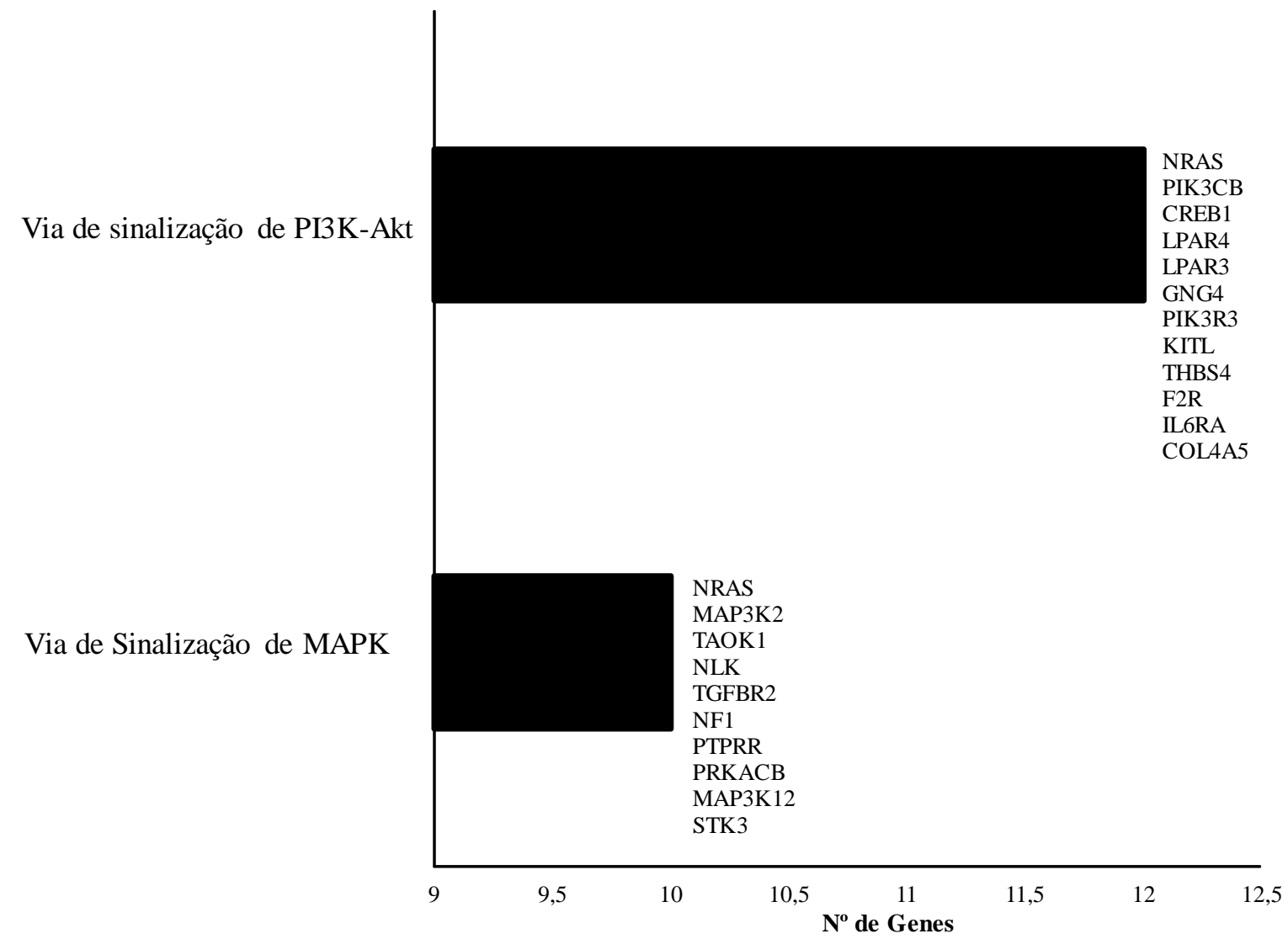

Figura 16. Genes alvos presentes nas Vias de sinalização de PI3K-AKT e MAPK para os microRNAs -133a-5p, 208a-3p e -215-5p selecionados no estudo. Via de sinalização de PI3K-Akt: Nras - Neuroblastoma ras oncogene; Phosphatidylinositol 3-kinase, catalytic, beta polypeptide; CREB1- cAMP responsive element binding protein 1; Lpar4 - Lysophosphatidic acid receptor 4; LPAR3- Lysophosphatidic acid receptor 3; GNG4- Guanine nucleotide binding protein (G protein), gamma 4; PIK3R3- Phosphatidylinositol 3 kinase, regulatory subunit, polypeptide 3 (p55); KITL- Kit ligand; THBS4- Thrombospondin 4; F2R- Coagulation factor II (thrombin) receptor; IL6RAInterleukin 6 receptor; COL4A5- Collagen, type IV, alpha 5. Via de Sinalização de MAPK: NRAS- Neuroblastoma ras oncogene; MAP3K2- Mitogen-activated protein kinase kinase kinase 2; TAOK1- TAO kinase 1; NLK- Nemo like kinase; TGFBR2- Transforming growth factor, beta receptor II; NF1- Neurofibromatosis 1; PTPRR- Protein tyrosine phosphatase, receptor type, $\mathrm{R}$; PRKACB- Protein kinase, cAMP dependent, catalytic, beta; MAP3K12Mitogen-activated protein kinase kinase kinase 12; STK3- Serine/threonine kinase 


\section{Imagem 1}

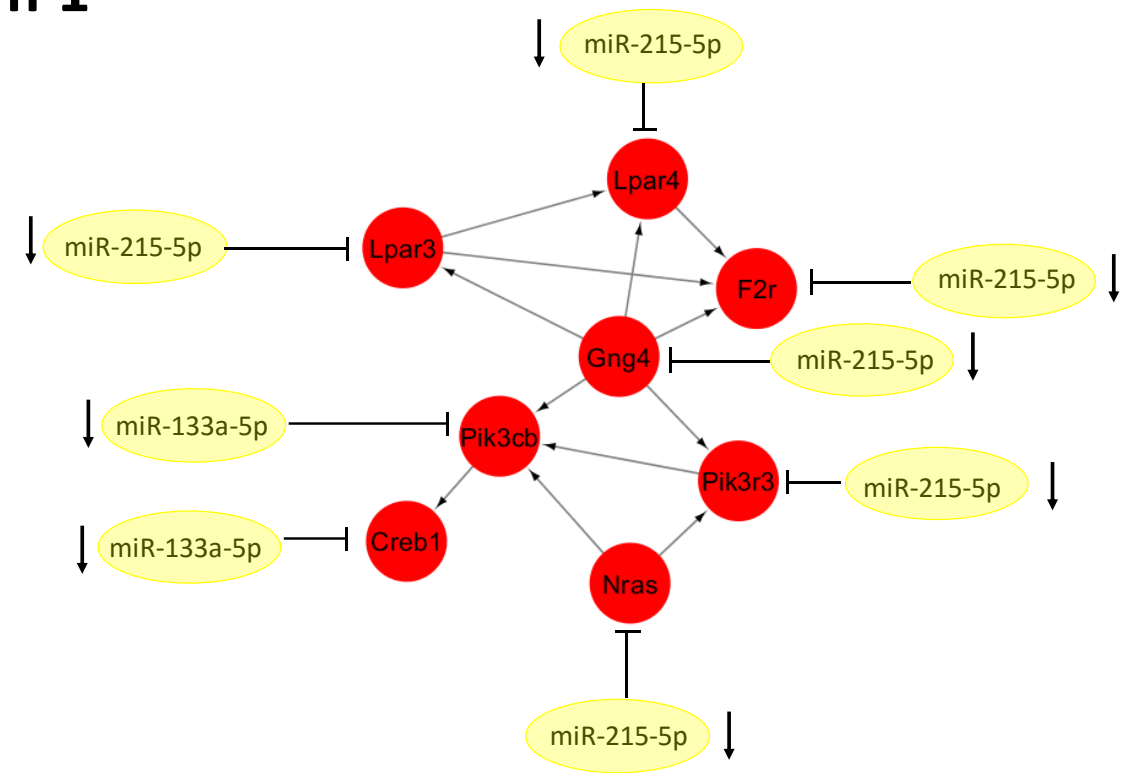

Interação entre genes alvos dos microRNAs -133a-5p, -208a-3p e -215-5p na via de sinalização de PI3k-AKT.

\section{Imagem 2}

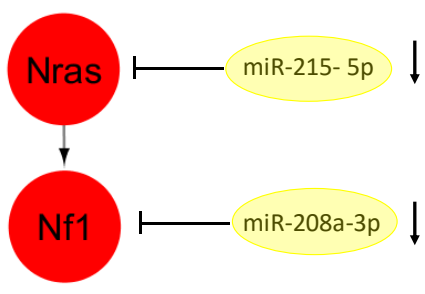

Interação entre genes alvos dos microRNAs -133a-5p, -208a-3p e -215-5p na via de sinalização de MAPK.

7.8 Expressão Gênica dos Genes Alvo para os MicroRNAs -133a-5p, -208a-3p e -215$5 p$

A figura 17 nos mostra os dados da expressão gênica para os genes validados pela técnica de RT- qPCR das vias de sinalização de PI3K-AKT e MAPK. Como resultado, apenas obtivemos diferença estatisticamente significativa no gene Pi3kr3, que estava aumento no grupo TR em relação aos grupos SED e ECA2 $2^{+/+}$. 


\section{FIGURA 17}

A)

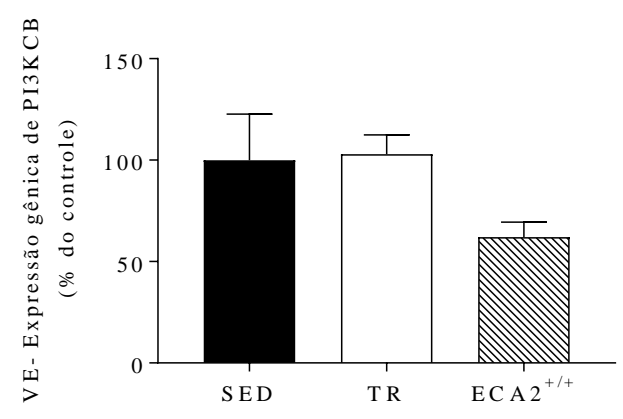

C)

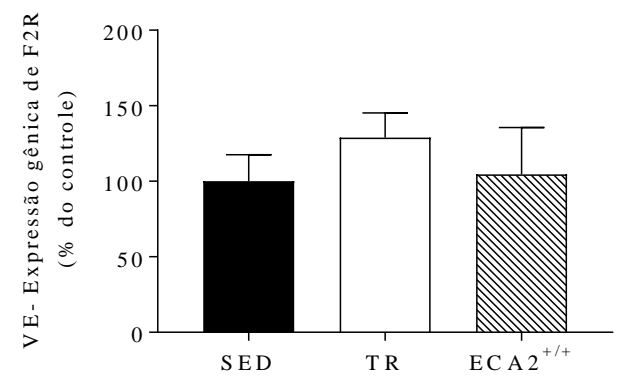

E)

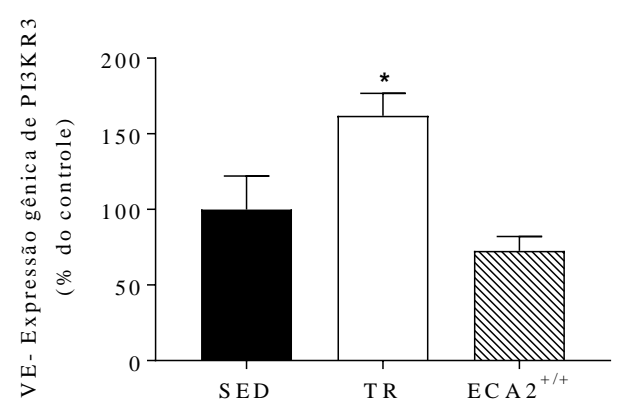

B)

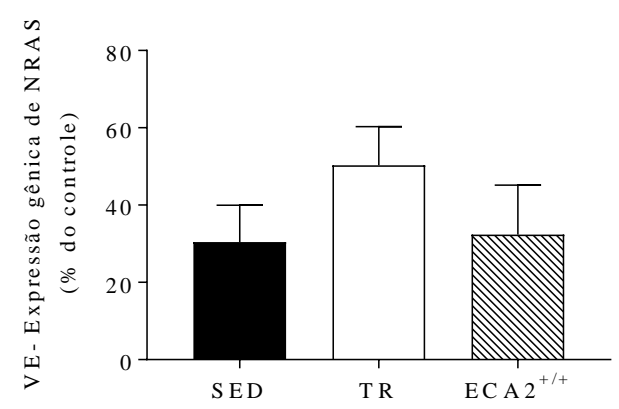

D)

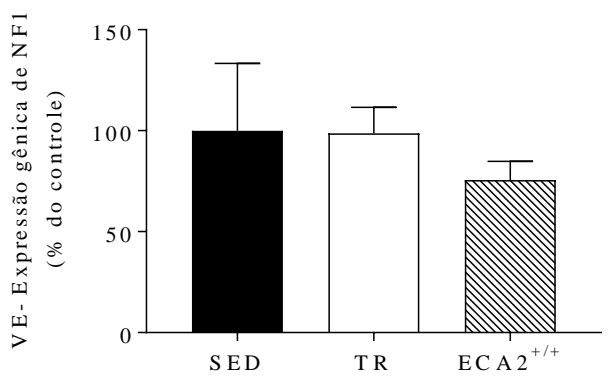

Figura 17. Expressão gênica dos genes alvos preditos: Nras - Neuroblastoma ras oncogene; Phosphatidylinositol 3-kinase, catalytic, beta polypeptide; PIK3R3- Phosphatidylinositol 3 kinase , regulatory subunit, polypeptide 3 (p55); KITL- Kit ligand; THBS4- Thrombospondin 4; F2R- Coagulation factor II (thrombin) receptor; Via de Sinalização de MAPK: NRASNeuroblastoma ras oncogene; NF1- Neurofibromatosis 1; para os microRNAs- 215-5p, -208a$3 p$ e -133a-5p pela ténica de RT- qPCR nos grupos: sedentário (SED), treinado (TR) e com superexpressão da enzima conversora de angiotensina $2\left(\mathrm{ECA}^{+/+}\right){ }^{*} \mathrm{p}<0,05 \mathrm{TR}$ vs. ECA2 $2^{+/+}$ e.SED. 


\section{DISCUSSÃO}

No presente estudo, foram utilizados animais com superexpressão da enzima ECA2, enzima chave para o SRA não canônico e animais submetidos ao treinamento físico aeróbio crônico em esteira. Uma vez que nosso grupo demonstrou que o treinamento é capaz de modular componentes do SRA canônico e não-canônico, assim como alguns microRNAs envolvidos neste processo, o objetivo deste estudo foi traçar um perfil de expressão dos microRNAs, na busca de alvos relacionados ao processo de remodelamento cardíaco. Embora apenas o grupo $\mathrm{ECA} 2^{+/+}$tenha apresentado diferença significativa no remodelamento cardíaco, o treinamento físico realizado foi capaz de induzir diminuição na frequência cardíaca, aumento de a-MCP e ainda tivemos uma melhora discreta na função diastólica, pela análise do pico de onda $\mathrm{E}$, analisado por ecocardiografia (Tabela 3 nos suplementos). Além disso, o treinamento mostrou-se eficiente em diminuir razão Ang-Il:Ang-(1-7) circulantes, assim como diminuir a atividade de ECA plasmática. Com relação ao grupo $E C A 2^{+/+}$, demonstramos que a expressão de ECA2 especificamente cardíaca é capaz de aumentar os níveis circulantes de Ang-(1-7), podendo exercer um importante papel sistêmico está modulação.

Após a análise do microArray e da confirmação dos microRNAs pela técnica de RT-qPCR, nós identificamos três microRNAs que podem estar envolvidos no processo de remodelamento cardíaco acarretado por modulações no SRA não canônico resultantes da superexpressão da enzima chave ECA2, sendo eles os microRNAs 133a-5p, -208a-3p e -215-5p. Ainda, a partir das análises de bioinformática identificamos genes alvos destes microRNAs que poderiam desempenhar papel chave para que este remodelamento ocorra.

Identificamos o gene Phosphoinositide-3-Kinase Regulatory Subunit 3 (Pik3r3) como um importante alvo para as adaptações cardíacas ocorridas com o treinamento físico aeróbio. No entanto, não encontramos nenhum resultado estatisticamente significativo deste gene nos animais com superexpressão de ECA2 cardíaca.

No presente estudo, encontramos uma forte correlação entre a expressão do microRNA- 215-5p e o gene Pik3r3 sendo este um possível regulador das adaptações cardíacas decorrentes do treinamento físico. No entanto, este resultado não foi o 
mesmo encontrado para o grupo com superexpressão de ECA2 cardíaca, possivelmente por apresentar uma distinção na ativação de vias hipertróficas que devem ser analisadas em estudos futuros.

Nós mostramos uma maior eficiência da capacidade física aeróbia associada a maior tolerância à realização de esforço, avaliada pelo teste máximo em esteira. A partir da realização do teste máximo, nós determinamos a máxima fase estável de lactato, na qual os animais realizaram o protocolo de treinamento, sendo que esta foi reajustada na metade do protocolo (4 semanas), onde já é possível notar diferenças entre os grupos sedentário quando comparado ao grupo treinado. Ainda, a capacidade de tolerância ao esforço foi reavaliada novamente em teste máximo no final do protocolo (8 semanas). A partir destes testes nós podemos acompanhar que os animais submetidos ao treinamento físico aeróbio tiveram um aumento no tempo de realização do teste, na velocidade máxima atingida e na distância percorrida.

A melhora nestes parâmetros provavelmente está associada a uma melhora na capacidade oxidativa do músculo esquelético, como demonstrado em estudos anteriores (FERREIRA et al., 2007; BUENO et al., 2010; FERNANDES et al., 2011; SOCl et al., 2011). Para comprovar esta melhora na capacidade oxidativa, nós avaliamos a atividade da enzima citrato sintase, sendo esta uma enzima chave para o metabolismo aeróbio (ALP; NEWSHOLME; ZAMMIT, 1976). Corroborando com estudo anteriores, nós mostramos um aumento da atividade desta enzima no grupo que realizou o treinamento físico aeróbio de esteira por 8 semanas.

Além destas adaptações funcionais e adaptações moleculares periféricas, o treinamento físico aeróbio é capaz de produzir mudanças autonômicas melhorando a função cardiovascular (MEDEIROS et al., 2004). Assim, um dos principais marcadores de treinamento físico aeróbio é a bradicardia de repouso. Ao final do protocolo de treinamento, nós realizamos as medidas hemodinâmicas por plestimografia de cauda e encontramos diferenças significantes no grupo que realizou o treinamento físico aeróbio de esteira em relação ao grupo sedentário.

Porém, não encontramos diferenças significantes ao medirmos a PA destes animais. Este dado é condizente com a literatura, uma vez que a redução da PA em resposta ao treinamento físico não é alterada em animais normotensos (FERNANDES; SOCI; OLIVEIRA, 2011; HASHIMOTO; FERNANDES; OLIVEIRA, 
2011; SOCl et al., 2011). No entanto, a literatura mostra amplamente que o treinamento físico é fator chave para o controle da hipertensão arterial (FORJAZ et al., 2000).

Desde a descoberta dos primeiros componentes do SRA foi vista uma importante relação com a pressão arterial e adaptações cardiovasculares. Tigerstedt e Bergman em 1898 explicaram que a associação entre doença renal e hipertrofia cardíaca era devido a uma substância vasoativa que induzia constrição dos vasos (BASSO; TERRAGNO, 2001). Posteriormente foi possível detectar expressão de componentes do SRA em diversos tecidos, inclusive no coração (DZAU et al., 1987). No coração a expressão destes componentes parece exercer importante papel no processo de remodelamento cardíaco, tanto em situações de estímulos patológicos como por meio de estímulos fisiológicos como o exercício físico (BARAUNA et al., 2008).

Com a descoberta do SRA não- canônico muitos estudos vêm apontando sua importância na contra regulação do SRA canônico, inclusive controlando a hipertrofia cardíaca patológica induzida pelo SRA clássico (ISHIYAMA et al., 2004; YAMAMOTO et al., 2006; MERCURE et al., 2008; FERNANDES et al., 2011; MCCOLLUM; GALLAGHER; ANN TALLANT, 2012; SHAH et al., 2012; BERTAGNOLLI et al., 2014; OCARANZA et al., 2014).

No presente trabalho, somos o primeiro grupo a demonstrar que os níveis de Ang-(1-7) plasmático está aumentado em camundongos com superexpressão de $\mathrm{ECA}^{+/+}$cardíaca em relação aos grupos SED e TR. Infelizmente, não temos os dados funcionais de pressão arterial e frequência cardíaca destes animais.

Estes resultados corroboram com dados anteriores de nosso grupo, 0 treinamento levou à uma diminuição dos níveis plasmáticos de Ang-II (FERNANDES et al., 2011). Além disso, no presente estudo, quando realizamos a razão entre os níveis de Ang-II/Ang-(1-7), temos uma diminuição significativa em ECA2 ${ }^{+/+}$e TR comparados ao grupo sedentário.

Ainda, no presente estudo, quando comparamos o grupo $\mathrm{ECA}^{+/+}$versus o grupo controle e grupo treinado, nós encontramos um aumento da massa cardíaca, tanto na razão massa cardíaca:massa corporal como na massa cardíaca:comprimento 
da tíbia. Muitos estudos têm demonstrado que a ECA2 contra regula os efeitos hipertróficos do SRA canônico seguido de infarto de miocárdio e hipertensão arterial (BURRELL et al., 2005; HUENTELMAN et al., 2005; DÍEZ-FREIRE et al., 2006; YAMAMOTO et al., 2006; DER SARKISSIAN et al., 2008; FERREIRA et al., 2011b; ZHANG et al., 2014). No entanto, alguns estudos têm sugerido que a superexpressão crônica de ECA2 leva ao aumento de fibrose e disfunção cardíaca (MASSON et al., 2016). Em estudo de Donoghue, foi demonstrado que a superexpresão de ECA2 no coração levou a arritimias e morte súbita (DONOGHUE et al., 2003). Além disso, Masson e colaboradores demonstraram que a superexpressão de ECA2 por 11 semanas levou ao um aumento exacerbado de fibrose cardíaca, sugerindo que a superexpressão crônica talvez provoque efeitos deletérios no miocárdio (MASSON et al., 2016).

Assim, para avaliar se esta hipertrofia seria acompanhada de um fenótipo de hipertrofia cardíaca patológico realizamos a expressão gênica dos marcadores de hipertrofia cardíaca patológica. Estes genes marcadores são expressos durante o desenvolvimento embrionário do coração e começam a ser re-expressos durante o processo de remodelamento patológico, mas não são expressos na hipertrofia induzida pelo treinamento físico aeróbio (SOCl et al., 2011). No presente estudo, houve diminuição significativa na expressão da $\alpha$-actina esquelética e da $\beta$-MCP em $\mathrm{ECA} 2^{+/+}$em relação aos grupos sedentário e treinado. Este achado sugere que há uma possível ativação de vias hipertróficas preferenciais induzida pela superexpressão de ECA2 que levam à um fenótipo de hipertrofia cardíaca mais voltado à fisiológica como a induzida pelo treinamento. Interessantemente, a $\beta$-MCP no grupo $\mathrm{ECA}^{+/+}$foi reduzida drasticamente comparada ao grupo controle. Nós especulamos que possivelmente há um mecanismo cardioprotetor ligado à superexpressão de ECA2 no coração via microRNA-208a-MED-13 (Mediator complex subunit 13) regulando a expressão de $\beta$-MCP (GRUETER et al., 2012).

Ainda que nosso protocolo de treinamento utilizado no presente estudo não tenha acarretado diminuição nos genes de reprogramação fetal, este dado vai de encontro aos observados em estudos anteriores de nosso grupo, onde apenas o treinamento de alta frequência acarretou em mudanças significantes na expressão destes genes. No entanto, no presente estudo nós obtivemos um aumento da a-MCP 
como resultado do treinamento, sendo este um importante marcador do remodelamento cardíaco fisiológico (FERNANDES et al., 2011; SOCl et al., 2011).

Além dos marcadores de hipertrofia, para determinar se este remodelamento cardíaco encontrado apresentava um fenótipo mais próximo ao fisiológico, realizamos a expressão dos genes de colágeno IAI e IIIAI que estão associados a diversas desordens cardíacas. Não encontramos nenhuma diferença estatisticamente significativa em relação a expressão do COLIAI que apresenta característica de resistência à tensão (JUNQUEIRA LC e CARNEIRO J, 10ª Ed. 2004), ou seja, possivelmente não havia uma sobrecarga crônica imposta ao coração destes animais. No entanto, ao realizar a expressão do COLIIIAI encontramos uma forte tendência estatística ao seu aumento no grupo ECA2, este colágeno tem como função à manutenção da estrutura de órgãos expansíveis (JUNQUEIRA LC e CARNEIRO J, 10aㅡ Ed. 2004) mostrando que possivelmente há um mecanismo indutor nestes animais com superexpressão de ECA2 cardíaca ao fenótipo de hipertrofia cardíaca.

Tentando compreender os possíveis mecanismos moleculares que levaram à hipertrofia cardíaca nestes animais transgênicos, foi demonstrado em estudo de VELLOSO e colaboradores (1996) que há um cross-talk entre SRA e os receptores de insulina (IRS), podendo estar associada ao desenvolvimento de diabetes e doenças cardiovasculares (VELLOSO et al., 1996). Passados 10 anos e a caracterização de uma nova via do SRA, Giani e colaboradores demonstraram que há um cross-talk envolvendo o receptor MAS, os autores observaram que a infusão de Ang-(1-7) estimulou a fosforilação de AKT e esta foi cessada com a administração do agonista do receptor MAS, o A779 (GIANI et al., 2007). No presente estudo, vemos que a expressão gênica do receptor MAS no coração estava aumentada no grupo $\mathrm{ECA}^{+/+}$em relação ao grupo SED, sendo assim, levantamos a hipótese de que possivelmente a superexpressão de ECA2 cardíaca, acarreta em modulação da via não canônica do SRA, como podemos ver, com o aumento de Ang-(1-7) circulante, assim, estimulando vias hipertróficas como a AKT/mTOR que estão envolvidas a um remodelamento cardíaco com padrão mais próximo do fisiológico (porém, sabemos que não exclusivamente).

$\mathrm{Na}$ busca por novos mecanismos moleculares envolvidos no fenótipo encontrado, realizamos a técnica de microArray, buscando por microRNAs 
apresentassem um padrão de expressão similar tanto no grupo TR como no ECA2 $2^{+/+}$ quando comparados ao grupo SED. Curiosamente, alguns dos microRNAs encontrados nesta análise de varredura têm sido diretamente implicados no processo de remodelamento cardíaco, com destaque aos microRNA-133a-5p e -208a-3p e 215-5p, que foram validados pela técnica de RT-qPCR (CARÈ et al., 2007; VAN ROOIJ; OLSON, 2007). Estes microRNAs estavam diminuídos tanto no TR como no ECA2 ${ }^{+/+}$quando comparados ao grupo SED.

O microRNA-133 é expresso abundantemente na musculatura cardíaca e esquelética (CARÈ et al., 2007; RANA et al., 2015). Este microRNA tem sua expressão diminuída tanto no remodelamento patológico como no fisiológico, mostrando um importante papel regulador deste fenótipo. Alguns estudos têm apontando que a superexpressão deste microRNA cessa o processo de remodelamento hipertrófico (CARÈ et al., 2007). Nosso dado sobre a expressão deste microRNA, analisada pela técnica microArray e confirmada por RT-qPCR, corroboram ao que é demonstrado na literatura (SOCl et al., 2011).

O microRNA-208a é expresso exclusivamente no coração e é codificado pelo íntron 27 do gene da a-miosina de cadeia pesada ( $\alpha-M C P$ ). No presente estudo, este microRNA aparece significantemente diminuído quando avaliamos sua expressão pela técnica de microArray e pela técnica de RT-qPCR. Está diminuição explicaria um possível mecanismo da redução na expressão da proteína $\beta$-MCP. Uma vez que esta proteína tem sua regulação feita de forma indireta pelo microRNA-208a via regulação de MED-13 (GRUETER et al., 2012; SOCl et al., 2016). Estudo do grupo do professor Olson demonstrou que animais KO para este microRNA não apresentam aumento significante na expressão da $\beta$-MCP quando submetidos a constrição aórtica. Ainda, este mecanismo de cardioproteção ocorre com participação do receptor tireoideano (VAN ROOIJ et al., 2007).

O microRNA-215, tem sido implicado como promissor supressor tumoral, uma vez que este alveja diretamente o gene AKT1 diminuindo processo de proliferação em câncer de mama (YAO J, ZHANG P, LI J, 2017). No entanto, poucos estudos têm mostrado a participação do microRNA-215 no coração. Em estudo de Wang $\mathrm{J}$ publicado em 2014, este microRNA foi um dos quatro microRNAs identificados aumentados na circulação de pacientes com doença coronariana atípica, podendo 
servir como importante biomarcador para esta desordem cardíaca. No presente estudo a diminuição da expressão deste microRNA no tecido cardíaco pode ser um indicativo do papel cardioprotetor tanto do treinamento físico aeróbio como da superexpressão de ECA2 cardíaca (WANG et al., 2014).

Após a confirmação destes três microRNAs pela técnica de RT-qPCR, realizamos então uma busca por genes alvos preditos para estes microRNAs. A análise in silico, como mostrado em nossos resultados, gerou uma lista de 418 genes que foram submetidos a análise de bioinformática para buscar as vias de sinalização enriquecida, que nos resultou em 24 vias de sinalização via KEGG PATHWAY (Tabela 2 suplementos).

Dentre as vias de sinalização enriquecidas, identificamos os genes presentes nas vias PI3K/AKT e MAPK alvos para os três microRNAs selecionados. Realizamos também a validação destes genes pela técnica de RT-qPCR, de dez genes selecionados, apenas 5 apresentaram expressão significativa $(-\triangle \Delta C T<30)$. Interessantemente, encontramos o gene Pik3r3, pertencente a via de PI3K/ AKT, com sua expressão aumentada no grupo TR em relação aos grupos SED e ECA2 ${ }^{+/+}$, sendo este gene alvo predito para o microRNA-215-5p. Este gene nos despertou bastante interesse, pois, como revisado por Oudit GY e Penninger JM em 2009, as Phosphoinositide 3-kinases (PI3Ks) são enzimas classificadas pela especificidade de seus substratos, modo de ativação e estrutura molecular (OUDIT; PENNINGER, 2009). As PI3Ks estão ligadas a diversos processos celulares como crescimento, metabolismo e motilidade celular. A Pik3r3 pertence à classe IA sendo está uma enzima heterodimérica composta de uma subunidade regulatória adaptadora junto à uma subunidade catalítica (OUDIT; PENNINGER, 2009). A classe IA de PI3K são geradas por produtos altamente homólogos p85a (pik3r1), p85 $\beta$ (pik3r2) e p55y (pik3r3) (OUDIT; PENNINGER, 2009). Está classe IA de PI3K tem como função lançar o segundo mensageiro phosphatidylinositol-3,4,5-trisphosphate (PIP3) que por sua vez ativa a proteína serina-treonina kinase Akt (PKB) (OUDIT; PENNINGER, 2009).

Ainda, em estudo de Luo J publicado em 2005, é demonstrado que animas com deleção da subunidade p85 apresentam um tamanho de coração reduzido, porém, sem alterações na função cardíaca e na análise histológica do coração destes animais (LUO et al., 2005). Ainda, neste mesmo estudo, foi demonstrado que quando 
submetidos ao treinamento aeróbio de natação, estes animais knockout para p85 tem o remodelamento cardíaco fisiológico cessado (LUO et al., 2005). Em 2015, Li e colaboradores demonstraram um importante papel de Pik3r3 no controle de proliferação de células musculares lisas na carótida de animais submetidos a injuria por balão (Ll et al., 2015). No presente estudo, este gene parece aumentado no grupo TR em relação ao grupo SED, apresentando correlação negativa com a expressão do microRNA-215-5p que a tem como alvo predito. Infelizmente, embora haja uma diminuição deste microRNA também no grupo $E C A 2^{+/+}$em relação ao grupo SED, não tivemos resultados estatisticamente significativo em relação a expressão do gene Pik3r3 quando comparado ao grupo sedentário. No entanto, não realizamos nenhuma análise de causa e efeito, como a modulação deste microRNA para determinar a efetividade deste em controlar a expressão gênica de Pi3kr3.

Além do Pi3kr3, conseguimos obter expressão significativa por RT-qPCR dos genes da via de PI3K/Akt: F2R e Pi3kcb e da via de sinalização de MAPK os genes: Nf1 e Nras, no entanto, para estes genes não foram encontradas nenhuma diferença estatisticamente significante.

\section{CONCLUSÃO}

Tanto o treinamento físico aeróbio como a superexpressão de ECA2 cardíaca acarretam na modulação de componentes circulantes de RAS. Além disso, ambos tiveram diferenças na expressão de uma série de microRNAs, no entanto, os mecanismos moleculares das adaptações cardíacas decorrentes desta modulação gênica e do treinamento parecem ser distintos. 


\section{MATERIAL SUPLEMENTAR}

\begin{tabular}{|lcccr|}
\hline \multicolumn{1}{c}{ Vias de sinalização } & Genes & pValue & \multicolumn{1}{c|}{ Fold Enrichment } & \multicolumn{1}{c|}{ FDR } \\
\hline HTLV-I infection & 15 & 0,001 & 2.653 .164 .092 .929 .470 & 17.978 .616 .064 .247 .600 \\
\hline Progesterone-mediated oocyte maturation & 8 & 0,002 & 4.521 .560 .875 .613 .140 & 2.266 .969 .693 .146 .910 \\
\hline Cholinergic synapse & 9 & 0,002 & 3.916 .351 .953 .102 .980 & 24.658 .251 .123 .008 .200 \\
\hline Ubiquitin mediated proteolysis & 10 & 0,002 & 3.462 .815 .107 .203 .730 & 281.317 .617 .309 .893 \\
\hline Pathways in cancer & 16 & 0,014 & 19.817 .420 .462 .385 .000 & 164.053 .664 .716 .878 \\
\hline AMPK signaling pathway & 8 & 0,014 & 30.974 .472 .140 .027 .000 & 1.655 .817 .707 .290 .790 \\
\hline Chronic myeloid leukemia & 6 & 0,015 & 4.097 .664 .543 .524 .410 & 1.727 .384 .089 .042 .520 \\
\hline Oocyte meiosis & 7 & 0,024 & 3.129 .125 .651 .418 .640 & 2.610 .136 .940 .267 .640 \\
\hline Endocytosis & 12 & 0,025 & 21.225 .312 .743 .435 .800 & 27.321 .841 .229 .080 .400 \\
\hline Oxytocin signaling pathway & 8 & 0,041 & 24.897 .202 .289 .768 .600 & 4.082 .551 .237 .959 .220 \\
\hline Estrogen signaling pathway & 6 & 0,048 & 30.105 .290 .523 .852 .800 & 46.193 .309 .304 .907 .200 \\
\hline Protein processing in endoplasmic reticulum & 8 & 0,054 & 23.415 .225 .962 .996 .600 & 50.070 .368 .350 .826 .700 \\
\hline Vasopressin-regulated water reabsorption & 4 & 0,055 & 4.574 .137 .164 .864 .460 & 5.133 .542 .711 .548 .030 \\
\hline Signaling pathways regulating pluripotency of stem cells & 7 & 0,060 & 2.494 .230 .591 .710 .510 & 544.644 .054 .499 .979 \\
\hline Rap1 signaling pathway & 9 & 0,068 & 20.679 .802 .369 .188 .600 & 588.795 .654 .204 .155 \\
\hline MAPK signaling pathway & 10 & 0,070 & 1.943 .556 .305 .228 .970 & 6.012 .800 .182 .043 .050 \\
\hline Bacterial invasion of epithelial cells & 5 & 0,073 & 31.520 .496 .488 .649 .300 & 61.362 .329 .777 .683 .300 \\
\hline Thyroid hormone signaling pathway & 6 & 0,078 & 26.109 .013 .020 .686 .500 & 6.426 .102 .715 .528 .440 \\
\hline RNA degradation & 5 & 0,084 & 2.998 .291 .129 .408 .100 & 6.685 .781 .405 .684 .880 \\
\hline Endometrial cancer & 4 & 0,087 & 37.824 .595 .786 .379 .200 & 6.843 .455 .501 .740 .220 \\
\hline Viral carcinogenesis & 9 & 0,096 & 19.157 .912 .151 .542 .700 & 7.188 .986 .519 .286 .420 \\
\hline PI3K-Akt signaling pathway & 12 & 0,098 & 16.810 .931 .460 .612 .900 & 7.278 .986 .870 .922 .850 \\
\hline ErbB signaling pathway & 5 & 0,099 & 2.825 .975 .547 .258 .210 & 7.313 .731 .094 .620 .130 \\
\hline GABAergic synapse & 5 & 0,099 & 2.825 .975 .547 .258 .210 & 7.313 .731 .094 .620 .130 \\
\hline
\end{tabular}

Tabela 2. Via de enriquecidos para a lista de genes-alvo preditos para os 3 microRNAs selecionados no estudo. 


\begin{tabular}{cccc}
\cline { 1 - 2 } Parâmetros Ecocardiográficos & Grupos & & \\
\hline \hline & SED & TR & p-value \\
\hline \hline Função Sistólica & & & \\
FE (\%) & $80 \pm 1,22$ & $79 \pm 3,52$ & $\mathrm{~ns}$ \\
DsVE (mm) & $1,83 \pm 0,11$ & $2,00 \pm 0,07$ & $\mathrm{~ns}$ \\
DdVE (mm) & $3,12 \pm 0,24$ & $3,31 \pm 0,10$ & $\mathrm{~ns}$ \\
Septo (mm) & $1,01 \pm 0,06$ & $1,10 \pm 0,07$ & $\mathrm{~ns}$ \\
Função Diastólica & & & \\
E (m/s) & $0,63 \pm 0,03$ & $0,75 \pm 0,02^{*}$ & \multirow{2}{*}{0,0061} \\
A (m/s) & $0,3 \pm 0,03$ & $0,37 \pm 0,03$ & $\mathrm{~ns}$ \\
E/A (m/s) & $2,04 \pm 0,21$ & $2,12 \pm 0,13$ & $\mathrm{~ns}$ \\
Hipertrofia Cardíaca & $0,71 \pm 0,02$ & $0,71 \pm 0,01$ & $\mathrm{~ns}$ \\
Massa $(\mathrm{g})$ & & & \\
\hline
\end{tabular}

Tabela 4. Característica ecocardiográficas do ventrículo esquerdo dos animais sedentários (SED) e treinados (TR) em repouso. Fração de ejeção do ventrículo esquerdo (FE); Diâmetro diastólico (DdVE) e Sistólico (DsVE), espessura do septo em diástole (Septo); Relação entre o pico de velocidade de entrada das ondas $E$ e A no fluxo de entrada ventricular (E/A); Massa cardíaca (massa). ${ }^{*} p<0,01$ TR vs. SED. 
FIGURA 1 sup.

A)

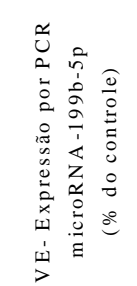

C)
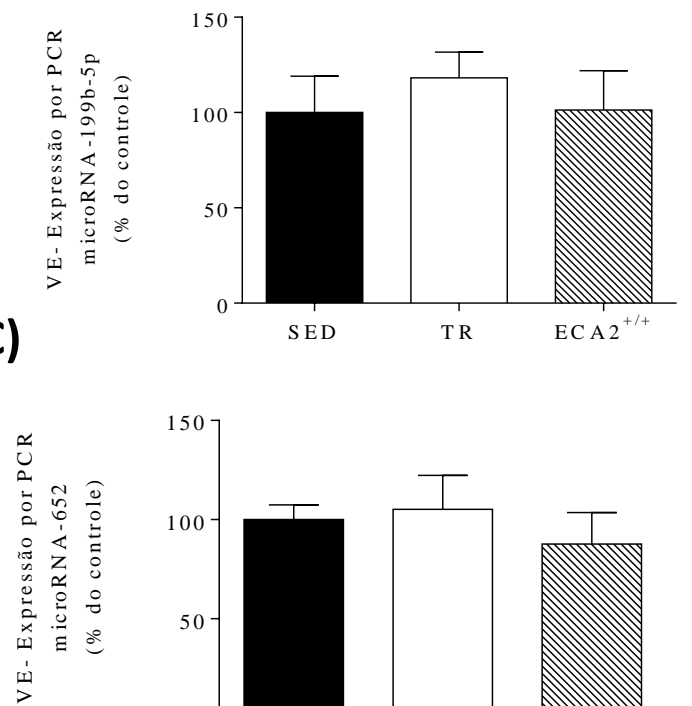

E)

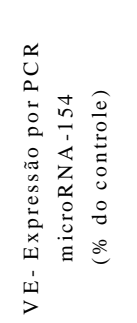

G)

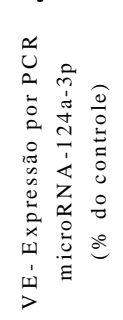

B)
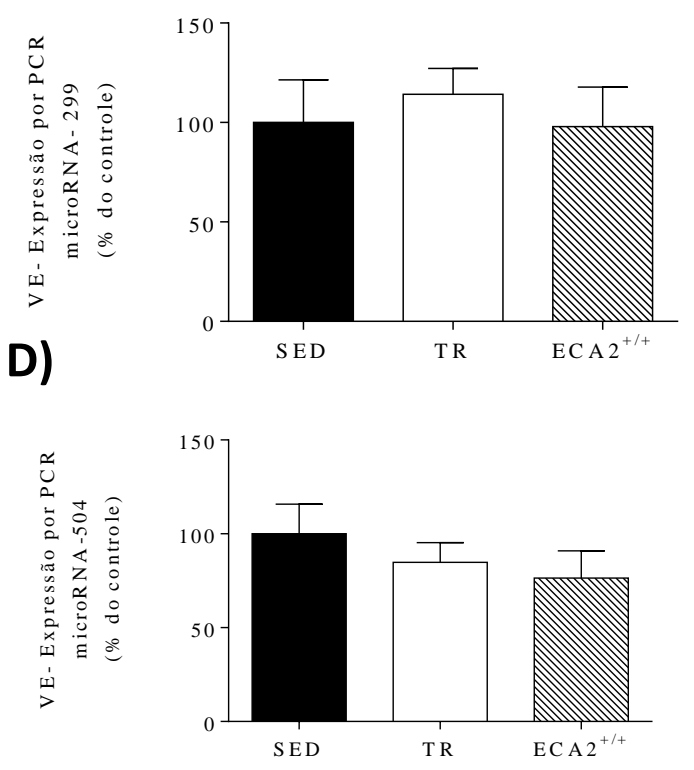

F)

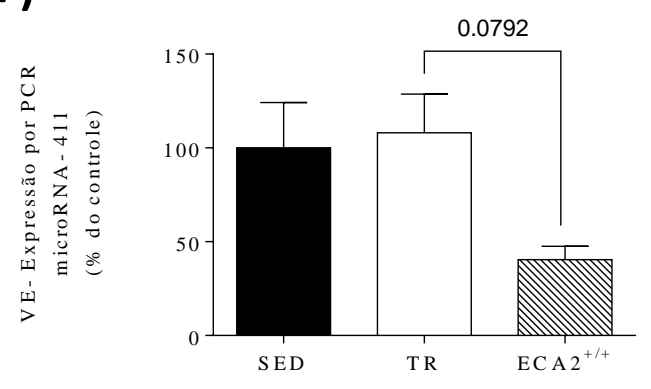

H)

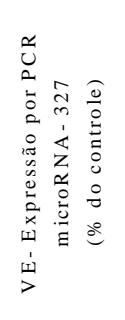

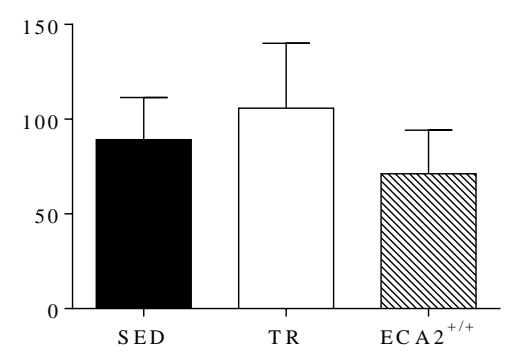

Figura 1 suplementar. Expressão gênica dos microRNAs- 199b-5p (A), -299 (B), -652 (C) $504(D),-154(E),-411(F),-124 a-3 p$ e 327 pela ténica de RT- qPCR nos grupos: sedentário (SED), treinado (TR) e com superexpressão da enzima conversora de angiotensina 2 $\left(\mathrm{ECA}^{+/+}\right)$. 


\section{FIGURA 1.1 sup.}

A)
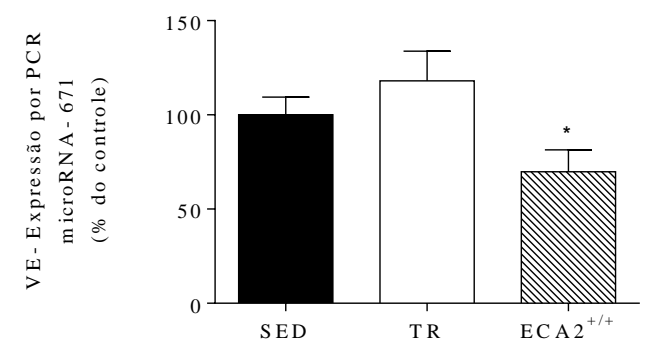

C)

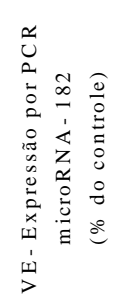

B)
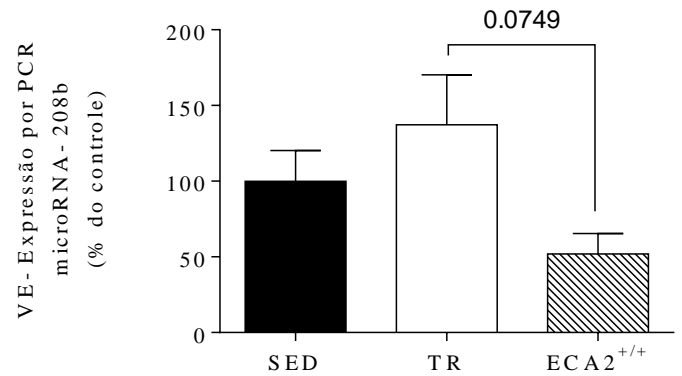

Figura 1.1 suplementar. Expressão gênica dos microRNAs- $671(A),-208 b(B)$ e -182 (C) pela ténica de RT- qPCR nos grupos: sedentário (SED), treinado (TR) e com superexpressão da enzima conversora de angiotensina $2\left(\mathrm{ECA}^{+/+}\right){ }^{*} \mathrm{p}<0,01 \mathrm{ECA} 2^{+/+} \mathrm{vs}$. TR. 


\section{REFERÊNCIAS}

ALP, P. R.; NEWSHOLME, E. a; ZAMMIT, V. a. Activities of citrate synthase and NAD+-linked and NADP+-linked isocitrate dehydrogenase in muscle from vertebrates and invertebrates. The Biochemical journal, v. 154, n. 3, p. 689-700, 1976.

ARNOLD, N.; KOPPULA, P. R.; GUL, R.; LUCK, C.; PULAKAT, L. Regulation of cardiac expression of the diabetic marker microRNA miR-29. PLoS ONE, v. 9, n. 7, 2014.

AUGUSTO, R.; SANTOS, S.; FAGUNDES-MOURA, C. R.; CRISTINA, A. Artigos Efeitos cardiovasculares e renais do sistema. v. 7, n. 3, p. 227-236, 2000.

AVELAR, E.; CLOWARD, T. V.; WALKER, J. M.; FARNEY, R. J.; STRONG, M.; PENDLETON, R. C.; SEGERSON, N.; ADAMS, T. D.; GRESS, R. E.; HUNT, S. C.; LITWIN, S. E. Left ventricular hypertrophy in severe obesity: Interactions among blood pressure, nocturnal hypoxemia, and body mass. Hypertension, v. 49, n. 1, p. 34-39, 2007.

BADER, M. Tissue renin-angiotensin-aldosterone systems: Targets for pharmacological therapy. Annual review of pharmacology and toxicology, v. 50, p. 439-465, 2010.

BARAUNA, V. G.; JUNIOR, M. L. B.; COSTA ROSA, L. F. B. P.; CASARINI, D. E.; KRIEGER, J. E.; OLIVEIRA, E. M. Cardiovascular adaptations in rats submitted to a resistance-training model. Clinical and Experimental Pharmacology and Physiology, v. 32, n. 4, p. 249-254, 2005.

BARAUNA, V. G.; MAGALHAES, F. C.; KRIEGER, J. E.; OLIVEIRA, E. M. AT1 receptor participates in the cardiac hypertrophy induced by resistance training in rats. American journal of physiology. Regulatory, integrative and comparative physiology, v. 295, n. 2, p. R381-R387, ago. 2008. Disponível em: <http://www.ncbi.nlm.nih.gov/pubmed/18495827>. Acesso em: 8 set. 2014.

BARRETTI, D. L. M.; MAGALHÃES, F. de C.; FERNANDES, T.; DO CARMO, E. C.; ROSA, K. T.; IRIGOYEN, M. C.; NEGRÃO, C. E.; OLIVEIRA, E. M. Effects of Aerobic Exercise Training on Cardiac Renin-Angiotensin System in an Obese Zucker Rat Strain. PLoS ONE, v. 7, n. 10, p. 1-10, 2012.

BASSO, N.; TERRAGNO, N. a. History About the Discovery of the Renin-Angiotensin System. Hypertension, v. 38, n. 6, p. 1246-1249, 1 dez. 2001. Disponível em: <http://hyper.ahajournals.org/cgi/doi/10.1161/hy1201.101214>. Acesso em: 8 set. 2014.

BERNARDO, B. C.; GAO, X. M.; THAM, Y. K.; KIRIAZIS, H.; WINBANKS, C. E.; OOI, J. Y. Y.; BOEY, E. J. H.; OBAD, S.; KAUPPINEN, S.; GREGOREVIC, P.; DU, X. J.; LIN, R. C. Y.; MCMULLEN, J. R. Silencing of miR-34a attenuates cardiac dysfunction in a setting of moderate, but not severe, hypertrophic cardiomyopathy. PLoS ONE, v. 9, n. 2, 2014.

BERTAGNOLLI, M.; CASALI, K. R.; DE SOUSA, F. B.; RIGATTO, K.; BECKER, L.; SANTOS, S. H. S.; DIAS, L. D.; PINTO, G.; DARTORA, D. R.; SCHAAN, B. D.; MILAN, R. D. S.; IRIGOYEN, M. C.; SANTOS, R. A. S. An orally active angiotensin-(1-7) inclusion compound and exercise training produce similar cardiovascular effects in 
spontaneously hypertensive rats. Peptides, v. 51, p. 65-73, 2014.

BIRD, I. M. High performance liquid chromatography: principles and clinical applications. BMJ (Clinical research ed.), v. 299, n. 6702, p. 783-7, 1989. Disponível em:

$<$ http://www.pubmedcentral.nih.gov/articlerender.fcgi?artid=1837629\&tool=pmcentre z\&rendertype $=$ abstract $>$.

BOSTRÖM, P.; MANN, N.; WU, J.; QUINTERO, P. a; PLOVIE, E. R.; GUPTA, R. K.; XIAO, C.; MACRAE, C. a; ROSENZWEIG, A.; SPIEGELMAN, B. M. NIH Public Access. v. 143, n. 7, p. 617-632, 2011.

BUENO, C. R.; FERREIRA, J. C. B.; PEREIRA, M. G.; BACURAU, A. V. N.; BRUM, $P$. C. Aerobic exercise training improves skeletal muscle function and $\mathrm{Ca} 22$ handlingrelated protein expression in sympathetic hyperactivity-induced heart failure. J Appl Physiol, v. 109, p. 702-709, 2010.

BURRELL, L. M.; RISVANIS, J.; KUBOTA, E.; DEAN, R. G.; MACDONALD, P. S.; LU, S.; TIKELLIS, C.; GRANT, S. L.; LEW, R. A.; SMITH, A. I.; COOPER, M. E.; JOHNSTON, C. I. Myocardial infarction increases ACE2 expression in rat and humans. European Heart Journal, v. 26, n. 4, p. 369-375, 2005.

CAMPBELL, D. J.; HABENER, J. F. Angiotensinogen gene is expressed and differentially regulated in multiple tissues of the rat. The Journal of clinical investigation, v. 78, n. 1, p. 31-9, 1986. Disponível em: <http://www.pubmedcentral.nih.gov/articlerender.fcgi?artid=329527\&tool=pmcentrez \&rendertype $=$ abstract $>$.

CARÈ, A.; CATALUCCI, D.; FELICETTI, F.; BONCI, D.; ADDARIO, A.; GALLO, P.; BANG, M.-L.; SEGNALINI, P.; GU, Y.; DALTON, N. D.; ELIA, L.; LATRONICO, M. V. G.; HØYDAL, M.; AUTORE, C.; RUSSO, M. a; DORN, G. W.; ELLINGSEN, O.; RUIZLOZANO, P.; PETERSON, K. L.; CROCE, C. M.; PESCHLE, C.; CONDORELLI, G. MicroRNA-133 controls cardiac hypertrophy. Nature medicine, v. 13, n. 5, p. 613-8, 2007.

CHAPPELL, M. C. Emerging evidence for a functional angiotensin-converting enzyme 2-angiotensin-(1-7)-MAS receptor axis: more than regulation of blood pressure? Hypertension, v. 50, n. 4, p. 596-9, out. 2007. Disponível em: <http://www.ncbi.nlm.nih.gov/pubmed/17785634>. Acesso em: 8 set. 2014.

CRACKOWER, M. a; SARAO, R.; OUDIT, G. Y.; YAGIL, C.; KOZIERADZKI, I.; SCANGA, S. E.; OLIVEIRA-DOS-SANTOS, A. J.; DA COSTA, J.; ZHANG, L.; PEI, Y.; SCHOLEY, J.; FERRARIO, C. M.; MANOUKIAN, A. S.; CHAPPELL, M. C.; BACKX, P. H.; YAGIL, Y.; PENNINGER, J. M. Angiotensin-converting enzyme 2 is an essential regulator of heart function. Nature, v. 417, n. 6891, p. 822-828, 2002.

DARTORA DR, IRIGOYEN MC, CASALI KR, MORAES-SILVA IC, BERTAGNOLLI M, BADER M, S. R. Improved cardiovascular autonomic modulation in transgenic rats expressing an Ang-(1-7)-producing fusion protein. Can J Physiol Pharmacol., p. 993998, 2017.

DE ANGELIS, K.; WICHI, R. B.; JESUS, W. R. a; MOREIRA, E. D.; MORRIS, M.; KRIEGER, E. M.; IRIGOYEN, M. C. Exercise training changes autonomic cardiovascular balance in mice. Journal of applied physiology (Bethesda, Md.: 
1985), v. 96, n. 6, p. 2174-2178, 2004.

DE GASPARO, M., CATT, K. J., INAGAMI, T, WRIGHT, J. W. AND UNGER, T. H. International Union of Pharmacology . XIII . Pharmacological Reviews, v. 49, n. 3, p. 415-472, 2000.

DE MELLO, W. C.; DANSER, A. H. Angiotensin II and the heart: on the intracrine renin-angiotensin system. Hypertension, v. 35, n. 6, p. 1183-8, 2000. Disponível em: <http://www.ncbi.nlm.nih.gov/pubmed/10720595\%5Cnhttp://www.ncbi.nlm.nih.gov/pu bmed/10856260>.

DER SARKISSIAN, S.; GROBE, J. L.; YUAN, L.; NARIELWALA, D. R.; WALTER, G. A.; KATOVICH, M. J.; RAIZADA, M. K. Cardiac overexpression of angiotensin converting enzyme 2 protects the heart from ischemia-induced pathophysiology. Hypertension, v. 51, n. 3, p. 712-718, 2008.

DIAS-PEIXOTO, M. F.; FERREIRA, A. J.; ALMEIDA, P. W. M.; BRAGA, V. B. a; COUTINHO, D. C. O.; MELO, D. S.; GOMES FILHO, A.; MELO, M. B.; GRECO, L.; CAMPAGNOLE-SANTOS, M. J.; LIMA, R. F.; SANTOS, R. a S.; GUATIMOSIM, S. The cardiac expression of Mas receptor is responsive to different physiological and pathological stimuli. Peptides, v. 35, n. 2, p. 196-201, jun. 2012. Disponível em: <http://www.ncbi.nlm.nih.gov/pubmed/22504011>. Acesso em: 19 ago. 2014.

DÍEZ-FREIRE, C.; VÁZQUEZ, J.; CORREA DE ADJOUNIAN, M. F.; FERRARI, M. F. R.; YUAN, L.; SILVER, X.; TORRES, R.; RAIZADA, M. K. ACE2 gene transfer attenuates hypertension-linked pathophysiological changes in the SHR. Physiological genomics, v. 27, n. 1, p. 12-19, 3 out. 2006. Disponível em: <http://www.ncbi.nlm.nih.gov/pubmed/16788004>. Acesso em: 8 set. 2014.

DINIZ, G. P.; LINO, C. A.; GUEDES, E. C.; NASCIMENTO MOREIRA, L. do; BARRETO-CHAVES, M. L. M. Cardiac microRNA-133 is down-regulated in thyroid hormone-mediated cardiac hypertrophy partially via Type 1 Angiotensin II receptor. Basic Research in Cardiology, v. 110, n. 5, p. 1-11, 2015.

DONOGHUE, M.; HSIEH, F.; BARONAS, E.; GODBOUT, K.; GOSSELIN, M.; STAGLIANO, N.; DONOVAN, M.; WOOLF, B.; ROBISON, K.; JEYASEELAN, R.; BREITBART, R. E.; ACTON, S. A Novel Angiotensin-Converting Enzyme-Related Carboxypeptidase (ACE2) Converts Angiotensin I to Angiotensin 1-9. Circulation Research, v. 87, n. 5, p. e1-e9, 2000. Disponível em: $<$ http://circres.ahajournals.org/content/87/5/e1.short>.

DONOGHUE, M.; WAKIMOTO, H.; MAGUIRE, C. T.; ACTON, S.; HALES, P.; STAGLIANO, N.; FAIRCHILD-HUNTRESS, V.; XU, J.; LORENZ, J. N.; KADAMBI, V.; BERUL, C. I.; BREITBART, R. E. Heart block, ventricular tachycardia, and sudden death in ACE2 transgenic mice with downregulated connexins. Journal of Molecular and Cellular Cardiology, v. 35, n. 9, p. 1043-1053, 2003.

DZAU, V. J.; BURT, D. W.; PRATT, R. E. Molecular biology of the renin-angiotensin system. The American journal of physiology, v. 255, n. 4 Pt 2, p. F563-F573, 1988.

DZAU, V. J.; ELLISON, K. E.; BRODY, T.; INGELFINGER, J.; PRATT, R. E. A comparative study of the distributions of renin and angiotensinogen messenger ribonucleic acids in rat and mouse tissues. Endocrinology; Endocrinology, v. 120, n. 6, p. 2334-2338, 1987. 
EULALIO, A.; MANO, M.; DAL FERRO, M.; ZENTILIN, L.; SINAGRA, G.; ZACCHIGNA, S.; GIACCA, M. Functional screening identifies miRNAs inducing cardiac regeneration. Nature, v. 492, n. 7429, p. 376-81, 2012. Disponível em: $<$ http://www.ncbi.nlm.nih.gov/pubmed/23222520>.

FERNANDES, T.; BARAÚNA, V. G.; NEGRÃO, C. E.; PHILLIPS, M. I.; OLIVEIRA, E. $M$. Aerobic exercise training promotes physiological cardiac remodeling involving a set of microRNAs. American journal of physiology. Heart and circulatory physiology, v. $309, \quad$ n. $4, \quad$ p. H543-52, 2015. Disponível em: <http://www.ncbi.nlm.nih.gov/pubmed/26071549\%0Ahttp://www.pubmedcentral.nih.g ov/articlerender.fcgi?artid=PMC4537939>.

FERNANDES, T.; HASHIMOTO, N. Y.; MAGALHÃES, F. C.; FERNANDES, F. B.; CASARINI, D. E.; CARMONA, A. K.; KRIEGER, J. E.; PHILLIPS, M. I.; OLIVEIRA, E. $M$. Aerobic exercise training-induced left ventricular hypertrophy involves regulatory MicroRNAs, decreased angiotensin-converting enzyme-angiotensin ii, and synergistic regulation of angiotensin-converting enzyme 2-angiotensin (1-7). Hypertension, v. 58, n. 2, p. 182-9, ago. 2011.

FERNANDES, T.; SOCI, U. P. R.; OLIVEIRA, E. M. Eccentric and concentric cardiac hypertrophy induced by exercise training: MicroRNAs and molecular determinants. Brazilian Journal of Medical and Biological Research, v. 44, n. 9, p. 836-847, 2011.

FERREIRA, A. J.; MORAES, P. L.; FOUREAUX, G.; ANDRADE, A. B.; SANTOS, R. a S.; ALMEIDA, A. P. The angiotensin-(1-7)/Mas receptor axis is expressed in sinoatrial node cells of rats. The journal of histochemistry and cytochemistry: official journal of the Histochemistry Society, v. 59, n. 8, p. 761-768, ago. 2011a. Disponível em: $<$ http://www.pubmedcentral.nih.gov/articlerender.fcgi?artid=3261602\&tool=pmcentre z\&rendertype =abstract $>$. Acesso em: 8 set. 2014.

FERREIRA, a J.; SHENOY, V.; QI, Y.; FRAGA-SILVA, R. a; SANTOS, R. a; KATOVICH, M. J.; RAIZADA, M. K. Angiotensin-converting enzyme 2 activation protects against hypertension-induced cardiac fibrosis involving extracellular signalregulated kinases. Exp Physiol, v. 96, n. 3, p. 287-294, mar. 2011b. Disponível em: <http://www.pubmedcentral.nih.gov/articlerender.fcgi?artid=3077555\&tool=pmcentre z\&rendertype=abstract $>$. Acesso em: 8 set. 2014.

FERREIRA, J. C. B.; ROLIM, N. P. L.; BARTHOLOMEU, J. B.; GOBATTO, C. A.; KOKUBUN, E.; BRUM, P. C. Maximal lactate steady state in running mice: Effect of exercise training. Clinical and Experimental Pharmacology and Physiology, v. 34, n. 8, p. 760-765, 2007.

FILHO, a. G.; FERREIRA, a. J.; SANTOS, S. H. S.; NEVES, S. R. S.; SILVA CAMARGOS, E. R.; BECKER, L. K.; BELCHIOR, H. a.; DIAS-PEIXOTO, M. F.; PINHEIRO, S. V. B.; SANTOS, R. a. S. Selective increase of angiotensin(1-7) and its receptor in hearts of spontaneously hypertensive rats subjected to physical training. Experimental Physiology, v. 93, n. 5, p. 589-598, 29 fev. 2008. Disponível em: <http://ep.physoc.org/cgi/doi/10.1113/expphysiol.2007.041293>. Acesso em: 8 set. 2014.

FORJAZ, C. L.; TINUCCI, T.; ORTEGA, K. C.; SANTAELLA, D. F.; MION, D.; NEGRÃO, C. E. Factors affecting post-exercise hypotension in normotensive and 
hypertensive humans. Blood pressure monitoring, v. 5, n. 5-6, p. 255-62, 2000.

FRISBEE, J. C.; SAMORA, J. B.; PETERSON, J.; BRYNER, R. Exercise training blunts microvascular rarefaction in the metabolic syndrome. American Journal of Physiology. Heart and Circulatory Physiology, v. 291, n. 5, p. H2483-H2492, 2006.

GAVA, E.; DE CASTRO, C. H.; FERREIRA, A. J.; COLLETA, H.; MELO, M. B.; ALENINA, N.; BADER, M.; OLIVEIRA, L. a.; SANTOS, R. a S.; KITTEN, G. T. Angiotensin-(1-7) receptor Mas is an essential modulator of extracellular matrix protein expression in the heart. Regulatory Peptides, v. 175, n. 1-3, p. 30-42, 10 abr. 2012. Disponível em: <http://www.ncbi.nlm.nih.gov/pubmed/22285513>. Acesso em: 8 set. 2014.

GIANI, J. F.; GIRONACCI, M. M.; MUÑOZ, M. C.; PEÑA, C.; TURYN, D.; DOMINICI, F. P. Angiotensin-(1 7) stimulates the phosphorylation of JAK2, IRS-1 and Akt in rat heart in vivo: role of the AT1 and Mas receptors. American journal of physiology. Heart and circulatory physiology, v. 293, n. 2, p. H1154-H1163, 2007.

GIANI, J. F.; MUÑOZ, M. C.; MAYER, M. a; VEIRAS, L. C.; ARRANZ, C.; TAIRA, C. a; TURYN, D.; TOBLLI, J. E.; DOMINICI, F. P. Angiotensin-(1-7) improves cardiac remodeling and inhibits growth-promoting pathways in the heart of fructose-fed rats. American journal of physiology. Heart and circulatory physiology, v. 298, n. 3, p. H1003-H1013, mar. 2010. Disponível em: <http://www.ncbi.nlm.nih.gov/pubmed/20061544>. Acesso em: 8 set. 2014.

GRUETER, C. E.; VAN ROOIJ, E.; JOHNSON, B. A.; DELEON, S. M.; SUTHERLAND, L. B.; QI, X.; GAUTRON, L.; ELMQUIST, J. K.; BASSEL-DUBY, R.; OLSON, E. N. A cardiac MicroRNA governs systemic energy homeostasis by regulation of MED13. Cell, v. 149, n. 3, p. 671-683, 2012. Disponível em: <http://dx.doi.org/10.1016/j.cell.2012.03.029>.

GU, Q.; WANG, B.; ZHANG, X. F.; MA, Y. P.; LIU, J. D.; WANG, X. Z. Contribution of renin-angiotensin system to exercise-induced attenuation of aortic remodeling and improvement of endothelial function in spontaneously hypertensive rats. Cardiovascular Pathology, v. 23, n. 5, p. 298-305, 2014.

HARADA, K.; SUGAYA, T.; MURAKAMI, K.; YAZAKI, Y.; KOMURO, I. Angiotensin II type $1 \mathrm{~A}$ receptor knockout mice display less left ventricular remodeling and improved survival after myocardial infarction. Circulation, v. 100, n. 20, p. 2093-9, 1999.

HASHIMOTO, N. Y.; FERNANDES, T.; OLIVEIRA, E. M. De. Determinantes Moleculares da Hipertrofia Cardíaca Induzida por Diferentes Volumes de Treinamento Aeróbio. v. 24, n. 3, p. 153-162, 2011.

HUENTELMAN, M. J.; GROBE, J. L.; VAZQUEZ, J.; STEWART, J. M.; MECCA, A. P.; KATOVICH, M. J.; FERRARIO, C. M.; RAIZADA, M. K. Protection from angiotensin IIinduced cardiac hypertrophy and fibrosis by systemic lentiviral delivery of ACE2 in rats. Experimental physiology, v. 90, n. 5, p. 783-90, 2005. Disponível em: <http://www.ncbi.nlm.nih.gov/pubmed/16049057>.

ISHIYAMA, Y.; GALLAGHER, P. E.; AVERILL, D. B.; TALLANT, E. A.; BROSNIHAN, K. B.; FERRARIO, C. M. Upregulation of Angiotensin-Converting Enzyme 2 after Myocardial Infarction by Blockade of Angiotensin II Receptors. Hypertension, v. 43, n. 5, p. 970-976, 2004. 
IWAI, M.; HORIUCHI, M. Devil and angel in the renin-angiotensin system: ACEangiotensin II-AT1 receptor axis vs. ACE2-angiotensin-(1-7)-Mas receptor axis. Hypertension research : official journal of the Japanese Society of Hypertension, v. 32, n. 7, p. 533-536, 2009.

KASCHINA, E.; UNGER, T. Angiotensin AT1/AT2 receptors: regulation, signalling and function. Blood Press., v. 12, n. November, p. 70-88, 2003.

LAUTNER, R. Q.; VILLELA, D. C.; FRAGA-SILVA, R. A.; SILVA, N.; VERANOBRAGA, T.; COSTA-FRAGA, F.; JANKOWSKI, J.; JANKOWSKI, V.; SOUSA, F.; ALZAMORA, A.; SOARES, E.; BARBOSA, C.; KJELDSEN, F.; OLIVEIRA, A.; BRAGA, J.; SAVERGNINI, S.; MAIA, G.; PELUSO, A. B.; PASSOS-SILVA, D.; FERREIRA, A.; ALVES, F.; MARTINS, A.; RAIZADA, M.; PAULA, R.; MOTTA-SANTOS, D.; KEMPLIN, F.; PIMENTA, A.; ALENINA, N.; SINISTERRA, R.; BADER, M.; CAMPAGNOLESANTOS, M. J.; SANTOS, R. A. S. Discovery and characterization of alamandine: A novel component of the renin-angiotensin system. Circulation Research, v. 112, n. 8, p. 1104-1111, 2013.

LEE, Y.; AHN, C.; HAN, J.; CHOI, H.; KIM, J.; YIM, J.; LEE, J.; PROVOST, P.; RÅDMARK, O.; KIM, S.; KIM, V. N. The nuclear RNase III Drosha initiates microRNA processing. Nature, v. 425, n. 6956, p. 415-419, 2003.

LEVY, D.; ANDERSON, K. M.; SAVAGE, D. D.; KANNEL, W. B.; CHRISTIANSEN, J. C.; CASTELLI, W. P. Echocardiographically detected left ventricular hypertrophy: Prevalence and risk factors. The Framingham heart study. Annals of Internal Medicine, v. 108, n. 1, p. 7-13, 1988.

LI, G.; XIE, N.; YAO, Y.; ZHANG, Y.; GUO, J.; FENG, Y.; LV, F.; XIAO, R. P.; CAO, C. $M$. Identification of PI3K regulatory subunit p55 as a novel inhibitor of vascular smoothmuscle cell proliferation and neointimal formation. Cardiovascular Research, v. 105, n. 1, p. 75-85, 2015.

LIU, X.; XIAO, J.; ZHU, H.; WEI, X.; PLATT, C.; DAMILANO, F.; XIAO, C.; BEZZERIDES, V.; BOSTRÖM, P.; CHE, L.; ZHANG, C.; SPIEGELMAN, B. M.; ROSENZWEIG, A. MiR-222 is necessary for exercise-induced cardiac growth and protects against pathological cardiac remodeling. Cell Metabolism, v. 21, n. 4, p. 584595, 2015.

LO, J.; PATEL, V. B.; WANG, Z.; LEVASSEUR, J.; KAUFMAN, S.; PENNINGER, J. M.; OUDIT, G. Y. Angiotensin-converting enzyme 2 antagonizes angiotensin II-induced pressor response and NADPH oxidase activation in Wistar-Kyoto rats and spontaneously hypertensive rats. Experimental physiology, v. 98, n. 1, p. 109-22, jan. 2013. Disponível em: <http://www.ncbi.nlm.nih.gov/pubmed/22750422>. Acesso em: 8 set. 2014 .

LUO, J.; ZHANG, L.; DORFMAN, A. L.; SHERWOOD, M. C.; LOGSDON, M. N.; HORNER, J. W.; DEPINHO, R. a; IZUMO, S.; CANTLEY, L. C. Class I. Society, v. 25, n. 21, p. 9491-9502, 2005.

LUZARDO, R.; SILVA, P. A.; MONNERAT-CAHLI, G.; PEREIRA-ACA, A.; SAMPAIO, L. S.; LUNA-LEITE, M. A.; LARA, L. S.; EINICKER-LAMAS, M.; MEDEI, E.; VIEYRA, A. Mechanisms Involving Ang II and MAPK / ERK1 / 2 Signaling Pathways Underlie Cardiac and Renal Alterations during Chronic Undernutrition. v. 9, n. 7, 2014. 
MACHADO-SILVA, A.; PASSOS-SILVA, D.; SANTOS, R. A.; SINISTERRA, R. D. Therapeutic uses for Angiotensin-(1-7)Expert Opinion on Therapeutic Patents, 2016.

MARKS, L. S.; MAXWELL, M. H. Tigerstedt and the discovery of renin. An historical note. Hypertension, v. 1, p. 384-388, 1898.

MASSON, R.; NICKLIN, S. A.; CRAIG, M. A.; MCBRIDE, M.; GILDAY, K.; GREGOREVIC, P.; ALLEN, J. M.; CHAMBERLAIN, J. S.; SMITH, G.; GRAHAM, D.; DOMINICZAK, A. F.; NAPOLI, C.; BAKER, A. H. Onset of Experimental Severe Cardiac Fibrosis Is Mediated by Overexpression of Angiotensin-Converting Enzyme 2. 2016.

MCCOLLUM, L. T.; GALLAGHER, P. E.; ANN TALLANT, E. Angiotensin-(1-7) attenuates angiotensin II-induced cardiac remodeling associated with upregulation of dual-specificity phosphatase 1. AJP: Heart and Circulatory Physiology, v. 302, n. 3, p. H801-H810, 1 fev. 2012. Disponível em: <http://www.pubmedcentral.nih.gov/articlerender.fcgi?artid=3353789\&tool=pmcentre z\&rendertype=abstract $>$. Acesso em: 8 set. 2014.

MCMULLEN, J. R.; JENNINGS, G. L. Differences between pathological and physiological cardiac hypertrophy: Novel therapeutic strategies to treat heart failure. Clinical and Experimental Pharmacology and Physiology, v. 34, n. 4, p. 255-262, 2007.

MCMULLEN, J. R.; SHIOI, T.; HUANG, W. Y.; ZHANG, L.; TARNAVSKI, O.; BISPING, E.; SCHINKE, M.; KONG, S.; SHERWOOD, M. C.; BROWN, J.; RIGGI, L.; KANG, P. M.; IZUMO, S. The Insulin-like Growth Factor 1 Receptor Induces Physiological Heart Growth via the Phosphoinositide 3-Kinase(p110??) Pathway. Journal of Biological Chemistry, v. 279, n. 6, p. 4782-4793, 2004.

MEDEIROS, A.; OLIVEIRA, E. M.; GIANOLLA, R.; CASARINI, D. E.; NEGR??O, C. E.; BRUM, P. C. Swimming training increases cardiac vagal activity and induces cardiac hypertrophy in rats. Brazilian Journal of Medical and Biological Research, v. 37, n. 12, p. 1909-1917, 2004.

MEHTA, P. K.; GRIENDLING, K. K. Angiotensin II cell signaling: physiological and pathological effects in the cardiovascular system. American Journal of Physiology Cell Physiology, v. 292, n. 1, p. C82-C97, 2007.

MELO, S. F.; BARAUNA, V. G.; FERNANDES, T.; CARMO, E. C.; CARVALHO, C. R.; OLIVEIRA, E. M. Cardiac AT1 receptor-dependent and IGF1 receptor-independent signaling is activated by a single bout of resistance exercise. Physiological research, 2017. Disponível em: <http://www.ncbi.nlm.nih.gov/pubmed/28937244>

MELO, S. F. S.; FERNANDES, T.; BARA??NA, V. G.; MATOS, K. C.; SANTOS, A. A. S.; TUCCI, P. J. F.; OLIVEIRA, E. M. Expression of microRNA-29 and collagen in cardiac muscle after swimming training in myocardial-infarcted rats. Cellular Physiology and Biochemistry, v. 33, n. 3, p. 657-669, 2014.

MENDOZA-TORRES, E.; OYARZÚN, A.; MONDACA-RUFF, D.; AZOCAR, A.; CASTRO, P. F.; JALIL, J. E.; CHIONG, M.; LAVANDERO, S.; OCARANZA, M. P. ACE2 and vasoactive peptides: novel players in cardiovascular/renal remodeling and hypertension. Therapeutic advances in cardiovascular disease, v. 9, n. 4, p. 217- 
37, 2015. Disponível em: <http://www.ncbi.nlm.nih.gov/pubmed/26275770>.

MERCURE, C.; YOGI, A.; CALLERA, G. E.; ARANHA, A. B.; BADER, M.; FERREIRA, A. J.; SANTOS, R. A. S.; WALTHER, T.; TOUYZ, R. M.; REUDELHUBER, T. L. Angiotensin(1-7) blunts hypertensive cardiac remodeling by a direct effect on the heart. Circulation Research, v. 103, n. 11, p. 1319-1326, 2008.

MONTGOMERY, H. Editorial Should the contribution of ACE gene polymorphism to left ventricular hypertrophy be reconsidered? Heart (British Cardiac Society), v. 6, p. 489-490, 1997.

MONTGOMERY, H. E.; CLARKSON, P.; DOLLERY, C. M.; PRASAD, K.; LOSI, M. A.; HEMINGWAY, H.; STATTERS, D.; JUBB, M.; GIRVAIN, M.; VARNAVA, A.; WORLD, M.; DEANFIELD, J.; TALMUD, P.; MCEWAN, J. R.; MCKENNA, W. J.; HUMPHRIES, $S$. Association of angiotensin-converting enzyme gene I/D polymorphism with change in left ventricular mass in response to physical training. Circulation, v. 96, n. 3, p. 7417, 1997. Disponível em: <http://www.ncbi.nlm.nih.gov/pubmed/9264477>.

MONTGOMERY, H. E.; MARSHALL, R.; HEMINGWAY, H.; MYERSON, S.; CLARKSON, P.; DOLLERY, C.; HAYWARD, M.; HOLLIMAN, D. E.; JUBB, M.; WORLD, M.; THOMAS, E. L.; BRYNES, A. E.; SAEED, N.; BARNARD, M.; BELL, J. D.; PRASAD, K.; RAYSON, M.; TALMUD, P. J.; HUMPHRIES, S. E. Human gene for physical performance. Nature, v. 393, n. 6682, p. 221-222, 1998. Disponível em: <http://www.nature.com/nature/journal/v393/n6682/full/393221a0.html\%5Cnhttp://ww w.nature.com/nature/journal/v393/n6682/pdf/393221a0.pdf>.

MORRIS, J. N.; CRAWFORD, M. D. Coronary heart disease and physical activity of work; evidence of a national necropsy survey. British medical journal, v. 2, n. 5111, p. 1485-96, 1958. Disponível em: $<$ http://www.pubmedcentral.nih.gov/articlerender.fcgi?artid=2027542\&tool=pmcentre z\&rendertype $=$ abstract $>$.

MOTTA-SANTOS, D.; DOS SANTOS, R. A. S.; OLIVEIRA, M.; QADRI, F.; POGLITSCH, M.; MOSIENKO, V.; KAPPES BECKER, L.; CAMPAGNOLE-SANTOS, M. J.; M PENNINGER, J.; ALENINA, N.; BADER, M. Effects of ACE2 deficiency on physical performance and physiological adaptations of cardiac and skeletal muscle to exercise. Hypertension Research, n. October 2015, p. 1-7, 2016. Disponível em: <http://www.nature.com/doifinder/10.1038/hr.2016.28>.

OCARANZA, M. P.; MOYA, J.; BARRIENTOS, V.; ALZAMORA, R.; HEVIA, D.; MORALES, C.; PINTO, M.; ESCUDERO, N.; GARCÍA, L.; NOVOA, U.; AYALA, P.; DÍAZ-ARAYA, G.; GODOY, I.; CHIONG, M.; LAVANDERO, S.; JALIL, J. E.; MICHEA, L. Angiotensin-(1-9) reverses experimental hypertension and cardiovascular damage by inhibition of the angiotensin converting enzyme/Ang II axis. Journal of hypertension, v. 32, n. 4, p. 771-83, 2014. Disponível em: <http://www.ncbi.nlm.nih.gov/pubmed/24463937>.

OLIVEIRA, E. M.; SASAKI, M. S.; CERÊNCIO, M.; BARAÚNA, V. G.; KRIEGER, J. E. Local renin-angiotensin system regulates left ventricular hypertrophy induced by swimming training independent of circulating renin: a pharmacological study. Journal of the renin-angiotensin-aldosterone system : JRAAS, v. 10, n. 1, p. 15-23, mar. 2009. Disponível em: <http://www.ncbi.nlm.nih.gov/pubmed/19286754>. Acesso em: 8 set. 2014. 
OPPENHEIMER, G. M. Framingham Heart Study: The First 20 Years. Progress in Cardiovascular Diseases, v. 53, n. 1, p. 55-61, 2010.

OUDIT, G. Y.; PENNINGER, J. M. Cardiac regulation by phosphoinositide 3-kinases and PTEN. Cardiovascular Research, v. 82, n. 2, p. 250-260, 2009.

PATEL, S. K.; VELKOSKA, E.; FREEMAN, M.; WAI, B.; LANCEFIELD, T. F.; BURRELL, L. M. From gene to protein-experimental and clinical studies of ACE2 in blood pressure control and arterial hypertension. Frontiers in physiology, v. 5, n. June, p. 227, jan. 2014.

PAUL, M.; POYAN MEHR, A.; KREUTZ, R. Physiology of local renin-angiotensin systems. Physiological reviews, v. 86, n. 3, p. 747-803, jul. 2006. Disponível em: <http://www.ncbi.nlm.nih.gov/pubmed/16816138>. Acesso em: 19 jul. 2014.

PEDERSEN, K. B.; SRIRAMULA, S.; CHHABRA, K. H.; XIA, H.; LAZARTIGUES, E. Species-specific inhibitor sensitivity of angiotensin-converting enzyme 2 ( ACE2) and its implication for ACE2 activity assays. v. 2, p. 1293-1299, 2011.

PHYSIOLOGICAL, N. E. W.; OF, C.; RENIN, T. H. E. NEW PHYSIOLOGICAL CONCEPTS OF THE RENIN ANGIOTENSIN. v. 55, n. 2, p. 445-452, 2011.

PIERUZZI, F.; ABASSI, Z. A.; KEISER, H. R. Expression of Renin-Angiotensin System Components in the Heart, Kidneys, and Lungs of Rats With Experimental Heart Failure. Circulation, v. 92, n. 10, p. 3105-3112, 15 nov. 1995. Disponível em: <http://circ.ahajournals.org/content/92/10/3105.abstract>.

PLUIM, B. M.; ZWINDERMAN, a. H.; VAN DER LAARSE, a.; VAN DER WALL, E. E. The Athlete s Heart: A Meta-Analysis of Cardiac Structure and Function. Circulation, v. 101, n. 3, p. 336-344, 2000.

PORRELLO, E. R.; DELBRIDGE, L. M. D.; THOMAS, W. G. The angiotensin II type 2 (AT2) receptor: an enigmatic seven transmembrane receptor. Frontiers in bioscience : a journal and virtual library, v. 14, p. 958-972, 2009. Disponível em: <http://www.ncbi.nlm.nih.gov/pubmed/19273111>.

RANA, I.; VELKOSKA, E.; PATEL, S. K.; BURRELL, L. M.; CHARCHAR, F. J. MicroRNAs mediate the cardioprotective effect of angiotensin converting enzyme inhibition in acute kidney injury. American journal of physiology. Renal physiology, v. 309 , n. 11 , p. ajprenal.00183.2015, 2015. Disponível em: <http://ajprenal.physiology.org/content/309/11/F943.abstract?etoc>.

SADOSHIMA, J.; IZUMO, S. Molecular characterization of angiotensin II--induced hypertrophy of cardiac myocytes and hyperplasia of cardiac fibroblasts. Critical role of the AT1 receptor subtype. Circulation Research, v. 73, n. 3, p. 413-423, 1 set. 1993. Disponível em: <http://circres.ahajournals.org/cgi/doi/10.1161/01.RES.73.3.413>. Acesso em: 5 set. 2014.

SAMYN, M. E.; PETERSHACK, J. A.; BEDELL, K. A.; MATHEWS, M. S.; SEGAR, J. $\mathrm{L}$. Ontogeny and regulation of cardiac angiotensin types 1 and 2 receptors during fetal life in sheep. Pediatr Res, v. 44, n. 3, p. 323-329, 1998.

SANTOS, R. A. S.; SIMOES E SILVA, A. C.; MARIC, C.; SILVA, D. M. R.; MACHADO, R. P.; DE BUHR, I.; HERINGER-WALTHER, S.; PINHEIRO, S. V. B.; LOPES, M. T.; BADER, M.; MENDES, E. P.; LEMOS, V. S.; CAMPAGNOLE-SANTOS, M. J.; 
SCHULTHEISS, H.-P.; SPETH, R.; WALTHER, T. Angiotensin-(1-7) is an endogenous ligand for the $G$ protein-coupled receptor Mas. Proceedings of the National Academy of Sciences of the United States of America, v. 100, n. 14, p. 8258-63, 2003. Disponível em: <http://www.pnas.org/content/100/14/8258.full>.

SAYED-TABATABAEI, F. A.; OOSTRA, B. A.; ISAACS, A.; VAN DUIJN, C. M.; WITTEMAN, J. C. M. ACE polymorphisms. Circulation Research, v. 98, n. 9, p. 11231133, 2006.

SHAH, A.; OH, Y.-B.; LEE, S. H.; LIM, J. M.; KIM, S. H. Angiotensin-(1-7) attenuates hypertension in exercise-trained renal hypertensive rats. American journal of physiology. Heart and circulatory physiology, v. 302, n. 11, p. H2372-80, 1 jun. 2012. Disponível em: <http://www.ncbi.nlm.nih.gov/pubmed/22467306>. Acesso em: 8 set. 2014.

SHARMA, G. \&. The athlete â $€^{T M} s$ heart. Trends in Urology \& men's health, v. i, p. 9-13, 2012.

SILVA, D. M. R.; GOMES-FILHO, A.; OLIVON, V. C.; SANTOS, T. M. S.; BECKER, L. K.; SANTOS, R. a S.; LEMOS, V. S. Swimming training improves the vasodilator effect of angiotensin-(1-7) in the aorta of spontaneously hypertensive rat. Journal of applied physiology (Bethesda, Md.: 1985), v. 111, n. 5, p. 1272-7, dez. 2011. Disponível em: <http://www.ncbi.nlm.nih.gov/pubmed/21903888>. Acesso em: 31 ago. 2014.

SILVA, S. D.; ZAMPIERI, T. T.; RUGGERI, A.; CERONI, A.; ARAGÃO, D. S.; FERNANDES, F. B.; CASARINI, D. E.; MICHELINI, L. C. Downregulation of the vascular renin-angiotensin system by aerobic training - focus on the balance between vasoconstrictor and vasodilator axes - . Circulation journal : official journal of the Japanese Circulation Society, v. 79, n. 6, p. 1372-80, 2015. Disponível em: <http://www.ncbi.nlm.nih.gov/pubmed/25808225>.

SKEGGS, L.; KAHN, J.; SHUMWAY, N. The preparation and function of the hypertensin-converting enzyme. Journal of Experimental Medicine, v. 103, n. 3, p. 295-299, 1956.

SOCI, U. P. R.; FERNANDES, T.; BARAUNA, V. G.; HASHIMOTO, N. Y.; MOTA, G. de F. A.; ROSA, K. T.; IRIGOYEN, M. C.; PHILLIPS, M. I.; DE OLIVEIRA, E. M. Epigenetic control of exercise training-induced cardiac hypertrophy by miR-208. Clinical science (London, England: 1979), p. CS20160480, 2016. Disponível em: $<$ http://www.ncbi.nlm.nih.gov/pubmed/27503950>.

SOCI, U. P. R.; FERNANDES, T.; HASHIMOTO, N. Y.; MOTA, G. F.; AMADEU, M. a; ROSA, K. T.; IRIGOYEN, M. C.; PHILLIPS, M. I.; OLIVEIRA, E. M. MicroRNAs 29 are involved in the improvement of ventricular compliance promoted by aerobic exercise training in rats. Physiological genomics, v. 43, n. 11, p. 665-673, 2011.

STECKELINGS, U. M.; WIDDOP, R. E.; PAULIS, L.; UNGER, T. The angiotensin AT2 receptor in left ventricular hypertrophy. Journal of Hypertension, v. 28, p. 50-55, $2010 . \quad$ Disponível em: $<$ http://content.wkhealth.com/linkback/openurl?sid=WKPTLP:landingpage\&an=00004 872-201009001-00009>.

TIMMERMANS, P. B.; DUNCIA, J. V; CARINI, D. J.; CHIU, A. T.; WONG, P. C.; WEXLER, R. R.; SMITH, R. D. Discovery of losartan, the first angiotensin II receptor 
antagonist. J Hum Hypertens, v. 9 Suppl 5, p. S3-18, 1995. Disponível em: $<$ http://www.ncbi.nlm.nih.gov/pubmed/8583479>.

TIPNIS, S. R.; HOOPER, N. M.; HYDE, R.; KARRAN, E.; CHRISTIE, G.; TURNER, A. $J$. A human homolog of angiotensin-converting enzyme: Cloning and functional expression as a captopril-insensitive carboxypeptidase. Journal of Biological Chemistry, v. 275, n. 43, p. 33238-33243, 2000.

VAN ROOIJ, E. Introduction to the series on MicroRNAs in the cardiovascular system. Circulation Research, v. 110, n. 3, p. 481-482, 2012.

VAN ROOIJ, E.; OLSON, E. N. MicroRNAs: Powerful new regulators of heart disease and provocative therapeutic targetsJournal of Clinical Investigation, 2007. .

VAN ROOIJ, E.; SUTHERLAND, L. B.; QI, X.; RICHARDSON, J. a; HILL, J.; OLSON, E. N. Control of stress-dependent cardiac growth and gene expression by a microRNA. Science (New York, N.Y.), v. 316, n. 5824, p. 575-579, 2007.

VEGA, R. B.; KONHILAS, J. P.; KELLY, D. P.; LEINWAND, L. A. Molecular Mechanisms Underlying Cardiac Adaptation to Exercise. Cell Metabolism, v. 25, n. 5, p. 1012-1026, 2017. Disponível em: <http://dx.doi.org/10.1016/j.cmet.2017.04.025>.

VELLOSO, L. A.; FOLLI, F.; SUN, X. J.; WHITE, M. F.; SAAD, M. J.; KAHN, C. R. Cross-talk between the insulin and angiotensin signaling systems. Proceedings of the National Academy of Sciences of the United States of America, v. 93, n. 22, p. 12490-5, 1996. Disponível em: <http://www.pubmedcentral.nih.gov/articlerender.fcgi?artid=38019\&tool=pmcentrez\&r endertype $=$ abstract $>$.

WANG, J.; PEI, Y.; ZHONG, Y.; JIANG, S.; SHAO, J.; GONG, J. Altered serum microRNAs as novel diagnostic biomarkers for atypical coronary artery disease. PLoS ONE, v. 9, n. 9, 2014.

YAMAMOTO, K.; OHISHI, M.; KATSUYA, T.; ITO, N.; IKUSHIMA, M.; KAIBE, M.; TATARA, Y.; SHIOTA, A.; SUGANO, S.; TAKEDA, S.; RAKUGI, H.; OGIHARA, T. Deletion of angiotensin-converting enzyme 2 accelerates pressure overload-induced cardiac dysfunction by increasing local angiotensin II. Hypertension, v. 47, n. 4, p. 718-726, 2006.

YAO J, ZHANG P, LI J, X. W. MicroRNA-215 acts as a tumor suppressor in breast cancer by targeting AKT serine/threonine kinase. Oncology Letters, v. 13, n. 3, p. 1097-1104, 2017.

ZAMO, F. S.; BARAUNA, V. G.; CHIAVEGATTO, S.; IRIGOYEN, M. C.; OLIVEIRA, E. $M$. The renin - angiotensin system is modulated by swimming training depending on the age of spontaneously hypertensive rats. Life Sciences, v. 89, n. 3-4, p. 93-99, 2011. Disponível em: <http://dx.doi.org/10.1016/j.lfs.2011.05.004>.

ZHANG, Y.; LI, B.; WANG, B.; ZHANG, J.; WU, J.; MORGAN, T. Alteration of cardiac ACE2/Mas expression and cardiac remodelling in rats with aortic constriction. Chinese Journal of Physiology, v. 57, n. 6, p. 335-342, 2014. 